\title{
THE MODERATING ROLE OF DIET PATTERNS IN THE RELATIONSHIP BETWEEN PERCEIVED STRESS AND COGNITIVE FUNCTION IN OLDER ADULTS
}

by

Danielle D'Amico

Bachelor of Science (Hons.), University of Ottawa, 2016

\author{
A thesis \\ presented to Ryerson University \\ in partial fulfillment of the \\ requirements for the degree of \\ Master of Arts \\ in the program of \\ Psychology
}

Toronto, Ontario, Canada, 2019

(C) Danielle D’Amico, 2019 


\section{AUTHOR'S DECLARATION FOR ELECTRONIC SUBMISSION OF A THESIS}

I hereby declare that I am the sole author of this thesis. This is the true copy of the thesis, including any required final revisions, as accepted by my examiners.

I authorise Ryerson University to lend this thesis to other institutions or individuals for the purpose of scholarly research.

I further authorize Ryerson University to reproduce this thesis by photocopying or by other means, in total or in part, at the request of other institutions or individuals for the purpose of scholarly research.

I understand that my thesis may be made electronically available to the public. 
The Moderating Role of Diet Patterns in the Relationship Between Perceived Stress and Cognitive Function in Older Adults

Master of Arts, 2019

Danielle D’Amico

Psychology

Ryerson University

\begin{abstract}
The current study examined the moderating role of adherence to a healthy prudent diet and an unhealthy Western diet in the relationship between perceived stress and cognitive function among community-dwelling older adults. It was hypothesized that the association between perceived stress and cognition would be buffered by prudent diet and exacerbated by Western diet intake. 201 adults aged 60 and older participated in the study. Prudent diet was a significant effect-modifier, such that higher perceived stress was associated with poorer executive functioning at low levels of prudent diet. Prudent diet did not moderate the association between perceived stress and episodic memory. Western diet was not a significant effectmodifier in the perceived stress-cognition relationship. These findings provide preliminary evidence that a healthy diet may buffer the association between perceived stress and executive function in older adults. Future research with a more diverse sample is needed to confirm these findings.
\end{abstract}




\section{Acknowledgements}

First and foremost, I would like to thank my supervisor, Dr. Alexandra Fiocco, for her ongoing, invaluable support and guidance. Thank you for challenging me to become a better writer, researcher, and creative thinker. I would also like to thank my supervisory committee, Dr. Julia Spaniol, for her feedback and support throughout this thesis, and thank you to Dr. Kristen Vickers for agreeing to be my external reviewer. I am grateful for the feedback and suggestions provided by such an esteemed committee. A special thank you to Dr. Matthew Parrott for sharing with me his expertise on dietary patterns.

I would also like to thank the members of the Stress and Healthy Aging Research Lab for their moral support through every stage of this thesis. A special thank you to Vivian Huang and Laura Krieger to which this project would not have been possible without. A sincere thank you to the wonderful research assistants who've dedicated their time and energy to this project including Kristina Devlin, Shruti Vyas, Ahsan Ali, Elizabeth Selezneva, Kyle Forman, and Julia Pietrangelo. I would also like to thank all of the amazing and inspiring individuals who participated in this study.

I would like to express my sincere gratitude to my friends and family for their unwavering support in all of my life endeavours, especially my graduate school journey thus far. A special thank you to Martin and Maya for providing me with the most caring and uplifting support system I could ask for. I truly would not have been able to do this without your love and light.

Lastly, I would like to dedicate this thesis to my grandparents - Mama and Papa, who have been my inspiration for pursuing a career in aging. I hope you are both happy and full of love wherever you are. 


\section{Table of Contents}

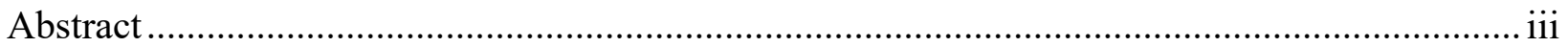

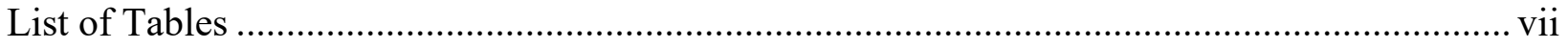

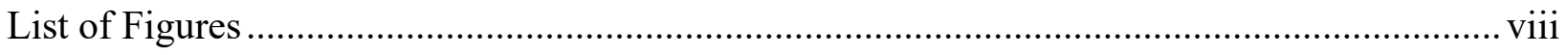

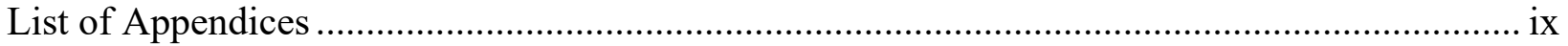

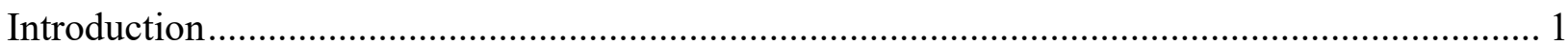

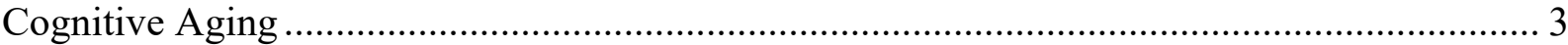

Individual differences in cognitive aging. ............................................................ 6

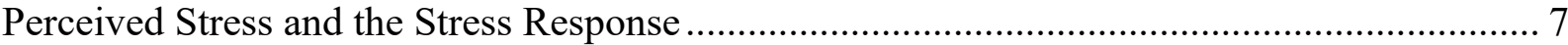

Stress and Individual Differences in Cognitive Aging................................................. 9

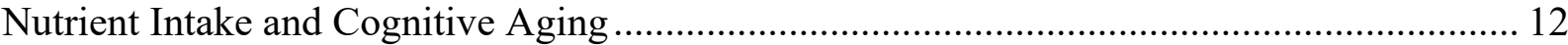

Diet Patterns as a Holistic View of Nutrition................................................................... 14

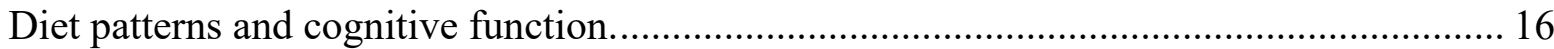

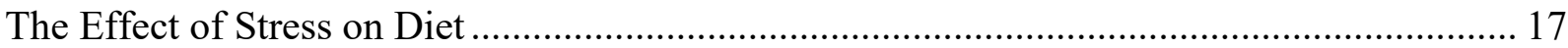

Study Objectives and Hypothesis..................................................................................... 19

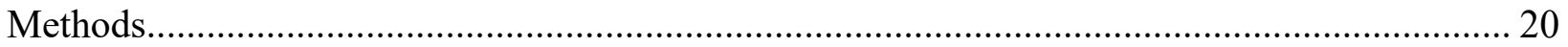

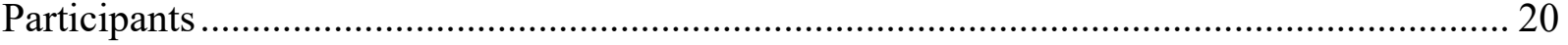

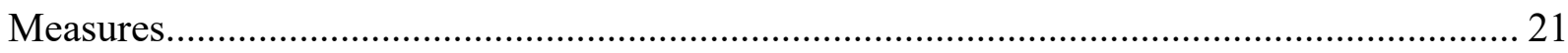

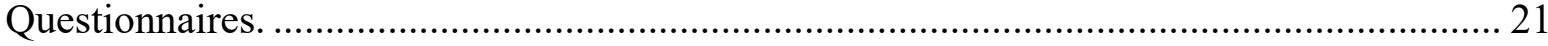

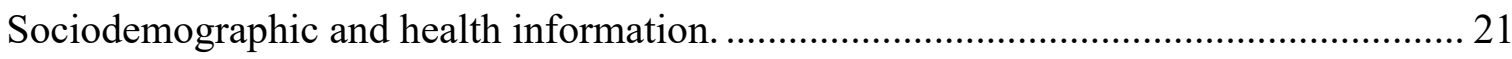

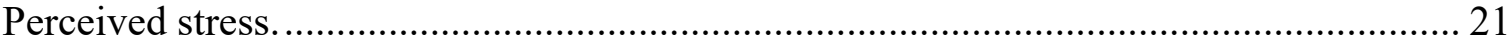

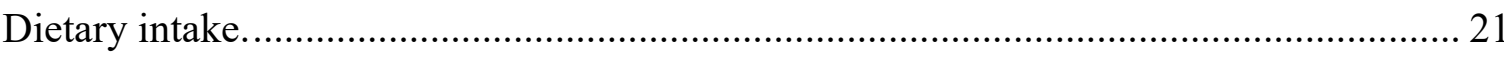

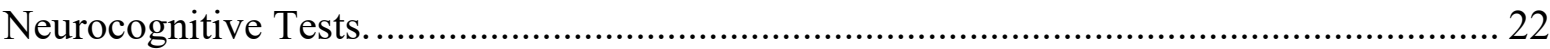

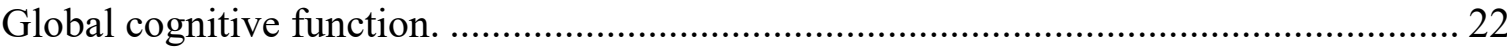

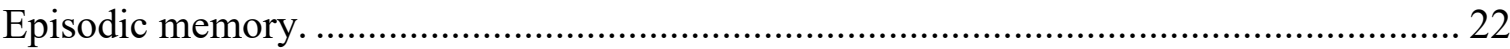

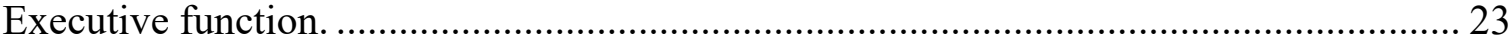

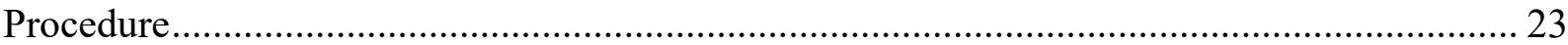

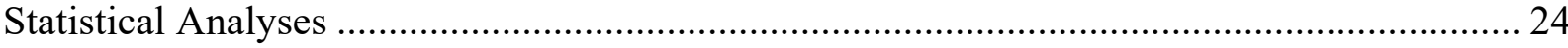

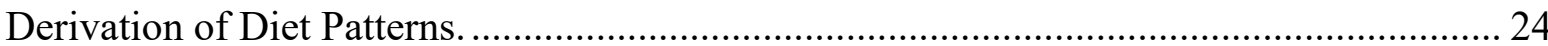

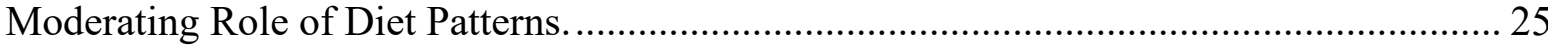

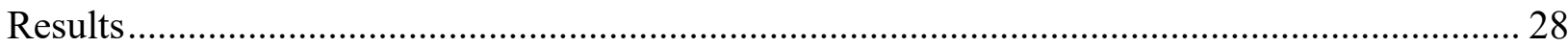

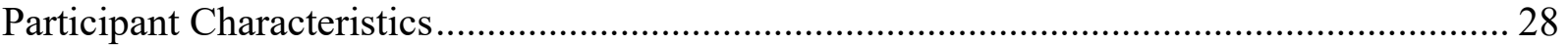

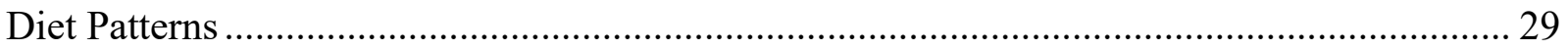




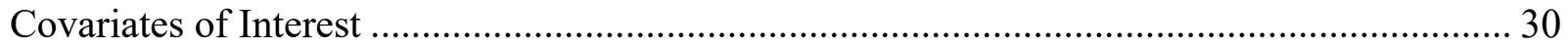

The Association Between Perceived Stress and Cognition...................................................... 33

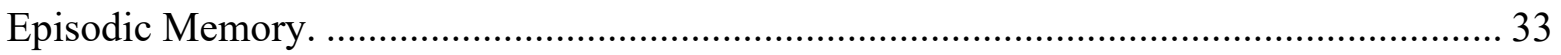

Executive Function.

The Association Between Diet Patterns and Cognition .............................................................. 34

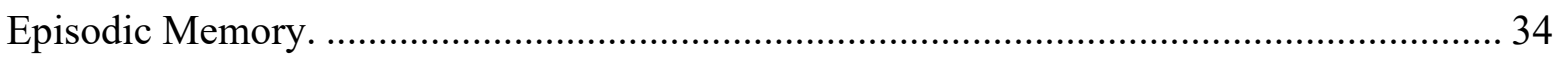

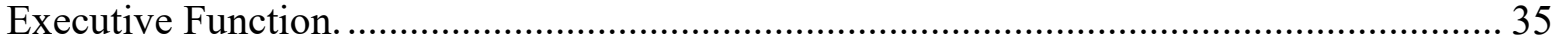

The Association Between Perceived Stress and Diet Patterns ................................................. 37

Diet as a Moderator of the Perceived Stress-Cognition Relationship........................................ 38

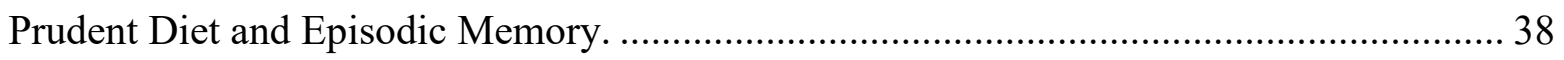

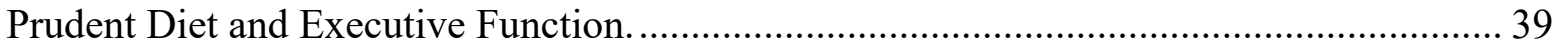

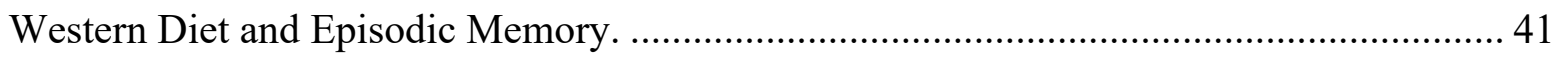

Western Diet and Executive Function............................................................................ 42

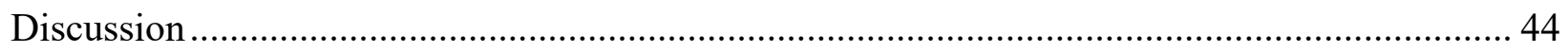

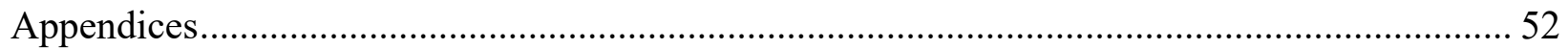

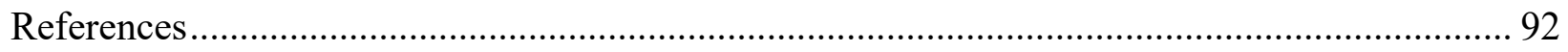




\section{List of Tables}

Table 1. Participant Demographic and Health-Related Characteristics................................. 28

Table 2. Factor Loadings for Dietary Patterns.............................................................. 29

Table 3. Pearson correlation coefficients of independent, moderator, and dependent variables

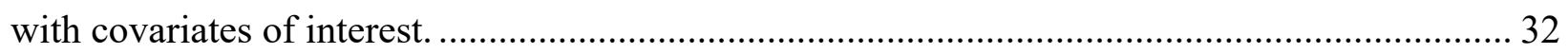

Table 4. Linear Regression Models of PSS-10 and CVLT-II................................................ 33

Table 5. Linear Regression Models of PSS-10 and TMT .................................................. 34

Table 6. Linear Regression Models of Diet Patterns and CVLT-II....................................... 35

Table 7. Linear Regression Models of Diet Patterns and TMT............................................. 36

Table 8. Linear Regression Models of PSS-10 and Diet Patterns. ........................................ 37

Table 9. Moderation Models of PSS-10 × Prudent Diet and CVLT-II....................................... 38

Table 10. Moderation Models of PSS-10 × Prudent Diet and TMT........................................ 39

Table 11. Moderation Models of PSS-10 × Western Diet and CVLT-II.................................. 42

Table 12. Moderation Models of PSS-10 × Western Diet and TMT.................................... 43 


\section{List of Figures}

Figure $1 \mathrm{a}, \mathrm{b}, \mathrm{c}, \mathrm{d}$. The proposed moderation models........................................................ 27

Figure 2. Conditional effects of PSS-10 and TMT-B performance at low, moderate, and high prudent diet intake. Error bars represent standard error of the mean... 


\section{List of Appendices}

Appendix A: Recruitment Advertisement .................................................................... 52

Appendix B: Telephone Screening Questionnaire ........................................................ 53

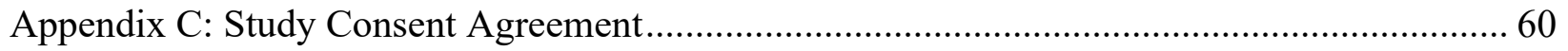

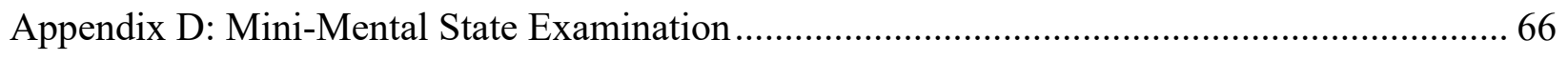

Appendix E: California Verbal Learning Test-II ................................................................ 68

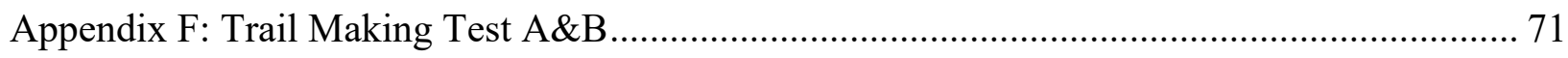

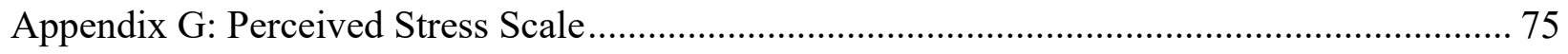

Appendix H: EPIC-Norfolk Food Frequency Questionnaire................................................ 76

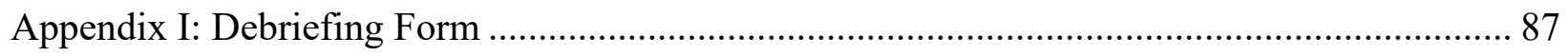

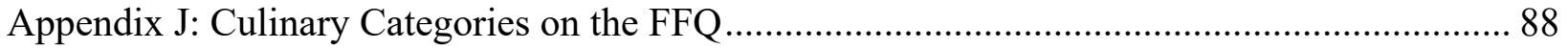


The Moderating Role of Diet Patterns in the Relationship Between Perceived Stress and Cognitive Function in Older Adults

Older adults are the fastest growing age cohort in Canada (Statistics Canada, 2016). It is projected that the proportion of older adults over the age of 65 will increase up to $25 \%$ by the year 2031 (Statistics Canada, 2011). With an aging population on the rise comes greater prevalence of neurodegenerative diseases such as dementia (Pelletier, Robitaille, Mcrae, \& Toews, 2017). Today, there are an estimated 564,000 Canadians living with dementia (Alzheimer's Society of Canada, 2016), which has a profound economic impact on Canada's health care system. According to Statistics Canada (2016b), the combined cost of dementia for the Canadian health care system and out-of-pocket caregiver services is approximately $\$ 10.4$ billion and is expected to increase to $\$ 16.6$ billion by 2031. Currently, there is no cure for dementia and related neurodegenerative disorders, and treatments only modestly improve symptoms. Therefore, the identification of risk factors that can slow cognitive deterioration and/or preserve cognitive health in late life is an urgent public health priority.

The maintenance of cognitive function in late life is fundamental for ensuring optimal aging (Rowe \& Kahn, 1987; Fiocco \& Yaffe, 2010), as cognitive deterioration is a significant antecedent to other indices of wellbeing in late life. Indeed, declines in cognitive abilities precede deterioration in other measures of health, such as increased incidence of stroke (Rostamian, Mahinrad, Stijnen, Sabayan, \& de Craen, 2014), falls (Muir, Gopaul, Odasso, 2012), poor adherence to medical instructions (Brown \& Park, 2003), reduced quality of life (Barrios et al., 2013), and early institutionalization (Gnjidic et al., 2012). Although age is the primary risk factor associated with declines in cognitive function, individual differences in cognitive aging are well documented (Yaffe et al., 2009; Barnes et al., 2007, Murman, 2015). 
Among the various individual-difference factors that contribute to variance in cognitive aging, the experience of stress has received a great deal of attention. Increased perceived stress is negatively associated with memory performance (Bremner \& Narayan, 1998) and executive functioning (Starcke, Wiesen, Trotzke, \& Brand, 2016), especially in older adults, who are particularly vulnerable to the detrimental effects of stress on cognition (Garrido, 2011). In a landmark study by Lupien et al. (1998), older adults who displayed a 5-year increase in the secretion of cortisol, a major stress hormone, presented with poorer memory function at followup compared with older adults who displayed stable or decreasing cortisol secretion. Further, in a study by Seeman, McEwen, Singer, Albert, and Rowe (1997), older women who reported reductions in stress over two years displayed improved performance on tests of memory, suggesting that the impact of stress on cognitive function is reversible. As such, it is valuable to consider factors that may aid in buffering the detrimental effect of stress on cognitive function in late life.

Consuming an adequate diet is suggested to be an essential component of successful aging (Shlisky et al., 2017). Specifically, adherence to specific diet patterns is a modifiable lifestyle behaviour that is associated with both stress and cognitive functioning in older adulthood. Consumption of foods constituting a diet pattern low in essential nutrients is associated with increased levels of stress (Laugero, Falcon, \& Tucker, 2011), and poorer cognitive functioning among older adults (Milte \& McNaughton, 2016). To date, however, there is a paucity of research that has investigated the interplay between perceived stress, cognitive function, and diet patterns in an older adult population.

This thesis aims to address this gap by investigating how adherence to an "unhealthy" Western diet pattern, or adherence to a "healthy" prudent diet pattern, moderates the relationship 
between perceived stress and cognitive function in non-demented, community-dwelling older adults. The following sections will provide an overview of the literature on cognitive aging, stress, diet intake, and the interrelationships among these factors.

\section{Cognitive Aging}

Changes in cognitive functioning with age have been well documented in the literature (Glisky, 2007). Contrary to what is recognized as a normal part of the aging process by nonexperts, cognitive aging is distinct from the diagnosis of neurodegenerative diseases such as Alzheimer's disease and other dementias that encompass pathological aging (Blazer, Yaffe, \& Karlawish, 2015). Instead, cognitive aging is best viewed as a continuum whereby some older adults exhibit minor to no changes and others exhibit major declines in cognitive abilities (Yaffe et al., 2009). Further, some cognitive abilities decrease with age such as episodic memory and executive functions, whereas other cognitive abilities are typically resilient and may even improve with age, such as language (Murman, 2015). Fluid and crystallized intelligence are classifications that have been proposed to characterize which domains of cognition often change, and which remain intact with aging.

Crystallized intelligence refers to acquired knowledge and practiced skills that are accumulated throughout the lifespan (Horn \& Cattell, 1967). These abilities include procedural memory, speech comprehension, and semantic memory (i.e., memory for facts and general knowledge; Horn \& Cattell, 1967). In contrast, fluid intelligence refers to cognitive abilities that require the capacity to learn and solve novel problems independent of knowledge gained in the past. These abilities include executive functions, which encompass higher-order mental processes such as abstract reasoning, problem-solving, planning for the future, attending to and organizing information, and response inhibition (Harada, Natelson Love, \& Triebel, 2013). 
Components of learning and memory are also constituents of fluid intelligence, and include episodic memory (i.e., memory for past specific events). In support of the distinction between fluid and crystallized intelligence, evidence from longitudinal studies suggests that age-related changes often involve a linear decline in speed of processing, reasoning, and episodic memory, while vocabulary demonstrates an upward trend until 50 years of age, and stability or minor declines with advancing age (Schaie, 1996; Salthouse, 2004).

Executive functioning is essential to perform novel tasks for which a set of habitual responses has not been learned. The ability to switch between tasks of different rules, or setshifting, is an element of executive functioning that requires cognitive flexibility and control to disengage from a previous response in favour of a novel or alternative response, and often declines into older adulthood (Zelazo, Craik, \& Booth, 2004; Wecker, Kramer, Hallam, \& Delis, 2005). Such complex cognitive processing requires considerable expenditure of attentional resources, which largely depend on the integrity of the frontoparietal control network and the prefrontal cortex (PFC), a neural structure which commonly displays changes throughout the course of normal aging (Zelazo et al., 2004). Executive functioning also facilitates the organization, integration, and maintenance of other cognitive abilities such as memory.

Declines in memory throughout the aging trajectory are well documented in the literature (Harada et al., 2013). Specifically, details and source accuracy of episodic memories (Harada et al., 2013) and prospective memory (i.e., remembering to perform an action in the future; Henry, MacLeod, Phillips, \& Crawford, 2004) are domains of memory that are affected by aging. Stages of memory including encoding and retrieval also decline with age (Friedman, Nessler, \& Johnson, 2007). In support of age-related changes in memory, Park et al. (2002) examined memory performance cross-sectionally in 324 adults ranging in age from 20 to 90 years, and 
found linear declines in speed of processing, short-term memory, and long-term memory. Maintenance of memory is largely dependent on the integrity of the PFC and the hippocampus (HC), a brain structure sensitive to changes with age (O'Shea, Cohen, Porges, Nissim, \& Woods, 2016; Reuben, Brickman, Muraskin, Steffener, \& Stern, 2011).

Memory performance measured by delayed free recall often declines with age, especially if learning requires mental manipulation of the material, if more than one task must be performed while learning, and if no cue is given for retrieval (Murman, 2015). Changes in memory performance are the result of reduced processing speed (Luszcz \& Bryan, 1999) and diminished attentional ability to ignore irrelevant stimuli (Darowski, Helder, Zacks, Hasher, \& Hambrick, 2008). This demonstrates the complex interaction between cognitive domains that are commonly treated as separate entities, given that the aforementioned abilities encompass components of both memory and executive functions (Craik, 2008). For example, Duff, Schoenberg, Scott, and Adams (2005) found a 55-60\% shared variance in performance on tests of executive functioning and learning and memory in older adults.

The maintenance of executive functioning and memory processes in older adulthood is important as both abilities have been identified as predictors of independent living and autonomy (Hart \& Bean, 2011), quality of life (Davis, Marra, Najafzadeh, \& Liu-Ambrose, 2010) and the ability to carry out activities of daily living (Gross, Rebok, Unverzagt, Willis, \& Brandt, 2011). Further, diminished executive functioning is associated with difficulties in carrying out healthpromoting behaviours such as adhering to medical regimens (Brown \& Park, 2003), as well as impaired driving which has been shown to increase the incidence of motor vehicle accidents in older adulthood (Wagner, Muri, Nef, \& Mosimann, 2011). 
Individual differences in cognitive aging. A central theme across the cognitive aging literature is the notion that age-related cognitive change is highly heterogeneous across individuals. Indeed, Rowe and Kahn (1987) posited that variability in the cognitive function of older adults is high, suggesting that some older adults show poor cognitive performance, while others show high cognitive performance. Particularly, Barnes et al. (2007) reported three distinct cognitive trajectories over a 15 -year period in a sample of community-dwelling women over the age of 65: major decliners with significant clinical decline (33\%), minor decliners $(58 \%)$, and maintainers $(9 \%)$ who exhibit no decline over 15 years. Those who maintained cognitive function exhibited a unique profile compared to minor and major declines. Namely, they were less likely to report comorbid medical conditions, less likely to have difficulty with daily activities and social integration, and more likely to engage in a healthy lifestyle. Three distinct trajectories of global cognitive function were also found in a longitudinal study by Yaffe et al. (2009), which evaluated predictors of declining and maintaining cognitive function over eight years in a biracial sample of 2,509 older adults 70-79 years of age at baseline. In comparing minor decliners with major decliners, being older, having less than a high school education, and having lower levels of social support predicted the risk of major cognitive decline. Conversely, in comparing minor decliners to cognitive maintainers, being younger, having a high school education, living with someone, engaging in moderate to vigorous weekly exercise, and not smoking predicted maintaining global cognitive function over eight years.

Together, these findings suggest that there are specific factors that differentiate high and low cognitive performers. One particular factor of interest that has been evaluated as an individual differences factor contributing to the heterogeneity of cognitive health is the perception of stress. 


\section{Perceived Stress and the Stress Response}

The term stress was first coined by Hans Selye (Selye, 1956) who described stress as a non-specific response to any demand placed upon the body. Currently, the stress response is understood as encompassing both psychological and physiological components. Lazarus's model of cognitive appraisal (Lazarus, 1966) can be used to conceptualize the psychological component of the stress response. The model posits that stress is experienced relative to: 1) how threatening the stressor is perceived to be (i.e., primary appraisals), and 2) the availability of resources available to cope with the stressor and terminate the stress response (i.e., secondary appraisals). Thus, an event is perceived as stressful when it is believed that the demands of the stressor exceed one's ability to cope. Further, situations appraised as novel, uncontrollable, unpredictable, and threatening to one's ego are more likely to be perceived as stressful, and subsequently facilitate activation of the body's biological stress response systems (Dickerson \& Kemeny, 2004).

The body's biological response to stress is facilitated by the sympathetic-adrenalmedullary (SAM) axis and the hypothalamic-pituitary-adrenal (HPA) axis (Piazza, Almeida, Dmitrieva, \& Klein, 2010), two stress-sensitive systems that begin their cascade of biological events through activation of the hypothalamus. The SAM axis is activated immediately following exposure to a stressful stimulus and is governed by the sympathetic nervous system, which releases catecholamines, adrenaline and noradrenaline, from the adrenal medulla into the bloodstream. These stress hormones trigger the fight-or-flight response characterized by autonomic indicators of sympathetic arousal such as pupil dilation, elevated heart rate and blood pressure, increased respiration, sweating, and energy mobilization to muscles (Piazza et al., 2010), all of which are vital in order to cope with an acute stressor. 
Concurrently, the slower-acting HPA axis involves a signalling cascade between the hypothalamus, pituitary gland, and adrenal cortex. In the face of a stressor, the hypothalamus releases corticotropin-releasing hormone $(\mathrm{CRH})$, which acts on the anterior pituitary gland, triggering the release of adrenocorticotropic hormone (ACTH) into the bloodstream. ACTH is transported via the blood to the adrenal cortex, which releases glucocorticoids (GCs) into the bloodstream. GCs are also called cortisol in humans and enable the individual to adapt to the stressor by further facilitating SAM axis activity, signalling immune system function, and distributing energy in the form of glucose to skeletal muscles and the brain (Piazza et al., 2010). After being released into the bloodstream, GCs cross the blood-brain barrier whereby they exert their influence on GC receptor-dense areas in the brain such as the HC and PFC (Conrad, 2008).

In order to maintain bodily homeostasis, the HPA axis is regulated by a negative feedback loop whereby cortisol signals to the hypothalamus that the stressor has subsided. Consequently, the release of cortisol is terminated in order to maintain homeostasis (Tsigos \& Chrousos, 2002). The negative feedback loop of the HPA axis is regulated in part by the HC, which as previously mentioned is a brain structure typically responsible for memory processes (Jacobson \& Sapolsky, 1991).

The systems underlying the stress response are adaptive in the short-term as they protect against adverse pressures of the environment by stabilizing and preparing the body to respond and cope, increasingly the likelihood of survival in the face of a threat (McEwen, 2007). However, chronic activation of these stress response systems in response to internal and external stressors and subsequent failure of these systems to shut down to achieve homeostasis can result in prolonged activations of stress-sensitive systems, which can have a negative impact on the body and brain (Sapolsky, Krey, \& McEwen, 1986). The glucocorticoid cascade hypothesis 
provides a mechanistic explanation for the dynamic relationship between stress and the brain. The theory posits that chronic GC secretion causes deficits in brain areas via neurotoxic effects on hippocampal neurons (Sapolsky et al., 1986). Specifically, excessive GCs released into the blood stream during periods of stress cross the blood-brain barrier and desensitize the $\mathrm{HC}$ to subsequent GC exposure by downregulating GC receptors. Over time, hippocampal damage occurs and HPA axis regulation by the $\mathrm{HC}$ becomes less effective, resulting in a feed-forward cycle of elevated GCs and continued hippocampal damage (Sapolsky et al., 1986). In support of

the glucocorticoid cascade hypothesis, Lupien et al. (1998) measured cortisol levels in 51 healthy older adults over a 5-year period and found that individuals with high basal cortisol levels had a $14 \%$ smaller hippocampal volume compared to those with moderate basal cortisol levels.

In addition to the HC, GCs also impact the integrity of the PFC. Dai, Buijis, and Swaab (2004) found that increased levels of GCs in humans resulted in diminished axonal transport of neurons in the PFC, which lead to reduced neuronal survival and function. Altogether, the abovementioned findings suggest an underlying biological mechanism for the impact of stress on cognitive performance. As such, the proceeding section will discuss research pertaining to the effects of stress on cognitive functioning.

\section{Stress and Individual Differences in Cognitive Aging}

Over three decades of research using cross-sectional and longitudinal study designs have supported the robust relationship between stress and cognitive functioning in late life. A groundbreaking study by Issa, Rowe, Gauthier, and Meaney (1990) was the first to show individual differences in cognitive performance as a function of GC activity in rodents. Specifically, this study found that basal and reactive levels of GCs were higher in cognitively impaired aged rats compared to cognitively intact aged rats. These findings were extended to 
humans in a study by Lupien et al. (1994), who examined the association between memory performance and cortisol secretion over four years in a sample of 19 healthy older adults. It was found that older adults who displayed increasing cortisol over the 4 -year period $(30 \%$ of the sample) performed more poorly on tasks assessing memory compared with older adults who displayed decreasing levels, or no change in cortisol levels over time. These results have been replicated in other studies showing that higher levels of cortisol predict declines in memory performance (Li et al. 2006; Lee, Glass, Wand, McAtee, \& Bandeen-Roche, 2008; Segerstrom, Geiger, Boggero, Schmitt, \& Sephton, 2016). Cortisol also impacts executive functioning (Sauro, Jorgensen, \& Pedlow, 2003). For example, Lee, Glass, and McAtee (2007) found that increased cortisol levels associated with worse performance on tasks of executive function. Together, these findings demonstrate the role of stress hormones on the trajectory of cognitive aging.

Robust associations between perceived stress and cognitive function have also been reported. A cross-sectional study by Korten, Comijs, Penninx, and Deeg (2017) showed that higher levels of self-reported stress were associated with worse performance on tasks of verbal memory and executive functioning in a sample of older adults between the ages of 64 and 100 . Further, in examining the association between perceived stress and cognitive function over a 2year period, higher levels of perceived stress predicted slowed performance in cognitive tasks across time (Munoz, Sliwinski, Scott, \& Hofer, 2015). Aggarwal et al. (2014) measured episodic memory using a battery of neuropsychological tests and found that perceived stress was related to lower baseline cognitive scores and a faster rate of cognitive decline over a 6.8-year period. In a recent 9-year prospective study examining perceived stress as a risk factor for cognitive decline, Turner, James, Capuano, Aggarwal, and Barnes (2017) reported that higher levels of 
perceived stress were related to faster declines in global cognition and episodic memory over time.

The relationship between stress and cognitive function is hypothesized to be a result of resource competition. Namely, stress impairs attention, which effects on performance on effortful cognitive tasks (Hasher \& Zacks, 1979). Thus, stress acts as a cognitive load, which creates a dual-task situation in which attention must be divided between cognitive task demands and coping with the demands of the stressor. When an event is perceived as stressful, cognitive resources must be allocated to cope with the demands of the stressor, thus reducing resources available to perform cognitive tasks (Stawski, Sliwinski, \& Smyth, 2006). Specifically, rumination and worrying in response to stress utilizes the cognitive capacity needed to perform such cognitive tasks, thereby reducing cognitive performance. Although the aforementioned effect of stress on cognition has been reported throughout the lifespan, it is thought to be amplified in older adults, given that attentional capacity, response inhibition, and the cognitive resources needed for coping often diminish with age (Stawski et al., 2006). In support of this notion, Stawski et al. (2006) reported that memory was worse on stressor-high days compared to stressor-free days, particularly among older adults, suggesting that older adults are especially sensitive to the adverse effects of stress on cognition.

Taken together, the aforementioned lines of research present strong evidence for the effect of stress on cognitive function and highlight the role of stress as a risk factor for cognitive decline. Thus, investigating factors that could alleviate the impact of stress on cognitive aging is important, especially given the vulnerability of older adults to the impact of stress on cognition (Sliwinski, Smyth, Hofer, \& Stawski, 2006), and the ability of cognitive performance to improve 
as stress decreases (Seeman et al., 1997). A potential moderating factor that is associated with stress and cognitive function in late life is diet and nutrient intake.

\section{Nutrient Intake and Cognitive Aging}

The main goal of nutrition research in the context of aging is to identify diets that promote optimal aging and prevent pathological aging. Most nutrition research to date focuses on individual nutrients or dietary constituents and their relationship to various health outcomes, including cognitive functioning (Morris, 2012).

Both micronutrients (i.e., vitamins and fatty acids) and macronutrients (i.e., carbohydrates, fats, and proteins) have been identified as having an impact on cognitive functioning (Staubo et al., 2017). Investigation of physiological changes at a molecular level has helped to elucidate possible mechanisms of action for changes in cognition pertaining to diet. Oxidative stress and inflammation are two potential mechanisms underlying the effects of poor nutritional intake on cognition (Butterfeld et al., 2002). Oxidative stress refers to an inability of the body to repair the harmful effects of free radical production, and triggers inflammatory processes, the body's protective mechanism against antigens (Lugrin, Rosenblatt-Velin, Parapanov, \& Liaudet, 2014). Although inflammation is advantageous in the short-term, it can have negative health consequences when chronically activated (Khansari, Shakiba, \& Mahmoudi, 2009). Specifically, oxidative stress and chronic inflammation have been identified as factors influencing the development of cognitive decline in older adulthood (Warnberg, Gomez-Martinez, Romeo, Diaz, \& Marcos, 2009). Diets low in fat-derived energy that reduce oxidative stress may be protective against cognitive decline, while a diet high in fat-derived energy that increases oxidative stress may be a risk factor for reduced cognitive function (Butterfeld et al., 2002). Inflammatory processes and oxidative stress may therefore be critical 
targets for the amelioration of declining brain function across the lifespan, which can be addressed through improved dietary intake.

Fatty acid intake is also associated with cognitive function. Dietary fatty acids are classified into saturated fatty acids and unsaturated fatty acids. Unsaturated fatty acids can be further divided into monounsaturated fatty acids (MUFAs) and polyunsaturated fatty acids (PUFAs). Among the numerous types of fatty acids, an important component of dietary fat is the level of omega-3 PUFAs, which are primarily derived from fish, nuts, and leafy vegetables (Harper \& Jacobson, 2003). Omega-3 fatty acids are associated with lower incidence of cognitive impairment through their direct influence on neuronal membrane integrity. Namely, omega-3 fatty acids consist of docosahexaenoic acid (DHA), which helps support the structural integrity and functionality of neurons (Smith \& Blumenthal, 2016). Further, foods high in omega-3 also have beneficial effects on cognitive function via brain-derived neurotropic factor (BDNF) and insulin-like growth factor-1 (IGF-1), which alter the protein pathways involved in neuronal function (Gomez-Pinilla, 2008). In support of this, Morris, Evans, Bienias, Tangney, and Wilson (2004) found that individuals with higher levels of omega-3 fatty acids were less likely to exhibit cognitive decline, while individuals with high intake of saturated fatty acids were at greater risk for cognitive decline.

Antioxidants including vitamins A, C, and E are derived from fruits and vegetables, and are also associated with cognitive function in late life. Brain tissue contains low levels of naturally occurring antioxidants and is susceptible to damage via oxidative stress in which dietary antioxidants serves as a protective factor (Lalkovicova \& Danielisova, 2016). Indeed, greater intake of foods high in antioxidants are associated with reduced rates of cognitive decline 
and improvements in cognitive performance over time (Morris, Evans, Bienias, Tangney, \& Wilson, 2002).

Additionally, macronutrients are dietary components that make up the majority of one's diet and include fat, carbohydrates, and proteins (Kritchevsky \& Houston, 2012). Diets high in saturated fats increase the risk of cognitive impairment via oxidative stress and inflammation (Freeman \& Granholm, 2012). Further, high intake of carbohydrates, specifically simple sugars such as glucose and sucrose, has been associated with poor cognitive functioning (Jurdak \& Kanarek, 2009). This effect is hypothesized to be due to sugar's involvement in insulin resistance, which limits blood flow and nutrient delivery to brain tissue, specifically the HC, impacting memory performance (Pathan, Gaikwad, Viswanad, \& Ramarao, 2008).

It is important to note that individual nutrients and foods are not consumed in isolation, and cognitive health is likely to be influenced by an interaction of multiple nutrients (Fowles, Sterling, \& Walker, 2007). Thus, examining nutrition from a dietary pattern perspective is beneficial as it may offer insights into the synergistic effects of combined nutrient patterns on cognitive functioning (Jacobs, Gross, \& Tapsell, 2009).

\section{Diet Patterns as a Holistic View of Nutrition}

In order to represent complex interactions and cumulative effects of nutrition on cognitive health, nutrition research has largely shifted to a dietary pattern analysis (Cespedes \& $\mathrm{Hu}, 2015)$. Dietary pattern analysis provides a comprehensive view of the overall diet in terms of frequency and quantity of foods consumed, the combination and variety of food groups, and their nutrients $(\mathrm{Hu}, 2002)$. The formulation of diet patterns may be theory-driven or data-driven. Theory-driven diet patterns evaluate dietary adherence to pre-existing dietary recommendations, such as the Mediterranean (Medi) diet and the Dietary Approaches to Stopping Hypertension 
(DASH) diet (Tangney et al., 2014). Conversely, data-driven diet patterns are identified via underlying correlation matrices of dietary behaviours using factor or cluster analyses based on individual food intake. Data-driven approaches are beneficial as they capture complex patterns of food intake as opposed to dichotomizing dietary behaviour into adhering to or not adhering to a specific pattern in question (Moeller et al., 2007). The Western and prudent diet are two diet patterns that are commonly derived from data-driven approaches in studies examining the relationship between diet and cognitive health (Shakersain et al., 2016). Although it is practically possible to consume foods that encompass both a prudent and Western diet pattern, data-driven approaches to deriving dietary patterns eliminate this possibility by preventing the factors from correlating in order to facilitate factor interpretability.

The Western diet is a dietary pattern that is generally characterized by low intake of essential vitamins and nutrients, and high intake of foods high in saturated fats and refined carbohydrates (Kanoski \& Davidson, 2011). Intake of red and processed meats, high-fat dairy products, white breads, butter, starchy foods (e.g., potatoes), fried foods, and foods high in processed sugars (e.g., baked goods, sugary drinks, and candy) has been identified as belonging to the Western diet pattern (Zhang et al., 2015). Conversely, a diet high in fruits, vegetables, whole grains, nuts and seeds, and moderate intake of olive oil, seafood, poultry, and low-fat dairy products characterize the prudent diet pattern (Feart, Samieri, Alles, \& Barberger-Gateau, 2013). The prudent diet pattern is suggested to be a health-conducive diet pattern due its source of B vitamins, antioxidants, and MUFAs, and lack of simple sugars and saturated fats, which provide protective effects on chronic diseases including neurodegenerative disorders (Petersson \& Philippou, 2016; Roman, Carta, Martinez-Gonzalez, \& Serra-Majem, 2008; Sofi, Abbate, \& Casini, 2008). Given that the risk for cognitive decline becomes greater with age (Salthouse, 
2009), investigating how diet patterns influence the aging brain is especially important to promote healthy aging.

Diet patterns and cognitive function. Modifiable factors include lifestyle behaviours such as diet and are especially useful as they have the potential to be altered in order to prevent or ameliorate cognitive decline in late life (Smith \& Blumenthal, 2016). Evidence linking lifestyle to brain health has highlighted the role of diet in the cognitive aging process (Milte \& McNaughton, 2016).

A number of prospective epidemiological studies have investigated adherence to a prudent diet pattern and its impact on cognitive function. For example, Panza et al. (2004) found that adherence to a prudent diet pattern high in energy intake from MUFAs was protective against age-related cognitive decline. Tangney, Kwasny, Wilson, Evans, and Morris (2011), Gardener et al. (2015), and Feart et al. (2009) also assessed the relationship between diet pattern adherence and neurocognitive performance in older adults and found that higher adherence to a prudent diet was associated with slower rates of decline in global cognition and executive functioning. Further, Anastasiou et al. (2017) found that adherence to a prudent diet in 1865 older adults was associated with better performance on neurocognitive tests of verbal episodic memory, as well as decreased odds of developing dementia. Adherence to a prudent diet is not only associated with slower cognitive decline but also attenuates the negative effects of a Western diet on cognitive performance (Shakersain et al., 2016). Although the aforementioned studies are observational in nature, a recent randomized controlled trial found that higher adherence to a diet rich in foods encompassing a prudent diet pattern associated with improvements in global cognitive function and episodic memory after a 1-year follow up 
(Marseglia et al., 2018). Altogether, these findings provide ample evidence for the protective effects of adherence to a prudent diet on cognitive function in late life.

Adherence to a Western diet pattern, which is typically high in simple sugars and saturated fats, causes neurological changes, with subsequent effects on cognitive functioning

(Attuguayefio et al., 2016). Shakersain et al. (2016) found that individuals adhering to a Western diet had greater declines in global cognitive function. As well, Jacka, Cherbuin, Anstey, Sachdev, and Butterworth (2015) found that higher consumption of a prudent diet pattern was associated with larger hippocampal volume and adherence to a Western diet pattern was associated with smaller hippocampal volume, possibly elucidating the structural mechanism through which diet patterns influences cognition.

While there are a number of factors that may determine choice of consuming a Western versus a prudent pattern diet, research has shown that the experience of stress may impact nutrient intake; especially Western-diet associated intakes of sugars, fat, and sodium.

\section{The Effect of Stress on Diet}

Stress is associated with changes in health-related behaviours including diet choice. Specifically, stress results in a preference for foods that are highly palatable, high in sugar, salt, and fat (Kandiah, Yake, Meyer, \& Jones, 2006), and a disfavour for low-fat foods including fruits and vegetables (Mikolajczyk, Ansari, \& Maxwell, 2009). Emotional eating (i.e., eating in response to negative affect) is associated with perceived stress (Thayer, 2001), and is thought to be a maladaptive coping mechanism for stress management. Additionally, physiological mechanisms involving chronic activation of the HPA axis and its subsequent effects on energy homeostasis provide a mechanism whereby stress impacts dietary behaviour. Namely, chronic activation of the HPA axis can alter glucose metabolism, promote insulin resistance, and 
influence appetite-related hormonal activity (Yau \& Potenza, 2013). Cortisol secretion is postulated to stimulate appetite, whereby those under chronic stress tend to show heightened preference for highly palatable, energy-dense foods high in sugars and fats (Takeda et al., 2004).

In line with this view, experimentally induced stress has been linked with increased intake of high-fat snack foods (Epel, Lapidus, McEwen, and Brownell, 2001). Rutters, Nieuwenhuizen, Lemmens, Born, and Westerterp-Plantenga (2009) also found that those exposed to an acute laboratory stressor consumed more foods with high-sugar and high-fat content in comparison to those administered a non-stressful task.

The results from experimental studies on stress and diet have been replicated in naturalistic settings. Newman, O'Conner, and Conner (2007) measured the number of daily hassles as a proxy of stress and found a positive association between number of daily hassles and high-fat snack intake among those with high stress-reactivity. Additionally, Ng and Jeffery (2003) and Barrington, Beresford, McGregor, and White (2014) found that greater perceived stress predicted adherence to a diet high in fat. Ansari and Berg-Beckhoff (2015) also found that higher perceived stress was associated with less frequent intake of fruits and vegetables. Further, results from the Boston Puerto Rican Health Study (Laugero et al., 2011) showed that stress was associated with poor dietary patterns (i.e., higher intake of sugary foods and saturated fats), among older adults.

Taken together, previous research has demonstrated robust associations between stress and cognition, diet and cognition, and stress and diet. No prior studies, however, have investigated the interplay between perceived stress, diet, and cognitive aging. 


\section{Study Objectives and Hypothesis}

With an aging population on the rise, it is crucial to study the factors that influence cognitive decline. Given that exposure to stress is associated with poor dietary habits, and poor diet is associated with accelerated age-related cognitive decline, investigating the ways in which stress and diet interact to impact cognition is important. Specifically, given that stress has been

identified as a detrimental, but potentially reversible factor for cognition in late life, investigating how diet intake moderates this relationship is warranted. Accordingly, this study aimed to investigate the moderating role of diet pattern adherence in the relationship between stress and cognitive function in older adults. It was hypothesized that: 1) adherence to a Western diet pattern would exacerbate the association between perceived stress and both memory and executive function, and 2) adherence to a prudent diet pattern would buffer the association between perceived stress and both memory and executive function. 


\section{Methods}

\section{Participants}

A total of 201 individuals participated in the current study. Data was obtained from a larger study examining the biological, psychological, and social factors contributing to brain health in community-dwelling older adults. A minimum sample size of 77 was needed based on a G*Power analysis (Faul, Erdfelder, Lang, \& Buchner, 2007) for a linear multiple regression model, with seven predictors, and a statistical power of $\beta=0.80$ at a significance level of $\alpha=0.05$ to detect a medium effect size of Cohen's $f^{2}=0.15$. The effect size was derived from previous studies examining the relationship between perceived stress and cognitive function in older adults that have reported a similar effect size (Korten et al., 2017).

Participants were recruited from the Greater Toronto Area through flyers, online advertisements (Kijiji) and from the Ryerson Senior Participant Pool. For recruitment material see Appendix A. To be eligible for the study, participants must have been at least 60 years of age and live independently in the community. Participants were excluded if they (a) learned English after age 12 and could not successfully obtain a score of 21 on the Shipley Vocabulary test (Shipley, 1946), (b) have undergone neuropsychological testing within the previous year, (c) presented with uncorrected vision or hearing impairment, (d) have ever undergone chemotherapy or radiation treatment, (e) had been diagnosed with a neurological disorder, learning disability, schizophrenia, or bipolar disorder, (f) had experienced a serious head injury, loss of consciousness, or had undergone general anaesthesia within the previous year, or $(\mathrm{g})$ presented with substance abuse/dependency. These exclusion criteria are important, as they are known to negatively influence cognitive function and performance on neurocognitive tests. 


\section{Measures}

Questionnaires. Participants completed a battery of psychosocial questionnaires. The following measures were analysed for the current study.

Sociodemographic and health information. A sociodemographic questionnaire (Appendix B) was administered as part of the screening process to determine eligibility for participation in the study. This screen was developed for similar studies conducted in the laboratory. Items inquired about demographic information such as age, sex, educational attainment, health-related characteristics, socioeconomic status, ethnicity, and languages spoken.

Perceived stress. The 10-item Perceived Stress Scale (PSS-10; Cohen, Kamarch \& Mermelstein, 1983) measures the degree to which situations in one's life are appraised as stressful. The questionnaire is comprised of 10 items that inquire about various thoughts and feelings experienced during the previous month; respondents answer from 0 (never) to 4 (very often). An example of an item is "In the last month, how often have you felt nervous or 'stressed?"'. Summing all items produces a total score after reverse-scoring four positively worded items, in which a larger total score is indicative of higher levels of perceived stress. The PSS-10 has a Cronbach's alpha of 0.84 to 0.86 and a test-retest reliability of 0.85 and has been validated for measurement of perceived stress among community-dwelling older adults (Ezzati et al., 2014). The PSS-10 demonstrated good internal consistency in the current sample $(\alpha=0.88)$.

Dietary intake. Dietary intake was measured using the EPIC-Norfolk Food Frequency Questionnaire (FFQ; Bingham et al., 1997), a 130-item semi-quantitative measure that records the average intake of foods consumed during the previous year. For all food items, respondents are asked to report the frequency of consumption on a 9-point scale for a medium serving, standard unit (e.g., tablespoon), or household measure (e.g., glass) from "never or less than once per month" to "more than 6 times per day". Food items are categorized into: fruit and fruit juices; 
meats, poultry, fish, and eggs; breads, cereals, and starches; dairy foods and fats; beverages; sweets and snacks; and miscellaneous foods. The questionnaire also contains items inquiring about consumption of types of fats cooked with, cereals, and milk products. Individual nutrients were converted into grams per day by using FETA statistical software (Mulligan et al., 2014), and principal component analysis (PCA) was used to derive Western and prudent diet patterns from individual food intake. The FFQ has been validated in older adults against a 16-day weighed food record and has a correlation of 0.60 to 0.70 to daily food diaries (Bingham et al., 1997; Bingham et al., 2001).

Neurocognitive Tests. Participants underwent a cognitive testing session that included tests of memory performance, executive functioning, and global cognitive functioning.

Global cognitive function. The Mini Mental State Examination (MMSE; Folstein, Folstein, \& McHugh, 1975) is an 11-item question-based measure that measures five areas of global cognitive functioning. These areas include orientation, registration, attention and calculation, recall, and language. The score for each item is summed in which a higher total score is indicative of better global cognitive functioning. The MMSE has a concurrent validity of 0.78 and a test-retest reliability of 0.89 and was administered to ensure that the sample under investigation was cognitively intact.

Episodic memory. The California Verbal Learning Test II (CVLT-II; Delis, Kramer, Kaplan, \& Ober, 2000) measures the learning and episodic remembering of verbal material (i.e., free and cued recall, serial position effects, semantic clustering, intrusions, interference, and recognition). A list of 16 items organized into four semantic categories (i.e., animals, vegetables, furniture, and ways of travelling) is presented to the participant over five immediate free recall trials and one cued recall trial. Free and cued recall is tested immediately and after a 25 -minute 
delay. A yes-no recognition trial of words is then presented. A higher free and cued immediate and delayed recall score is indicative of better episodic memory. A higher rate of change in scores over five immediate free recall trials corresponds to greater learning. The CVLT-II has been validated in older adults and has a test-retest reliability of 0.80 to 0.84 , and internal consistency of 0.78 to 0.94 (Delis et al., 2000).

Executive function. The Trail Making Task A and B (TMT-A\&B; Reitan, 1958) measures executive functioning, with a focus on attention and set-shifting. In condition A, participants are instructed to connect a set of 25 numbered circles as quickly and accurately as possible in numerical sequence. In condition B, participants are required to connect circled numbers and letters in alternating numeric and alphabetic sequence (i.e., 1, A, 2, B, etc.) starting from 1 and ending with 13. If an error is made, the test administrator corrects the examinee before advancing to the next circle. Errors and response time (in seconds) are recorded. Longer response times represent poorer executive function: times for condition A correspond to attention, while scores for condition B represent set-shifting. A ratio score (TMT-B/A) provides a sensitive index of prefrontal cortex functioning. Higher TMT-B/A scores represent poorer executive functioning. The TMT-A\&B has been validated in a sample of healthy older adults (Sanchez-Cubillo et al., 2009).

\section{Procedure}

As part of a larger study, participants who met inclusion/exclusion criteria were invited to visit the Stress and Healthy Aging Research Laboratory at Ryerson University. All testing sessions were scheduled to begin between 8:00 and 10:00 to ensure optimal cognitive performance (May, Hasher, \& Stoltzfus, 1993). Following the provision of consent (Appendix C), participants underwent neurocognitive testing, which included completion of the MMSE, 
CVLT-II, and the TMT-A\&B (Appendix D, E, and F). Participants then completed a battery of questionnaires including the PSS-10 and the FFQ (Appendix G and H). Blood pressure readings, height, and weight were also obtained. Upon study completion, participants were debriefed (Appendix I) and compensated $\$ 100$ for their participation. This study was approved by the Ryerson University Research Ethics Board (REB 2014-164).

\section{Statistical Analyses}

All statistical analyses were conducted using IBM SPSS Statistics v23, and two-tailed $p$ values of .05 were used for all analyses. Participant's data were removed if $10 \%$ or more of their questionnaire and neurocognitive test scores were missing; otherwise responses were imputed using mean substitution. Missing FFQ responses were inputting using median substitution. Outliers were detected using the outlier-labelling rule (Hoaglin \& Iglewicz, 1987), whereby the interquartile range is multiplied by a factor of 2.2. Participants were deemed as outliers and subsequently excluded from analyses if their scores exceeded or fell below 2.2 times the interquartile range of the sample score.

Derivation of Diet Patterns. Individual food consumption was converted from the FFQ scale to consumption per day on a 9-point scale from 0 times per day to 6 or more times per day. All 130 foods were collapsed into one of 35 food categories based on culinary usage (see Appendix J). These categories included: processed meats, poultry, organ meats, other meats, fish and seafood, fatty fish, tofu and soy-based foods, eggs and egg dishes, refined grains, while grains, potatoes, candy and added sugars, sweet baked goods, butter on bread and/or vegetables, margarine on bread and/or vegetables, condiments, salty snacks, fried and/or fast foods soups, sauces, high-fat dairy, low-fat dairy, cereals, cruciferous vegetables, leafy greens, other vegetables, nuts and seeds, legumes, berries, other fruits, sugary drinks, diet drinks, coffee and 
tea, alcohol, and other. Exposure to each category was calculated by adding the frequency score for each respective food item within the given group. From these collapsed categories, two dietary patterns were identified using varimax rotated PCA resulting in non-correlated factors to facilitate factor interpretability. Based on recommendations from Norman and Streiner (2000), factor loadings with an absolute value greater than $5.152 / \sqrt{ }(N-2)$ were considered significant contributors to the factor interpretation. Dietary pattern scores for each participant were calculated by converting the average score for each category belonging to the given pattern to zscores.

Moderating Role of Diet Patterns. To test for the moderating effect of diet patterns on the relationship between perceived stress (predictor variable) and cognitive functioning (outcome variable), SPSS PROCESS Macro (Hayes, 2017) was used. The score for total correct words recalled immediately and after the delay on the CVLT-II (i.e., CVLT-IFR and CVLT-LDFR, respectively) was used to measure episodic memory. Scores on TMT-A, TMT-B, and TMT-B/A were used to measure executive functioning. Simple slopes reflect conditional effects of the independent variable at the mean level of the moderator, and 1 standard deviation above and below the mean level of the moderator.

A total of 10 moderation models were run: 1) the moderating role of the Western diet pattern on the relationship between perceived stress and executive function (TMT-A, TMT-B-, and TMT-B/A), 2) the moderating role of the Western diet pattern on the relationship between perceived stress and episodic memory (CVLT-IFR and CVLT-LDFR), 3) the moderating role of the prudent diet pattern on the relationship between perceived stress and executive function (TMT-A, TMT-B-, and TMT-B/A), and 4) the moderating role of the prudent diet pattern on the 
relationship between perceived stress and episodic memory (CVLT-IFR and CVLT-LDFR). See Figures $1 \mathrm{a}, 1 \mathrm{~b}, 1 \mathrm{c}$, and $1 \mathrm{~d}$ for a visual representation of the moderation models.

A series of multiple linear regression models were also conducted to determine the association between: 1) perceived stress and episodic memory, 2) perceived stress and executive function, 3) prudent diet and episodic memory, 4) prudent diet and executive function, 5) Western diet and episodic memory, 6) Western diet and executive function, 7) perceived stress and prudent diet, and 8) perceived stress and Western diet.

Given that age (Salthouse, 2004), sex (McCarrey, An, Kitner-Triolo, Ferrucci, \& Resnick, 2016), and years of education (Wilson et al., 2009), is associated with cognitive function they were entered as a priori covariates in the aforementioned moderation models and all linear regression models. Daily energy intake (kCal) was also added into the models as an $a$ priori covariate in models with diet pattern as an independent, dependent, or moderator variable, in order to control for effects of calorie intake on cognitive function (Geda et al., 2013). Additional covariates were added to the tested models if they significantly associated with the dependent variable and/or independent variable. 
a)

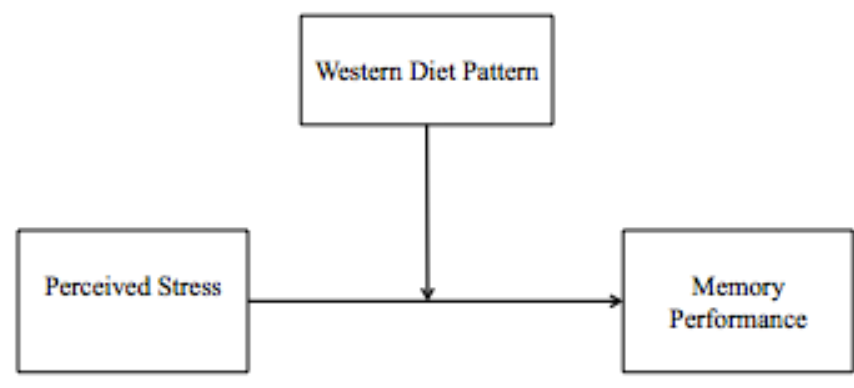

c)

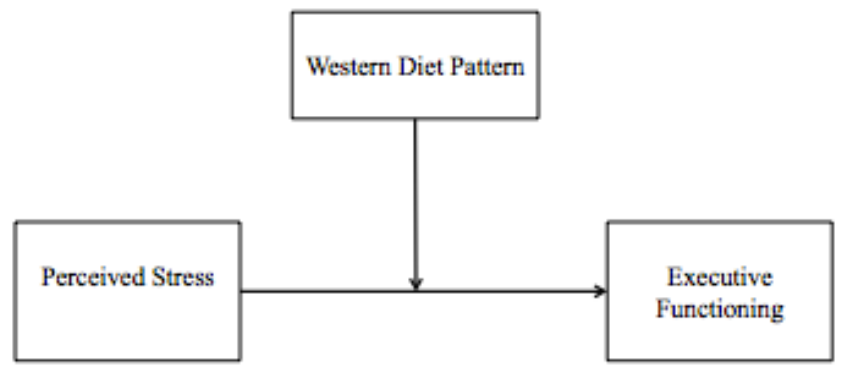

b)

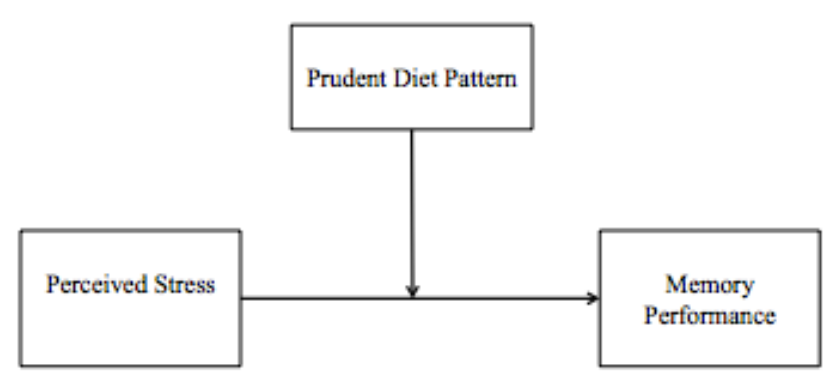

d)

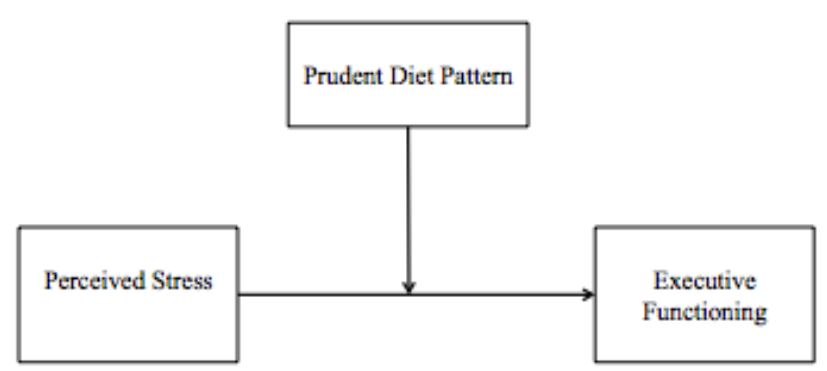

Figure 1. The proposed model of the moderating effect of a) adherence to a Western diet pattern on the relationship between perceived stress and memory performance, b) adherence to a prudent diet pattern on the relationship between perceived stress and memory performance, c) adherence to a Western diet pattern on the relationship between perceived stress and executive functioning, and d) adherence to a prudent diet pattern on the relationship between perceived stress and executive functioning. 


\section{Results}

\section{Participant Characteristics}

A total of 201 participants were recruited for the study. Three participants were excluded from analyses due to more than $10 \%$ of their neuropsychological test scores missing, two participants were removed due to extreme calorie values ( $<800$ or $>5,000$ calories), and four were excluded due to more than $10 \%$ of their FFQ responses missing. This resulted in a final sample of 192. One individual did not consent to having their ethnicity used in the analyses. No other missing data points were present, so missing data imputation was not conducted. Although statistical outliers were identified using the outlier labelling rule, they were not deemed to be theoretically meaningful to remove and were subsequently kept in the analyses. A complete list of participant demographic and health-related characteristics, including performance on neurocognitive tests, is shown in Table 1.

Table 1. Participant Demographic and Health-Related Characteristics.

\begin{tabular}{ll}
\hline$N=192$ & Mean (SD) \\
\hline Age & $68.45(.49)$ \\
Years of education & $16.75(.25)$ \\
Sex (\% female) & 64.1 \\
Ethnicity (\% Caucasian) & 86.5 \\
Perceived SES (\%) & \\
$\quad$ Low & 20.3 \\
$\quad$ Medium & 68.2 \\
$\quad$ High & 11.5 \\
MMSE score & $28.43(.11)$ \\
Hypertension (\%) & 21.9 \\
Diabetes (\%) & 5.7 \\
Systolic blood pressure (mmHg) & $131.07(1.26)$ \\
Diastolic blood pressure (mmHg) & $79.87(.72)$ \\
Body mass index & $26.79(.35)$ \\
Daily energy intake (kCal) & $1728.12(52.60)$ \\
PSS-10 & $11.86(0.46)$ \\
CVLT-IFR & $48.06(9.79)$ \\
CVLT-LDFR & $9.76(3.84)$ \\
TMT-A (seconds) & $34.04(0.80)$ \\
\hline
\end{tabular}


Notes. Percentage reflects proportion of respondents

$\mathrm{SD}=$ standard deviation; $\mathrm{SES}=$ socioeconomic status; MMSE $=$ Mini-Mental State

Examination; $\mathrm{kCal}=$ kilocalories; PSS-10 $=$ Perceived Stress Scale; CVLT-IFR $=$ California Verbal Learning Test Immediate Free Recall; CVLT-LDFR $=$ California Verbal Learning Test Long Delay Free Recall; TMT-A = Trail Making Test Part A; TMT-B = Trail Making Test Part B; TMT-B/A = Trail Making Test Part B/Part A

\section{Diet Patterns}

The two factors identified using PCA accounted for $13.47 \%$ and $10.19 \%$ of the variance in the model. The first pattern was characterized by high consumption of processed meats, refined grains, fried foods, potatoes, candy, baked goods, butter, condiments, and high-fat dairy; and was named the Western diet pattern. The second diet pattern was associated with high consumption of fruits, vegetables, fish and seafood, nuts and seeds, legumes, tofu and soy products, and low-fat dairy; and was labelled the prudent diet pattern. Factor loadings for each food category on the respective factors are shown in Table 2. The standardized individual scores ranged from -1.94 to 4.00 for the Western diet, and -2.24 to 2.67 for the prudent diet pattern.

Table 2. Factor Loadings for Dietary Patterns.

\begin{tabular}{lll}
\hline Food group & Pattern 1 (Western diet) & Pattern 2 (prudent diet) \\
\hline Processed meats & $\mathbf{0 . 5 9}$ & -0.22 \\
Meats (other) & $\mathbf{0 . 6 3}$ & -0.15 \\
Refined grains & $\mathbf{0 . 7 2}$ & -0.01 \\
Potatoes & $\mathbf{0 . 5 7}$ & -0.002 \\
Candy and sugars & $\mathbf{0 . 5 0}$ & 0.14 \\
Baked goods & $\mathbf{0 . 4 6}$ & 0.16 \\
Butter & $\mathbf{0 . 4 6}$ & 0.003 \\
Condiments & $\mathbf{0 . 6 5}$ & 0.14 \\
High-fat dairy & $\mathbf{0 . 4 0}$ & 0.23 \\
Fried foods & $\mathbf{0 . 5 9}$ & -0.11 \\
Fish and seafood & 0.20 & $\mathbf{0 . 4 0}$ \\
Fatty fish & 0.02 & $\mathbf{0 . 3 8}$ \\
Tofu and soy & -0.36 & $\mathbf{0 . 4 9}$ \\
Cruciferous vegetables & 0.09 & $\mathbf{0 . 6 6}$ \\
Leafy Vegetables & 0.13 & $\mathbf{0 . 6 7}$ \\
Vegetables (other) & 0.20 & $\mathbf{0 . 7 8}$ \\
Fruits & 0.08 & $\mathbf{0 . 6 6}$
\end{tabular}




$\begin{array}{lll}\text { Berries } & 0.04 & \mathbf{0 . 4 7} \\ \text { Nuts and seeds } & -0.01 & \mathbf{0 . 4 9} \\ \text { Legumes } & 0.04 & \mathbf{0 . 6 1} \\ \text { Low-fat dairy } & -0.11 & \mathbf{0 . 4 2} \\ \text { Poultry } & 0.30 & -0.03 \\ \text { Organ meats } & 0.20 & 0.04 \\ \text { Eggs and egg dishes } & 0.30 & 0.24 \\ \text { Whole grains } & 0.05 & 0.30 \\ \text { Margarine } & 0.22 & 0.08 \\ \text { Salty snacks } & 0.19 & 0.10 \\ \text { Soups } & 0.37 & 0.23 \\ \text { Dressings and dips } & 0.30 & 0.27 \\ \text { Cereals } & 0.13 & 0.18 \\ \text { Sugary drinks } & 0.28 & 0.04 \\ \text { Diet drinks } & 0.07 & -0.13 \\ \text { Coffee and tea } & 0.18 & 0.08 \\ \text { Alcohol } & 0.19 & -0.14 \\ \text { Other } & 0.30 & -0.08\end{array}$

Notes. Loadings represent the correlation of a food with overall dietary pattern score Loadings with absolute values $>0.374$ or $<-0.374$ (in bold) were considered when interpreting the obtained patterns

\section{Covariates of Interest}

Age, sex, years of education, and kCal were entered into all models as a priori covariates. BMI, hypertension, diabetes, perceived SES, and ethnicity were considered as additional covariates. Associations between covariates of interest and independent, moderator, and dependent variables are shown in Table 3. Higher age was associated with worse performance on the CVLT-LDFR, TMT-A, and TMT-B/A. Years of education was associated with lower scores on the PSS-10. Females scored higher than males on the PSS-10, CVLT-IFR, and CVLT-LDFR. Higher kCal was associated with higher prudent diet and Western diet intake. Lower BMI was associated with higher prudent diet adherence. Having hypertension was associated with worse performance on the CVLT-LDFR and higher Western diet pattern adherence. Presence of diabetes was associated with worse performance on TMT-B and TMT-B/A. PSS-10 was associated with perceived SES $(F(2,191)=7.61, p=0.001)$. Bonferroni corrected post-hoc 
comparisons revealed that those reporting low SES had lower PSS-10 scores than medium SES $(M=-3.38, p=0.01)$ and high SES $(M=-6.14, p=0.001)$. Ethnicity was, associated with prudent diet intake, such that non-Caucasians had higher prudent diet intake. 
Table 3. Pearson correlation coefficients of independent, moderator, and dependent variables with covariates of interest.

\begin{tabular}{lllllllll}
\hline & PSS-10 & Prudent diet & Western diet & CVLT-IFR & CVLT-LDFR & TMT-A & TMT-B & TMT-B/A \\
\hline Age & $-0.26^{* *}$ & -0.02 & -0.08 & -0.10 & $-0.17^{*}$ & $0.26^{* *}$ & 0.06 & $-0.15^{*}$ \\
Sex & $-0.16^{*}$ & -0.14 & 0.10 & $-0.18^{*}$ & $-0.18^{*}$ & -0.02 & -0.13 & -0.12 \\
Education & $-0.18^{*}$ & -0.14 & 0.13 & 0.05 & 0.13 & -0.05 & -0.13 & -0.10 \\
kCal & 0.09 & $0.46^{* *}$ & $0.61^{* *}$ & -0.01 & -0.01 & -0.11 & -0.07 & 0.05 \\
BMI & -0.01 & $-0.19^{*}$ & 0.12 & -0.07 & -0.02 & 0.01 & 0.06 & 0.05 \\
Hypertension & -0.01 & -0.09 & $0.15^{*}$ & -0.11 & -0.15 & 0.07 & 0.05 & 0.06 \\
Diabetes & 0.08 & 0.01 & 0.13 & -0.02 & -0.04 & 0.01 & $0.19^{* *}$ & $0.26^{* *}$ \\
Perceived SES & $-0.27^{* *}$ & 0.08 & -0.02 & 0.07 & 0.05 & -0.08 & -0.07 & -0.02 \\
Ethnicity & 0.08 & $-0.22^{* *}$ & -0.04 & -0.10 & -0.14 & 0.13 & 0.01 & -0.09 \\
\hline
\end{tabular}

Notes. PSS-10 = Perceived Stress Scale; CVLT-IFR = California Verbal Learning Test Immediate Free Recall; CVLT-LDFR =

California Verbal Learning Test Long Delay Free Recall; TMT-A = Trail Making Test Part A; TMT-B = Trail Making Test Part B;

TMT-B/A = Trail Making Test Part B/Part A; kCal = kilocalories; $\mathrm{BMI}=$ body mass index $\mathrm{SES}=$ socioeconomic status

$* p<0.05, * * p<0.01 *$ 


\section{The Association Between Perceived Stress and Cognition}

Episodic Memory. Two hierarchical linear regression models were conducted to examine the association of perceived stress and episodic memory via CVLT-IFR and CVLTLDFR performance. Controlling for age, sex, and years of education, the fully adjusted models revealed that all covariates and PSS-10 score combined accounted for $5.7 \%$ and $8.8 \%$ of the variance in CVLT-IFR and CVLT-LDFR, respectively. PSS-10 score, however, was not significantly associated with CVLT-IFR $(\beta=-0.08, t(191)=-1.17, p=0.24)$ or CVLT-LDFR performance $(\beta=-0.04, t(191)=-0.57, p=0.57)$. See Table 4 for model details. Perceived SES and hypertension were added into the linear regression models as additional covariates, but the association between PSS-10 and CVLT-II scores did not change ( $p$ s $>0.05)$.

Table 4. Linear Regression Models of PSS-10 and CVLT-II.

\begin{tabular}{lllll}
\hline & $B$ & $S E$ & $\beta$ & $p$ \\
\hline CVLT-IFR & & & & \\
\hline Age & -0.17 & 0.11 & -0.12 & 0.10 \\
Sex & -4.16 & 1.48 & -0.20 & $0.005^{* *}$ \\
Years of education & 0.21 & 0.21 & 0.07 & 0.32 \\
PSS-10 & -0.13 & 0.11 & -0.09 & 0.24 \\
\hline CVLT-LDFR & & & & \\
\hline Age & -0.10 & 0.04 & -0.18 & $0.01^{*}$ \\
Sex & -1.60 & 0.57 & -0.20 & $0.005^{*}$ \\
Years of education & 0.18 & 0.08 & 0.16 & $0.02^{*}$ \\
PSS-10 & -0.03 & 0.04 & -0.04 & 0.57 \\
\hline
\end{tabular}

Notes. CVLT-IFR = California Verbal Learning Test Immediate Free Recall; CVLT-LDFR $=$ California Verbal Learning Test Long Delay Free Recall; PSS-10 = Perceived Stress Scale CVLT-IFR: $R^{2}=0.06, F(4,191)=2.84, p=0.03$; CVLT-LDFR: $R^{2}=0.09, F(4,191)=4.50, p=$ 0.002. $* p<0.05, * * p<0.01$

Executive Function. Hierarchical linear regression models were conducted to determine the association between perceived stress and executive functioning (i.e., TMT-A, TMT-B, and TMT-B/A performance). Controlling for age, sex, and years of education, all covariates and PSS-10 accounted for $7.5 \%, 4.8 \%$, and $4.6 \%$ of the variance in TMT-A, TMT-B, and TMT-B/A, 
respectively. PSS-10 was not significantly associated with TMT-A $(\beta=0.07, t(191)=0.98, p=$ $0.33)$, TMT-B $(\beta=0.13, t(191)=1.68, p=0.10)$, or TMT-B $/ \mathrm{A}(\beta=0.06, t(191)=0.85, p=$ 0.40). See Table 5 for model details. Additional covariates were added into the models, but the association between PSS-10 and TMT performance remained insignificant $(p \mathrm{~s}>0.05)$.

Table 5. Linear Regression Models of PSS-10 and TMT.

\begin{tabular}{lllll}
\hline & $B$ & $S E$ & $\beta$ & $p$ \\
\hline TMT-A & & & & \\
\hline Age & 0.46 & 0.12 & 0.28 & $<0.001^{* *}$ \\
Sex & -0.28 & 1.66 & -0.01 & 0.87 \\
Years of education & -0.14 & 0.23 & -0.05 & 0.54 \\
PSS-10 & 0.13 & 0.13 & 0.07 & 0.33 \\
\hline TMT-B & & & & \\
\hline Age & 0.66 & 0.47 & 0.10 & 0.16 \\
Sex & -8.47 & 6.52 & -0.10 & 0.20 \\
Years of education & -1.23 & 0.91 & -0.10 & 0.18 \\
PSS-10 & 0.85 & 0.51 & 0.13 & \\
\hline TMT-B/A & & & & 0.08 \\
\hline Age & -0.02 & 0.01 & -0.13 & 0.22 \\
Sex & -0.20 & 0.16 & -0.09 & 0.32 \\
Years of education & -0.02 & 0.02 & -0.07 & 0.40 \\
PSS-10 & 0.01 & 0.01 & 0.06 & . \\
\hline
\end{tabular}

Notes. TMT-A $=$ Trail Making Test Part A; TMT-B $=$ Trail Making Test Part B; TMT-B/A = Trail Making Test Part B/Part A; PSS-10 = Perceived Stress Scale TMT-A: $R^{2}=0.08, F(4,191)=3.79, p=0.006$; TMT-B: $R^{2}=0.05, F(4,191)=2.37, p=0.05$; TMT-B/A: $R^{2}=0.05, F(5,191)=2.27, p=0.06{ }^{*} p<0.05, * * p<0.01$

\section{The Association Between Diet Patterns and Cognition}

Episodic Memory. Adjusting for age, sex, years of education, and kCal, four hierarchical linear regression models were conducted to examine the association between prudent and Western diet on episodic memory (CVLT-IFR and CVLT-LDFR performance). All covariates and prudent diet intake accounted for 5.1\% and 8.6\% of the variance in CVLT-IFR and CVLTLDFR performance, respectively. Prudent diet, however, was not associated with CVLT-IFR ( $\beta$ $=0.01, t(191)=0.09, p=0.93)$ or CVLT-LDFR $(\beta=-0.01, t(191)=-0.15, p=0.89)$. Western diet intake and all covariates accounted for $6.6 \%$ and $9.1 \%$ of the variance in CVLT-IFR and 
CVLT-LDFR, respectively. Western diet was not associated with CVLT-IFR $(\beta=0.16, t(191)=$ $1.77, p=0.08)$ or CVLT-LDFR $(\beta=0.09, t(191)=1.03, p=0.31)$. See Table 6 for model details. Additional covariates were entered into the models, but the association between diet patterns and CVLT-II scores remained insignificant $(p \mathrm{~s}>0.05)$.

Table 6. Linear Regression Models of Diet Patterns and CVLT-II.

\begin{tabular}{|c|c|c|c|c|}
\hline & $B$ & $S E$ & $\beta$ & $p$ \\
\hline \multicolumn{5}{|l|}{ CVLT-IFR } \\
\hline Age & -0.15 & 0.10 & -0.10 & 0.16 \\
\hline Sex & -3.89 & 1.51 & -0.19 & $0.01 *$ \\
\hline Years of education & 0.24 & 0.21 & 0.08 & $0.26^{*}$ \\
\hline $\mathrm{kCal}$ & $<0.001$ & 0.001 & -0.02 & 0.84 \\
\hline Prudent diet & 0.08 & 0.82 & 0.01 & 0.93 \\
\hline Age & -0.15 & 0.10 & -0.10 & 0.16 \\
\hline Sex & -4.18 & 1.47 & -0.21 & $0.005 * *$ \\
\hline Years of education & 0.30 & 0.21 & 0.11 & 0.14 \\
\hline $\mathrm{kCal}$ & -0.001 & 0.001 & -0.11 & 0.122 \\
\hline Western diet & 1.58 & 0.90 & 0.16 & 0.08 \\
\hline \multicolumn{5}{|l|}{ CVLT-LDFR } \\
\hline Age & -0.10 & 0.04 & -0.17 & $0.02 *$ \\
\hline Sex & -1.57 & 0.58 & -0.20 & $0.008 * *$ \\
\hline Years of education & 0.19 & 0.08 & 0.17 & $0.02 *$ \\
\hline $\mathrm{kCal}$ & $<0.001$ & $<0.001$ & -0.007 & 0.93 \\
\hline Prudent diet & -0.05 & 0.32 & -0.01 & 0.89 \\
\hline Age & -0.10 & 0.04 & -0.17 & $0.02 *$ \\
\hline Sex & -1.61 & 0.57 & -0.20 & $0.005 * *$ \\
\hline Years of education & 0.20 & 0.08 & 0.18 & $0.01 *$ \\
\hline $\mathrm{kCal}$ & $<0.001$ & $<0.001$ & -0.07 & 0.44 \\
\hline Western diet & 0.36 & 0.35 & 0.09 & 0.31 \\
\hline
\end{tabular}

Notes. CVLT-IFR $=$ California Verbal Learning Test Immediate Free Recall; CVLT-LDFR $=$ California Verbal Learning Test Long Delay Free Recall; PSS-10 = Perceived Stress Scale; kCal $=$ kilocalories

CVLT-IFR, prudent diet: $R^{2}=0.05, F(5,191)=1.99, p=0.08$; CVLT-IFR, Western diet: $R^{2}=$ $0.07, F(5,191)=2.64, p=0.03$; CVLT-LDFR, prudent diet: $R^{2}=0.09, F(5,191)=3.49, p=$ 0.005; CVLT-LDFR, Western diet: $R^{2}=0.09, F(5,191)=3.72, p=0.003 .{ }^{*} p<0.05,{ }^{*} p<0.01$

Executive Function. Hierarchical linear regression models were conducted to determine if prudent and Western diet were associated with executive function (TMT-A, TMT-B, and TMT-B/A performance). Adjusting for age, sex, years of education, and $\mathrm{kCal}$, all covariates and 
prudent diet intake accounted for $7.7 \%, 4.2 \%$, and $5.0 \%$ of the variance in TMT-A, TMT-B, and TMT-B/A, respectively. Prudent diet was not associated with TMT-A $(\beta=-0.03, t(190)=-0.33$, $p=0.74)$, TMT-B $(\beta=-0.07, t(190)=-0.86, p=0.39)$, or TMT-B/A $(\beta=-0.09, t(190)=-1.06, p$ $=0.29)$. All covariates and Western diet accounted for $7.8 \%, 4.8 \%$, and $5.9 \%$ of the variance in TMT-A, TMT-B, and TMT-B/A, respectively. Western diet, however, was not associated with TMT-A $(\beta=-0.05, t(190)=-0.49, p=0.62)$, TMT-B $(\beta=-0.12, t(190)=-1.36, p=0.17)$, or TMT-B/A $(\beta=-0.15, t(190)=-1.67, p=0.10)$. See Table 7 for model details. Additional covariates were entered into the models, but the association between diet patterns and TMT scores remained insignificant $(p s>0.05)$.

Table 7. Linear Regression Models of Diet Patterns and TMT.

\begin{tabular}{lllll}
\hline & $B$ & $S E$ & $\beta$ & $p$ \\
\hline TMT-A & & & & $<0.001^{* *}$ \\
\hline Age & 0.42 & 0.12 & 0.25 & 0.75 \\
Sex & -0.54 & 1.70 & -0.02 & 0.42 \\
Years of education & -0.19 & 0.24 & -0.06 & 0.48 \\
kCal & -0.001 & 0.001 & -0.06 & 0.74 \\
Prudent diet & -0.30 & 0.92 & -0.03 & $0.001^{* *}$ \\
\hline Age & 0.41 & 0.12 & 0.25 & 0.84 \\
Sex & -0.34 & 1.66 & -0.01 & 0.34 \\
Years of education & -0.23 & 0.24 & -0.07 & 0.63 \\
kCal & -0.001 & 0.001 & -0.04 & 0.62 \\
Western diet & -0.50 & 1.02 & -0.05 & \\
\hline TMT-B & & & & 0.34 \\
\hline Age & 0.45 & 0.46 & 0.07 & 0.10 \\
Sex & -10.96 & 6.69 & -0.12 & 0.13 \\
Years of education & -1.42 & 0.93 & -0.11 & 0.39 \\
kCal & -0.001 & 0.005 & -0.02 & 0.36 \\
Prudent diet & -3.13 & 3.63 & -0.07 & 0.18 \\
\hline Age & 0.42 & 0.46 & 0.07 & 0.06 \\
Sex & -8.80 & 6.55 & -0.10 & 0.79 \\
Years of education & -1.79 & 0.93 & 0.14 & 0.17 \\
kCal & 0.001 & 0.005 & 0.03 & 0.11 \\
Western diet & -5.46 & 4.00 & -0.13 & \\
\hline TMT-B/A & & & -0.14 & -0.12 \\
\hline Age & -0.02 & 0.01 & & \\
Sex & -0.26 & 0.16 & & \\
& & & & \\
\hline
\end{tabular}




\begin{tabular}{lllll} 
Years of education & -0.02 & 0.02 & -0.07 & 0.35 \\
kCal & $<0.001$ & $<0.001$ & 0.08 & 0.31 \\
Prudent diet & -0.09 & 0.09 & -0.09 & 0.29 \\
\hline Age & -0.02 & 0.01 & -0.14 & 0.05 \\
Sex & -0.19 & 0.16 & -0.09 & 0.22 \\
Years of education & -0.03 & 0.02 & -0.11 & 0.15 \\
kCal & $<0.001$ & $<0.001$ & 0.13 & 0.14 \\
Western diet & -0.16 & 0.10 & -0.15 & 0.10 \\
\hline
\end{tabular}

Notes. TMT-A = Trail Making Test Part A; TMT-B = Trail Making Test Part B; TMT-B/A =

Trail Making Test Part B/Part A; PSS-10 = Perceived Stress Scale; $\mathrm{kCal}=$ kilocalories TMT-A, prudent diet: $R^{2}=0.08, F(5,190)=3.08, p=0.01$; TMT-A, Western diet: $R^{2}=0.08$, $F(5,190)=3.11, p=0.01$; TMT-B, prudent diet: $R^{2}=0.04, F(5,190)=1.62, p=0.16$; TMT-B, Western diet: $R^{2}=0.05, F(5,190)=1.85, p=0.11$; TMT-B/A, prudent diet: $R^{2}=0.05, F(5,190)$ $=1.96, p=0.09$; TMT-B/A, Western diet: $R^{2}=0.06, F(5,190)=2.31, p=0.046 .{ }^{*} p<0.05,{ }^{* *} p$ $<0.01$

\section{The Association Between Perceived Stress and Diet Patterns}

In order to determine the association between perceived stress and both prudent and Western diet consumption, two hierarchical linear regression models were conducted.

Controlling for age, sex, years of education, and kCal, all covariates and PSS-10 accounted for $26.7 \%$ and $40.0 \%$ of the variance in prudent diet and Western diet, respectively. PSS-10, however, was not associated with prudent $\operatorname{diet}(\beta=-0.007, t(190)=-0.11, p=0.92)$ or Western diet consumption $(\beta=-0.03, t(190)=-0.47, p=0.64)$. See Table 8 for model details. Additional covariates were entered into the models, but the association between PSS-10 and diet patterns remained insignificant $(p s>0.05)$.

Table 8. Linear Regression Models of PSS-10 and Diet Patterns.

\begin{tabular}{lllll}
\hline & $B$ & $S E$ & $\beta$ & $p$ \\
\hline Prudent diet & & & & \\
\hline Age & 0.01 & 0.01 & 0.05 & 0.49 \\
Sex & -0.40 & 0.13 & -0.19 & $0.003^{* *}$ \\
Years of education & 0.05 & 0.02 & 0.16 & $0.01^{*}$ \\
kCal & 0.001 & $<0.001$ & 0.48 & $<0.001^{* *}$ \\
PSS-10 & -0.001 & 0.01 & -0.007 & 0.92 \\
\hline Western diet & & & & \\
\hline Age & -0.001 & 0.009 & -0.007 & 0.90 \\
Sex & 0.16 & 0.12 & 0.08 & 0.19
\end{tabular}




\begin{tabular}{lllll} 
Years of education & -0.04 & 0.02 & -0.14 & $0.02 *$ \\
kCal & 0.001 & $<0.001$ & 0.61 & $<0.001 * *$ \\
PSS-10 & -0.004 & 0.009 & -0.03 & 0.64 \\
\hline
\end{tabular}

Notes. PSS-10 $=$ Perceived Stress Scale; $\mathrm{kCal}=$ kilocalories

Prudent diet: $R^{2}=0.27, F(5,190)=13.49, p<0.001$; Western diet: $R^{2}=0.40, F(5,190)=24.65$, $p<0.001 . * p<0.05, * * p<0.01$

\section{Diet as a Moderator of the Perceived Stress-Cognition Relationship}

Prudent Diet and Episodic Memory. Two moderation models were conducted to

determine if prudent diet adherence moderates the relationship between perceived stress and episodic memory performance (CVLT-IFR and CVLT-LDFR). Adjusting for age, sex, years of education, and $\mathrm{kCal}$, the moderation models accounted for $5.8 \%$ of the variance in CVLT-IFR and $9.2 \%$ of the variance in CVLT-LDFR. No significant PSS- $10 \times$ prudent diet interaction was found for CVLT-IFR $(B=0.01, t(184)=0.10, p=0.92)$, or CVLT-LDFR $(B=0.04, t(184)=$ $0.87, p=0.39$ ). See Table 9 for model details.

Table 9. Moderation Models of PSS-10 $\times$ Prudent Diet and CVLT-II.

\begin{tabular}{llll}
\hline & $B$ & $S E$ & $p$ \\
\hline CVLT-IFR & & & \\
\hline Age & -0.17 & 0.11 & 0.11 \\
Sex & -4.13 & 1.53 & $0.007^{* *}$ \\
Years of education & 0.20 & 0.21 & 0.34 \\
kCal & $<-0.001$ & 0.001 & 0.89 \\
PSS-10 & -0.13 & 0.12 & 0.27 \\
Prudent diet & -0.06 & 1.54 & 0.97 \\
PSS-10 $\times$ prudent diet & 0.01 & 0.11 & 0.92 \\
$\quad$ Low prudent diet & -0.14 & 0.14 & 0.33 \\
$\quad$ Moderate prudent diet & -0.13 & 0.12 & 0.27 \\
$\quad$ High prudent diet & -0.12 & 0.17 & 0.49 \\
\hline CVLT-LDFR & & & \\
\hline Age & -0.10 & 0.04 & $0.02^{*}$ \\
Sex & -1.64 & 0.59 & $0.006^{* *}$ \\
Years of education & 0.18 & 0.08 & $0.03^{*}$ \\
kCal & $<0.001$ & $<0.001$ & 0.93 \\
PSS-10 & -0.02 & 0.05 & 0.70 \\
Prudent diet & -0.48 & 0.59 & 0.42 \\
PSS-10 $\times$ prudent diet & 0.04 & 0.04 & 0.39
\end{tabular}




$\begin{array}{llll}\text { Low prudent diet } & -0.05 & 0.06 & 0.34 \\ \text { Moderate prudent diet } & -0.02 & 0.05 & 0.70 \\ \text { High prudent diet } & 0.02 & 0.07 & 0.79\end{array}$

Notes. CVLT-IFR = California Verbal Learning Test Immediate Free Recall; CVLT-LDFR = California Verbal Learning Test Long Delay Free Recall; PSS-10= Perceived Stress Scale; kCal $=$ kilocalories

CVLT-IFR: $R^{2}=0.06, F(7,184)=1.60, p=0.14$; CVLT-LDFR: $R^{2}=0.09, F(7,184)=2.63, p=$ 0.01. $* p<0.05, * * p<0.01$

Prudent Diet and Executive Function. Moderation models were conducted to examine if prudent diet intake moderated the relationship between executive function via TMT-A, TMT$\mathrm{B}$, and TMT-B/A performance and perceived stress. Controlling for age, sex, years of education, and $\mathrm{kCal}$, the moderation model accounted for $8.6 \%, 8.7 \%$, and $6.8 \%$ of the variance in TMT-A, TMT-B, and TMT-B/A, respectively. No significant PSS-10 $\times$ prudent diet interaction was found for TMT-A $(B=-0.11, t(184)=-0.89, p=0.37)$ or TMT-B/A $(B=-0.02, t(184)=-1.69, p=$ 0.09). A significant PSS-10 $\times$ prudent diet interaction was found for TMT-B $(B=-1.13, t(184)=$ $-2.45, p=0.02)$. Conditional effects revealed a significant positive relationship between PSS-10 and TMT-B at low prudent diet intake only $(B=1.77, t(184)=2.84, p=0.005)$.

A second moderation model (Model 2) was conducted with TMT-B as the outcome adjusting further for BMI, diabetes, ethnicity, and perceived SES. The moderation model accounted for $12.8 \%$ of the variance in TMT-B performance. A significant PSS-10 $\times$ prudent diet interaction was found $(B=-1.07, t(179)=-2.30, p=0.02)$. Conditional effects (see Figure 2) showed that a positive relationship between PSS-10 and TMT-B was significant at low prudent diet intake only $(B=1.70, t(179)=2.70, p=0.008)$. See Table 10 for model details.

Table 10. Moderation Models of PSS-10 × Prudent Diet and TMT.

\begin{tabular}{llll}
\hline & $B$ & $S E$ & $p$ \\
\hline TMT-A & & & $<0.001^{* *}$ \\
\hline Age & 0.44 & 0.12 & 0.89 \\
Sex & -0.23 & 1.71 & 0.52
\end{tabular}




\begin{tabular}{|c|c|c|c|}
\hline $\mathrm{kCal}$ & $<-0.001$ & 0.001 & 0.46 \\
\hline PSS-10 & 0.11 & 0.13 & 0.40 \\
\hline Prudent diet & 1.00 & 1.72 & 0.56 \\
\hline PSS $-10 \times$ prudent diet & -0.11 & 0.12 & 0.37 \\
\hline Low prudent diet & 0.22 & 0.16 & 0.18 \\
\hline Moderate prudent diet & 0.11 & 0.13 & 0.40 \\
\hline High prudent diet & 0.006 & 0.19 & 0.98 \\
\hline \multicolumn{4}{|l|}{ TMT-B - Model 1} \\
\hline Age & 0.55 & 0.47 & 0.24 \\
\hline Sex & -8.69 & 6.64 & 0.19 \\
\hline Years of education & -1.17 & 0.93 & 0.21 \\
\hline $\mathrm{kCal}$ & -0.001 & 0.005 & 0.83 \\
\hline PSS-10 & 0.64 & 0.51 & 0.21 \\
\hline Prudent diet & 10.71 & 6.67 & 0.11 \\
\hline PSS- $10 \times$ prudent diet & -1.13 & 0.46 & $0.02 *$ \\
\hline Low prudent diet & 1.77 & 0.62 & $0.005 * *$ \\
\hline Moderate prudent diet & 0.64 & 0.51 & 0.21 \\
\hline High prudent diet & -0.49 & 0.75 & 0.51 \\
\hline \multicolumn{4}{|l|}{ TMT-B - Model 2} \\
\hline Age & 0.85 & 0.50 & 0.09 \\
\hline Sex & -10.36 & 6.66 & 0.12 \\
\hline Years of education & -0.83 & 0.95 & 0.39 \\
\hline $\mathrm{kCal}$ & -0.002 & 0.005 & 0.73 \\
\hline BMI & 0.32 & 0.68 & 0.64 \\
\hline Diabetes & 34.42 & 13.17 & $0.008 * *$ \\
\hline Ethnicity & -8.29 & 9.51 & 0.38 \\
\hline Perceived SES & -2.32 & 5.82 & 0.69 \\
\hline PSS-10 & 0.63 & 0.52 & 0.23 \\
\hline Prudent diet & 9.61 & 6.65 & 0.15 \\
\hline PSS- $10 \times$ prudent diet & -1.07 & 0.46 & $0.02 *$ \\
\hline Low prudent diet & 1.70 & 0.63 & $0.008^{* *}$ \\
\hline Moderate prudent diet & 0.63 & 0.52 & 0.23 \\
\hline High prudent diet & -0.43 & 0.76 & 0.57 \\
\hline \multicolumn{4}{|l|}{ TMT-B/A } \\
\hline Age & -0.02 & 0.01 & 0.08 \\
\hline Sex & -0.23 & 0.16 & 0.16 \\
\hline Years of education & -0.02 & 0.02 & 0.42 \\
\hline $\mathrm{kCal}$ & $<0.001$ & $<0.001$ & 0.31 \\
\hline PSS-10 & 0.006 & 0.01 & 0.63 \\
\hline Prudent diet & 0.14 & 0.16 & 0.39 \\
\hline PSS- $10 \times$ prudent diet & -0.02 & 0.01 & 0.09 \\
\hline Low prudent diet & 0.02 & 0.02 & 0.10 \\
\hline Moderate prudent diet & 0.006 & 0.01 & 0.63 \\
\hline High prudent diet & -0.01 & 0.02 & 0.47 \\
\hline
\end{tabular}


Notes. TMT-A $=$ Trail Making Test Part A; TMT-B $=$ Trail Making Test Part B; TMT-B $/ \mathrm{A}=$ Trail Making Test Part B/Part A; PSS-10 = Perceived Stress Scale; $\mathrm{kCal}=$ kilocalories; $\mathrm{BMI}=$ body mass index; SES = socioeconomic status

TMT-A: $R^{2}=0.09, F(7,184)=2.47, p=0.02$; TMT-B, Model $1: R^{2}=0.09, F(7,184)=2.48, p$ $=0.02$; TMT-B, Model 2: $R^{2}=0.13, F(11,179)=2.39, p=0.009$; TMT-B/A: $R^{2}=0.07, F(7$, $183)=1.91, p=0.07 . * p<0.05, * * p<0.01$

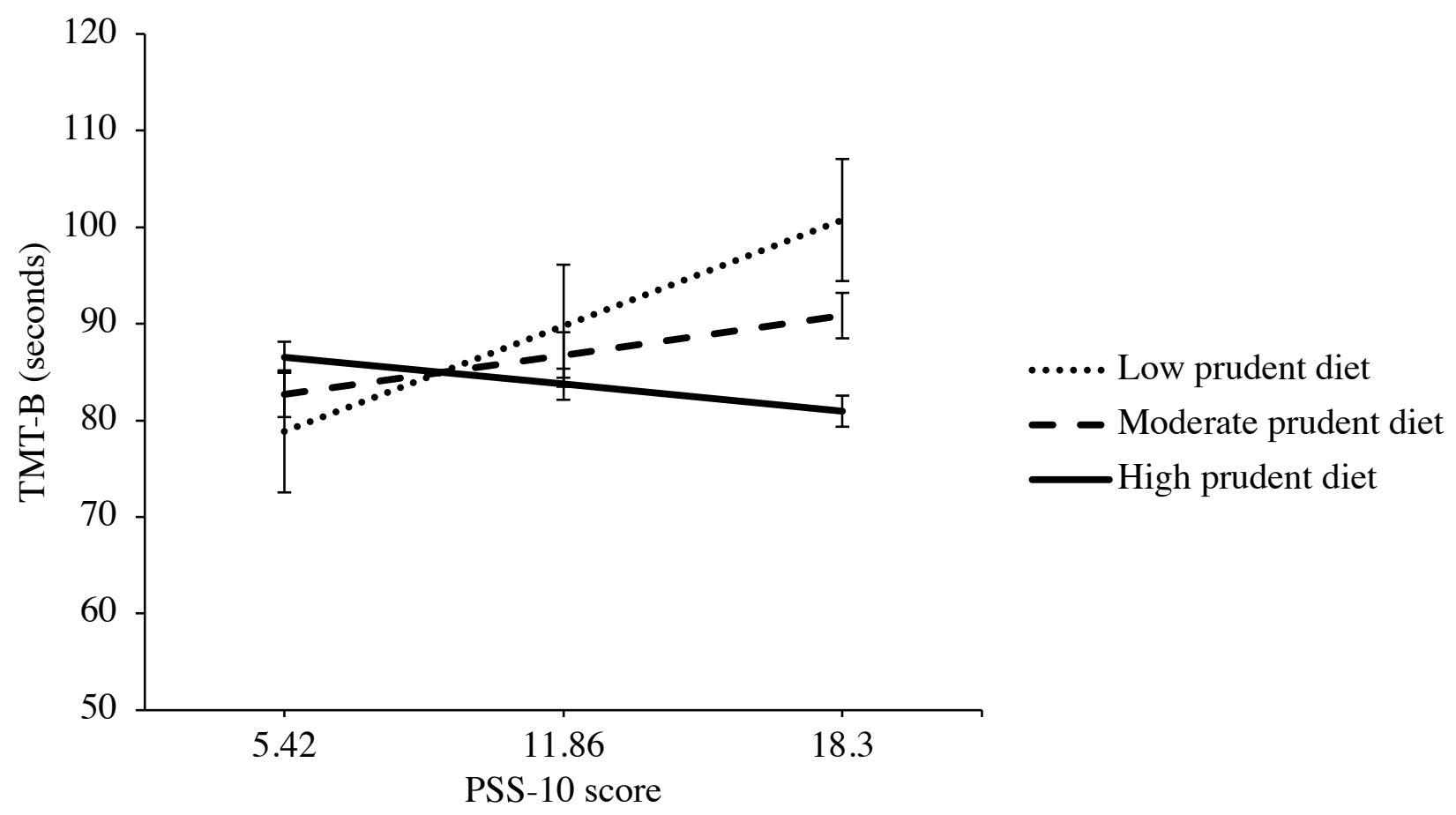

Figure 2. Conditional effects of PSS-10 and TMT-B performance at low, moderate, and high prudent diet intake. Error bars represent standard error of the mean.

Western Diet and Episodic Memory. Two moderation models were run to determine the moderating role of Western diet pattern on the relationship between perceived stress and episodic memory (CVLT-IFR and CVLT-LDFR). Controlling for age, sex, years of education, and $\mathrm{kCal}$, the moderation models accounted for $7.5 \%$ and $9.3 \%$ of the variance in CVLT-IFR and CVLT-LDFR, respectively. There was no significant PSS-10 $\times$ Western diet intake found for CVLT-IFR $(B=-0.08, t(184)=-0.71, p=0.48)$ or CVLT-LDFR $(B=<0.001, t(184)=0.001, p$ =1.00). See Table 11 for model details. 
Table 11. Moderation Models of PSS-10 × Western Diet and CVLT-II.

\begin{tabular}{llll}
\hline & $B$ & $S E$ & $p$ \\
\hline CVLT-IFR & & & 0.10 \\
\hline Age & -0.17 & 0.11 & $0.002^{* *}$ \\
Sex & -4.58 & 1.51 & 0.16 \\
Years of education & 0.30 & 0.21 & 0.31 \\
kCal & -0.001 & 0.001 & 0.24 \\
PSS-10 & -0.14 & 0.12 & 0.13 \\
Western diet & 2.59 & 1.71 & 0.48 \\
PSS-10 $\times$ Western diet & -0.08 & 0.12 & 0.74 \\
Low Western diet & -0.05 & 0.16 & 0.24 \\
Moderate Western diet & -0.14 & 0.12 & 0.21 \\
High Western diet & -0.22 & 0.18 & $0.01^{*}$ \\
CVLT-LDFR & & & $0.005^{* *}$ \\
Age & -0.10 & 0.04 & $0.02^{*}$ \\
Sex & -1.65 & 0.59 & 0.48 \\
Years of education & 0.20 & 0.08 & 0.61 \\
kCal & $<-0.001$ & $<0.001$ & 0.60 \\
PSS-10 & -0.02 & 0.05 & 1.00 \\
Western diet & 0.35 & 0.67 & 0.70 \\
PSS-10 $\times$ Western diet & $<0.001$ & 0.05 & 0.61 \\
Low Western diet & -0.02 & 0.06 & 0.73 \\
Moderate Western diet & -0.02 & 0.05 & 0.07 \\
High Western diet & -0.02 & 07 & \\
\hline
\end{tabular}

Notes. CVLT-IFR $=$ California Verbal Learning Test Immediate Free Recall; CVLT-LDFR $=$ California Verbal Learning Test Long Delay Free Recall; PSS-10 = Perceived Stress Scale; kCal $=$ kilocalories

CVLT-IFR: $R^{2}=0.07, F(7,184)=2.13, p=0.04$; CVLT-LDFR: $R^{2}=0.09, F(7,184)=2.67, p=$ 0.01. $* p<0.05, * * p<0.01$

Western Diet and Executive Function. Three moderation models were conducted to determine the moderating role of Western diet consumption in the relationship between perceived stress and executive functioning (TMT-A, TMT-B, and TMT-B/A). The moderation models accounted for $9.4 \%, 6.2 \%$, and $6.7 \%$ of the variance in TMT-A, TMT-B, and TMT-B/A, respectively. No significant PSS- $10 \times$ Western diet interaction was found for TMT-A $(B=-0.20$, $t(184)=-1.52, p=0.13)$, TMT-B $(B=-0.19, t(184)=-0.35, p=0.73)$, or TMT-B/A $(B=0.01$, $t(184)=1.06, p=0.29)$. See Table 12 for model details. 
Table 12. Moderation Models of PSS-10 × Western Diet and TMT.

\begin{tabular}{llll}
\hline & $B$ & $S E$ & $p$ \\
\hline TMT-A & & & \\
\hline Age & 0.44 & 0.12 & $<0.001^{* *}$ \\
Sex & -0.55 & 1.70 & 0.75 \\
Years of education & -0.11 & 0.24 & 0.65 \\
kCal & $<-0.001$ & 0.001 & 0.73 \\
PSS-10 & 0.11 & 0.13 & 0.40 \\
Western diet & 2.04 & 1.93 & 0.29 \\
PSS-10 $\times$ Western diet & -0.20 & 0.13 & 0.13 \\
Low Western diet & 0.31 & 0.18 & 0.08 \\
Moderate Western diet & 0.11 & 0.13 & 0.40 \\
High Western diet & -0.09 & 0.20 & 0.64 \\
\hline TMT-B & & & \\
Age & 0.61 & 0.47 & 0.20 \\
Sex & -7.75 & 6.69 & 0.25 \\
Years of education & -1.46 & 0.96 & 0.13 \\
kCal & 0.001 & 0.006 & 0.85 \\
PSS-10 & 0.83 & 0.51 & 0.11 \\
Western diet & -2.94 & 7.63 & 0.70 \\
PSS-10 $\times$ Western diet & -0.19 & 0.53 & 0.73 \\
Low Western diet & 1.02 & 0.69 & 0.14 \\
Moderate Western diet & 0.83 & 0.51 & 0.11 \\
High Western diet & 0.65 & 0.78 & 0.41 \\
\hline TMT-B/A & & & \\
\hline Age & -0.02 & 0.01 & 0.09 \\
Sex & -0.15 & 0.16 & 0.36 \\
Years of education & -0.03 & 0.02 & 0.14 \\
kCal & $<0.001$ & $<0.001$ & 0.21 \\
PSS-10 & 0.01 & 0.01 & 0.39 \\
Western diet & -0.33 & 0.19 & 0.08 \\
PSS-10 Western diet & -0.01 & 0.01 & 0.29 \\
Low Western diet & -0.003 & 0.02 & 0.87 \\
Moderate Western diet & 0.01 & 0.01 & 0.39 \\
High Western diet & 0.02 & 0.02 & .20 \\
\hline Not & & & \\
& & & \\
\hline
\end{tabular}

Notes. TMT-A $=$ Trail Making Test Part A; TMT-B $=$ Trail Making Test Part B; TMT-B/A =

Trail Making Test Part B/Part A; PSS-10 = Perceived Stress Scale; $\mathrm{kCal}=$ kilocalories

TMT-A: $R^{2}=0.09, F(7,184)=2.72, p=0.01$; TMT-B: $R^{2}=0.06, F(7,184)=1.74, p=0.10$;

TMT-B/A: $R^{2}=0.07, F(7,184)=1.89, p=0.07 .{ }^{*} p<0.05,{ }^{* *} p<0.01$ 


\section{Discussion}

The main objective of this study was to examine the moderating role of adherence to a healthy prudent diet and an unhealthy Western diet in the relationship between perceived stress and cognitive function (episodic memory and executive functioning) in a sample of nondemented, community-dwelling older adults. Given the possible reversible effects of stress on cognition (Seeman et al., 1997), and the neuroprotective effects of prudent diet intake (Shakersain et al., 2016), it was hypothesized that a higher prudent diet pattern would buffer the relationship between perceived stress and both episodic memory and executive function. The opposite was hypothesized for Western diet consumption, such that a higher Western diet was anticipated to exacerbate the negative relationship between stress and cognitive function. Overall, the proposed hypotheses were only partially supported in the current analyses. Specifically, prudent diet pattern moderated the association between perceived stress and executive function, namely set-shifting. Prudent diet did not moderate the relationship between perceived stress and episodic memory, and Western diet was not an effect-modifier in the stresscognition relationship. No direct association between perceived stress and episodic memory or executive function was found.

Before critically evaluating and interpreting the current study findings, attention must be drawn to the use of data-driven methods in determining dietary consumption as this is a relatively novel method in the field of nutrition. The current PCA analysis identified diet patterns that are consistent with previous research deriving dietary patterns using a data-driven approach. Specifically, Shakersain et al. (2016) derived a prudent and Western diet pattern using PCA and found that the Western diet was characterized by high intake of red and processed meats, sugars and sweets, potatoes, baked goods, high-fat dairy products, butter, refined grains, and alcohol 
consumption. The prudent diet was associated with high intake of fruits, vegetables, legumes, low-fat dairy, whole grains, fish, oil, cereals, and water (Shakersain et al., 2016). Gardener et al. (2015) also identified a prudent and Western diet using PCA and derived a Western diet characterized by high consumption of red and processed meats, refined grains, poultry, sweets, fast food, salty snacks, margarine, high-fat dairy, and potatoes. The prudent diet was characterized by high consumption of vegetables, fruits, whole grains, nuts, fish, and low-fat dairy (Gardener et al., 2015). Slight differences in the diet patterns derived in this study compared to previous studies are likely due to the use of different food frequency questionnaires and lower cut-off values for significant factor loadings. Further, differences across studies in the dietary patterns derived using an a posteriori approach limits inter-study comparison. However, data-driven approaches to dietary pattern analysis are beneficial as they provide insight into the dietary behaviour of the study participants without imposing predetermined guidelines for healthy eating behaviour.

Inconsistent with previous research linking perceived stress with cognition in older adults, there was no association between perceived stress and episodic memory or executive functioning in this study. Longitudinal studies examining the impact of perceived stress on cognitive change among older adults have consistently shown that increased levels of perceived stress were associated with higher rates of decline in memory and executive functioning (Aggarwal et al., 2014; Munoz et al., 2015; Turner et al., 2017). Findings from the current crosssectional study cannot be directly compared to longitudinal studies that assess a causal relationship between perceived stress and cognitive function. However, in a cross-sectional study examining the association between perceived stress using the PSS-10 and neurocognitive function in 1099 older adults, higher perceived stress was associated with worse performance on 
a delayed and immediate word recall task, and executive functioning measured using a digit span task (Korten et al., 2017). One potential explanation for the null association between perceived stress and cognitive functioning in the current study is the high-functioning cohort of participants. Specifically, the variability in perceived stress scores in the current sample was low, with a range in scores from 0 to 32 , and a standard deviation of 0.46 . Although the mean PSS-10 score was similar between the current study and Korten et al. (2017), the variability in PSS-10 in Korten et al. (2017) was much larger, with a range of 0 to 38 and a standard deviation of 5.67. Further, performance on the episodic memory task in the current study was higher than Korten et al. (2017). The limited variability in the present study may therefore be masking power to detect a relationship between perceived stress and cognitive performance.

Also inconsistent with the literature, there was no direct association between perceived stress and diet pattern consumption. Previous research showing a relationship between high stress and poor food choices have largely focused on younger and middle-aged adults (Ng \& Jeffery, 2003; Ansari \& Berg-Berkhoof, 2015; Newman et al., 2007), precluding the generalizability of these findings to the older adult population. However, two studies in older adults have suggested such an association. Namely, Laugero et al. (2011) found that higher perceived stress among older adults was associated with lower intake of fruits and vegetables, and higher intake of salty foods. Although Barrington et al. (2014) failed to show an association between stress and consumption of fruits and vegetables, they did find that older adults who reported higher perceived stress consumed more high-fat snacks and fast food items. Both Laurego et al. (2011) and Barrington et al. (2014), however, did not measure dietary intake using a data-driven, diet pattern approach, but rather examined the association between perceived stress and individual food consumption. Hence, perceived stress may not be associated with 
overall dietary pattern, but rather with intake of specific foods. However, this is purely speculative and additional research is required.

Western and prudent diet consumption were also not associated with episodic memory or executive functioning. Previous studies have reported that adherence to a high-fat, Western diet is associated with poor global cognition at baseline (Granic et al., 2016) and follow-up (Shakersain et al., 2016). Corley, Starr, McNeill, \& Deary (2013) also found that adherence to a Western-like diet pattern was associated with poorer performance on neurocognitive tests of memory. Other research, however, has found null associations between Western diet intake and cognitive function in late life (Wengreen, Neilson, Munger, \& Corcoran, 2009), corroborating current research findings. A possible explanation for the lack of association between Western diet and cognition is the protective effect of lean red meats on cognition via iron, protein, MUFA, and PUFA (Solfrizzi et al., 2017).

Previous studies have shown that greater adherence to a healthy prudent diet pattern is associated with slower rates of global cognitive decline and executive functioning (Shakersain et al., 2016; Gardener et al., 2015; Tangney et al., 2011) and better global cognition crosssectionally (Okubo et al., 2017). Feart et al. (2009) found that higher adherence to a prudent diet was not associated with change in verbal episodic memory, while Corley et al. (2013) reported that prudent diet adherence was associated with better memory performance. Given that mixed results have been found with respect to prudent diet intake and memory performance, the current results may suggest that prudent diet does not benefit memory and may be more important for executive functioning. Specifically, the nutrients present in the prudent diet including B vitamins, antioxidants, and MUFAs, may exert effects on neuronal integrity of the PFC and may not be as sensitive to the HC. However, memory and executive functioning are higher-order 
cognitive domains that rely on distributed, large-scale neural networks and are not localized to only one particular brain region. Therefore, neuronal correlates of diet intake require further investigation. Specifically, future research is needed to delineate how prudent diet intake impacts brain regions responsible memory performance and executive functioning. Taken together, however, current findings are incongruent with previous research showing the protective effects of a prudent diet on cognitive function in older adulthood.

In line with the proposed hypothesis, findings from the current study suggest that the prudent diet pattern may be a protective factor in the association between perceived stress and executive functioning, measuring via set-shifting performance. Specifically, no association between perceived stress and executive function was present at moderate and high levels of prudent diet consumption. Higher levels of perceived stress, however, was associated with worse executive functioning performance at low prudent diet intake. These results remained significant even after controlling for potential confounding variables including BMI, ethnicity, perceived socioeconomic status, and diabetes. Contrary to expected findings, prudent diet did not moderate the association between perceived stress and episodic memory, such that the relationship between perceived stress and episodic memory was null at low, moderate, and high levels of prudent diet intake. As previously mentioned, these findings suggest that the effects of a prudent diet may be more sensitive to executive functioning compared to memory performance. Previous studies, however, show that prudent diet is associated with both lower HC (Jacka et al., 2015) and PFC volumes (Gu et al., 2015). Given that stress has detrimental effects on the HC (Lupien et al., 1998) and PFC (Dai et al., 2004), it would be expected that diet intake alters the effects of both HC and PFC function. Future research is needed to determine the mechanisms through which prudent diet and stress interact to influence brain structure and function. 
Contrary to the expected findings, adherence to an unhealthy Western diet did not moderate the relationship between perceived stress and executive function or episodic memory. These findings are also incongruent with previous research linking Western diet and stress to integrity of the brain regions associated with such cognitive functions (Jacka et al., 2015; Lupien et al., 1998). This suggests, however, that a Western diet may not play a role in performance on neurocognitive tasks that rely on the structural integrity of brain regions that are sensitive to the effects of stress. Future research, however, is needed to elucidate this mechanism.

As mentioned previously, the primary limitation of this study is the high-functioning cohort of participants, which are a likely reason for null findings. Specifically, participants performed highly on the neurocognitive tasks and reported relatively low levels of perceived stress in comparison to other studies assessing such a relationship (Korten et al., 2017). The restricted range of scores may not have captured a large enough variability in order to detect an association between the observed relationships. A possibility for the lack of variation in the sample performance is the stringent exclusion criteria for study participation which was not designed to capture the variability in cognitive functioning in the general population. Given that health status is associated with perceived stress in older adulthood (Osmanovic-Thunstrom, Mossello, Akerstedt, Fratiglioni, \& Wang, 2015), the high functioning cohort may also contribute to low levels of perceived stress observed. Further, the current sample was welleducated with a majority of participants reporting medium or high socioeconomic status, which may minimize the ability to detect a relationship between the variables of interest. Indeed, Parrott et al. (2013) found a relationship between diet pattern intake and cognitive function among older adults in a socioeconomic position measured via income, education, and occupation. Education also moderates the association between stress and cognitive aging (Tschanz et al., 2012). These 
studies suggest that recruiting participants with a wide range of socioeconomic positions and educational attainment may better elucidate a relationship between stress, diet, and cognition.

Another limitation of this study is the cross-sectional design, which does not exclude the possibility of reverse causality such that cognitive functioning influences perceived stress and diet choices. Previous research indicates that poor cognitive health is a contributing factor to increasing stress with age (Osmanovic-Thunstrom et al., 2015). Additionally, this cross-sectional design does not rule out the possibility that poorer cognitive function results in behavioural changes including alterations in dietary habits, as supported by studies showing that poor cognitive health leads to unhealthy dietary choices (Crichton, Elias, Davey, Alkerwi, \& Dore, 2016). Hence, longitudinal studies are needed to examine whether diet pattern consumption influences how perceived stress leads to cognitive change in older adulthood.

A final study limitation is the Eurocentric nature of the food frequency questionnaire used to measure diet intake. Items on the EPIC-Norfolk FFQ (Bingham et al., 1997) were constructed to reflect foods and food brands commonly consumed in the United Kingdom, possibly limiting the generalizability of this FFQ to other countries such as Canada. Further, this questionnaire does not include foods from a diverse range of cuisines that may not reflect the eating patterns of individuals living in a multicultural city such as Toronto. Future research can benefit from using a more culturally diverse FFQ which may result in diet patterns comprised of different food constituents. It is also important to note that ethnicity was associated with prudent diet intake in the current study such that non-Caucasian individuals consumed a higher prudent diet compared to their Caucasian counterparts, suggesting that ethnicity plays a role in dietary choices. This raises the question of what is considered a prudent diet, given that the FFQ used in this study does not specify how the foods are prepared or cooked. The prudent dietary pattern is 
similar to a Mediterranean diet that is typical of cuisines in Mediterranean regions. The characteristic cuisine of other regions such as Asia is different from a Mediterranean diet but is comprised of similar foods that are prepared differently. Future research can benefit from utilizing an FFQ that assesses food item preparation in order to elucidate whether cooking style alters dietary patterns.

Overall, the study's main hypotheses were partially supported, suggesting that healthy dietary behaviour among older adults may protect against the adverse effects of stress on executive function. Given that maintenance of executive functioning is important for facilitating healthy aging, this study provides a novel pathway through which the detrimental impacts of stress may be mitigated. Despite the aforementioned limitations, this study contributes to the growing literature in the area of nutrition and cognitive aging, consolidating the connection between cognitive aging, perceived stress, and dietary intake in late life by providing an improved understanding of the relationship between perceived stress and cognition via a holistic view of nutrition. 


\title{
AGING and the BRAIN A study that examines the impact of biological, psychological and social factors on brain health in older adults
}

\author{
OLDER ADULT RESEARCH PARTICIPANTS \\ NEEDED!!!
}

\section{Ages: 60 YEARS AND OLDER}

Participation includes 2 testing sessions:

1. Blood, urine and saliva collection to measure biological markers of stress and aging followed by a testing session that will assess memory, attention, speed of processing, language, mood, and lifestyle behaviors. This session will take an estimated total of 4 hours.

2. Undergo a non-invasive test that measures your brain activity while at rest and during an activity, lasting an estimated total of 3 hours.

Eligible participants will be reimbursed for their participation.

If interested, please call

(416) 979-5000 ext 3233

or

Email: star.lab@psych.ryerson.ca

\begin{tabular}{|c|c|c|c|c|c|c|c|c|c|c|}
\hline 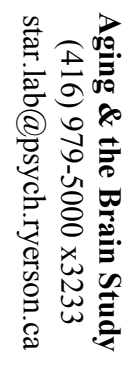 & 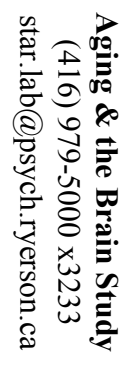 & 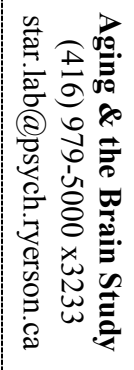 & 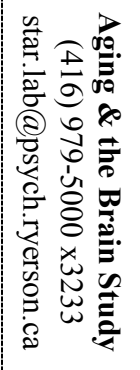 & 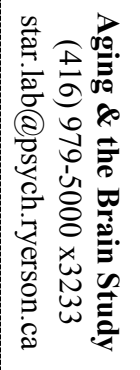 & 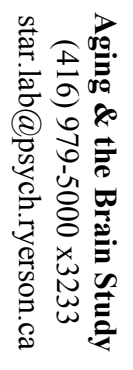 & 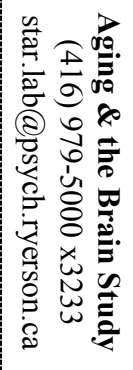 & 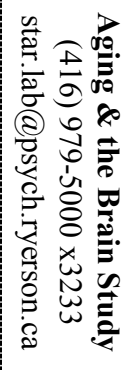 & 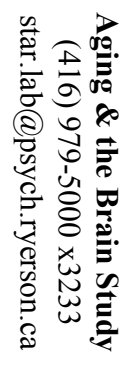 & 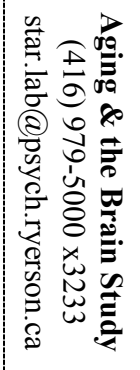 & 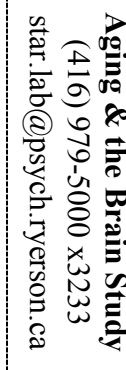 \\
\hline
\end{tabular}




\section{Appendix B}

\section{Phone Screening Questionnaire}

Researcher: To determine your eligibility for the study, I will now ask you a few questions about demographic and health information. This confidential information will be securely stored in our database and is restricted to members of the research team. You do not have to answer any questions that you are uncomfortable with; however, you may be excluded based on the information you choose to withhold.

\section{DEMOGRAPHIC QUESTIONS}

\begin{tabular}{|c|c|}
\hline Age: & \\
\hline Sex: & $\mathrm{M} \_\mathrm{F}$ \\
\hline Ethnicity (e.g., Caucasian, Hispanic, etc.): & \\
\hline Country of birth: & \\
\hline $\begin{array}{l}\text { Country/countries of descent (i.e., where you } \\
\text { would trace your ancestry to): }\end{array}$ & \\
\hline Languages you speak: & \\
\hline $\begin{array}{l}\text { If English is not your mother tongue, at what } \\
\text { age did you learn to speak English? } \\
\text { (Exclude if learned English after age 12) }\end{array}$ & \\
\hline Handedness: & Right ___ Left ___ Ambidextrous \\
\hline Do you drive? & $\begin{array}{l}\text { No _ } \mathrm{Yes}_{-} \\
\text {If no, do you have a driver's license? }\end{array}$ \\
\hline Are you retired? & $\begin{array}{l}\text { No } \_ \text {Yes } \\
\text { If yes, in what year did you retire? }\end{array}$ \\
\hline How many years of education do you have? & \\
\hline What is your perceived socioeconomic status? & High___ Medium __ Low \\
\hline $\begin{array}{l}\text { Do you smoke? Or have you ever smoked } \\
\text { before? } \\
\text { If yes, How many cigarettes do you smoke a } \\
\text { day? }\end{array}$ & No _ \\
\hline
\end{tabular}




\begin{tabular}{|c|c|}
\hline $\begin{array}{l}\text { Do you participate in a regular exercise } \\
\text { program? } \\
\text { (i.e. anything that increases heart rate } 3 x / \text { week; } \\
\text { e.g. aerobics, swimming, walking) }\end{array}$ & $\begin{array}{l}\text { No } \\
\text { Yes (describe) }\end{array}$ \\
\hline $\begin{array}{l}\text { Have you ever had any cognitive or } \\
\text { neuropsychological testing? } \\
\text { E.g., with a psychologist or for a study } \\
\text { (Exclude if within last year) }\end{array}$ & $\begin{array}{l}\text { No _ } \\
\text { Yes (reason) } \\
\text { When }\end{array}$ \\
\hline $\begin{array}{l}\text { Are you actively participating in any sort of } \\
\text { formal brain training activities, e.g., Lumosity, } \\
\text { Brain Metrix? } \\
\text { If Yes, how long (in months)? }\end{array}$ & $\begin{array}{l}\text { No }- \\
\text { Yes }- \\
\text { Duration: } \\
\text { Frequency: }\end{array}$ \\
\hline
\end{tabular}

\section{HEALTH-RELATED QUESTIONS}

\section{Have you ever had any of the following?}

\begin{tabular}{|c|c|}
\hline $\begin{array}{l}\text { Vision problems (glasses, operations): } \\
\text { (exclude if vision is not corrected) }\end{array}$ & 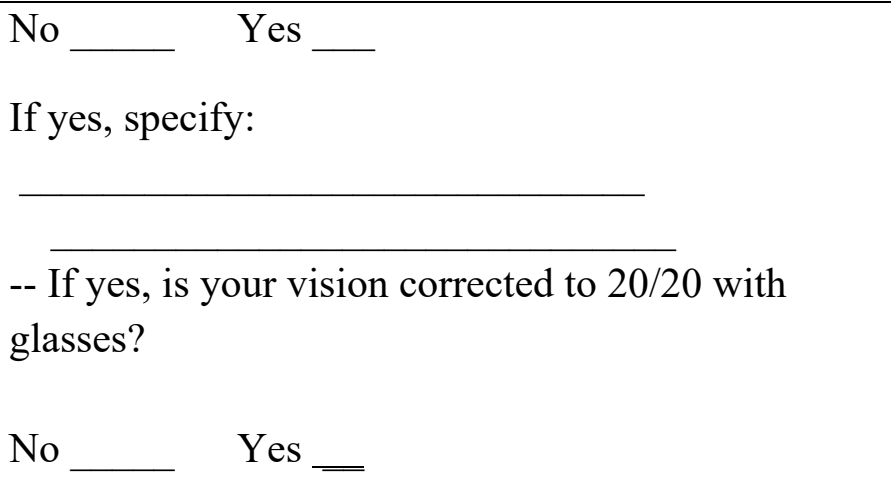 \\
\hline $\begin{array}{l}\text { Hearing problems (weak hearing, } \\
\text { hearing aids): } \\
\text { (exclude if hearing is not corrected) }\end{array}$ & $\begin{array}{l}\text { No _ Yes _ } \\
\text { If yes, specify: } \\
\text { Is your hearing corrected to normal with the hearing } \\
\text { aid? }\end{array}$ \\
\hline
\end{tabular}




\begin{tabular}{|c|c|}
\hline & No __ Yes \\
\hline $\begin{array}{l}\text { Diabetes: } \\
\text { If not medicated, ask if they are okay to fast } \\
\text { for } 12 \text { hours without complications. } \\
\text { If they cannot fast, exclude. } \\
\text { If they can, include with a note that they } \\
\text { must be given the snack IMMEDIATELY } \\
\text { after the blood test. }\end{array}$ & $\begin{array}{l}\text { No _ } \\
\text { If yes, when were you diagnosed? } \\
\text { Year: } \\
\text { Is it controlled with medication? } \\
\text { No ___ Yes __ } \\
\text { If yes, which medication? } \\
\text { Name: }\end{array}$ \\
\hline $\begin{array}{l}\text { Hypo or Hyperthyroidism: } \\
\text { (exclude if not controlled) }\end{array}$ & $\begin{array}{l}\text { No __ Yes __ } \\
\text { If yes, is it controlled with medication? } \\
\text { No ___ Yes ___ Name }\end{array}$ \\
\hline $\begin{array}{l}\text { Cancer: } \\
\text { (exclude if chemotherapy or radiation) }\end{array}$ & $\begin{array}{l}\text { No __ Yes } \\
\text { If yes, when were you diagnosed? } \\
\text { Year: } \\
\text { Did you receive chemotherapy or radiation? } \\
\text { No }\end{array}$ \\
\hline $\begin{array}{l}\text { Stroke: } \\
\text { (exclude if Ischemic or Hemorrhagic, } \\
\text { probe for details) }\end{array}$ & $\begin{array}{l}\text { No }- \text { Yes } \\
\text { If yes, when did this occur? } \\
\text { Was it Ischemic, Hemorrhagic or Transient } \\
\text { Ischemic? }\end{array}$ \\
\hline $\begin{array}{l}\text { Aneurysm: } \\
\text { (exclude) }\end{array}$ & No __ Yes \\
\hline Heart attack: & $\begin{array}{l}\text { No } \_ \text {Yes } \\
\text { If yes, when? }\end{array}$ \\
\hline High blood pressure: & No $\quad$ Yes \\
\hline
\end{tabular}




\begin{tabular}{|c|c|}
\hline$(\mathrm{SBP}>=140 ; \mathrm{DBP}>=90)$ & $\begin{array}{l}\text { If yes, is it controlled with medication? } \\
\text { No } \\
\text { medication name: }\end{array}$ \\
\hline $\begin{array}{l}\text { Learning disability: } \\
\text { (exclude) }\end{array}$ & No __ Yes \\
\hline $\begin{array}{l}\text { Neurological disease: } \\
\text { (exclude if: } \\
\text { Dementia,Parkinsons, MS, Huntingtons, } \\
\text { ALS, Stroke, Seizure Disorder) }\end{array}$ & No __ Yes \\
\hline $\begin{array}{l}\text { Seizure: } \\
\text { (exclude) }\end{array}$ & No ___ Yes \\
\hline $\begin{array}{l}\text { Epilepsy: } \\
\text { (exclude) }\end{array}$ & No __ Yes \\
\hline $\begin{array}{l}\text { Head injury: } \\
\text { (probe for seriousness; exclude if within } \\
\text { last year) }\end{array}$ & No __ Yes \\
\hline Serious car accident: & No __ Yes \\
\hline $\begin{array}{l}\text { Concussion: } \\
\text { (exclude if within last year) }\end{array}$ & $\begin{array}{l}\text { No } \_ \text {Yes } \\
\text { If yes, how many? When was the last one? }\end{array}$ \\
\hline $\begin{array}{l}\text { Have you ever been unconscious? } \\
\text { (exclude if within last year) }\end{array}$ & $\begin{array}{l}\text { No _ Yes } \\
\text { If yes, how long were you unconscious? } \\
\text { Duration: } \\
\text { If yes, what was the cause? } \\
\text { Cause: }\end{array}$ \\
\hline $\begin{array}{l}\text { Have you ever had surgery that required } \\
\text { general anesthesia? Or colonoscopy } \\
\text { within the last year? } \\
\text { (exclude if within last year) } \\
\text { (ask if colonoscopy was generalized or } \\
\text { localized anaesthetic: if generalized, } \\
\text { EXCLUDE, if localized, OKAY) }\end{array}$ & $\begin{array}{l}\text { No } \_ \text {Yes _ } \\
\text { If yes, when did you have this procedure? } \\
\text { Year: }\end{array}$ \\
\hline $\begin{array}{l}\text { Are you currently taking any hormonal } \\
\text { replacement therapy? }\end{array}$ & No __ Yes \\
\hline
\end{tabular}




\begin{tabular}{|c|c|}
\hline (For female participant) & $\begin{array}{l}\text { If yes, when did you start taking them? Year: } \\
\text { If yes, when did you start taking them? }\end{array}$ \\
\hline $\begin{array}{l}\text { When did you go through menopause? } \\
\text { (For female participant) }\end{array}$ & $\begin{array}{l}\text { No __ Yes } \\
\text { If yes, when did this begin? Year: ___ } \\
\text { If yes, did you ever take any hormone replacement } \\
\text { medication to treat your symptoms? } \\
\text { No__ Yes }\end{array}$ \\
\hline $\begin{array}{l}\text { HIV/AIDS } \\
\text { (Is it controlled? Probe for seriousness } \\
\text { of symptoms) }\end{array}$ & No __ Yes \\
\hline $\begin{array}{l}\text { Are you on any other medications or do } \\
\text { you have another medical condition we } \\
\text { have not spoken about? }\end{array}$ & $\begin{array}{l}\text { No _ Yes } \\
\text { If yes, what are they called and what is each one } \\
\text { for? } \\
\text { Name: } \\
\text { Name: Reason: } \\
\text { Name: Reason: }\end{array}$ \\
\hline
\end{tabular}

\section{Psychiatric disorder Next I am going to ask you some questions about your mood and behaviours in the last few months}

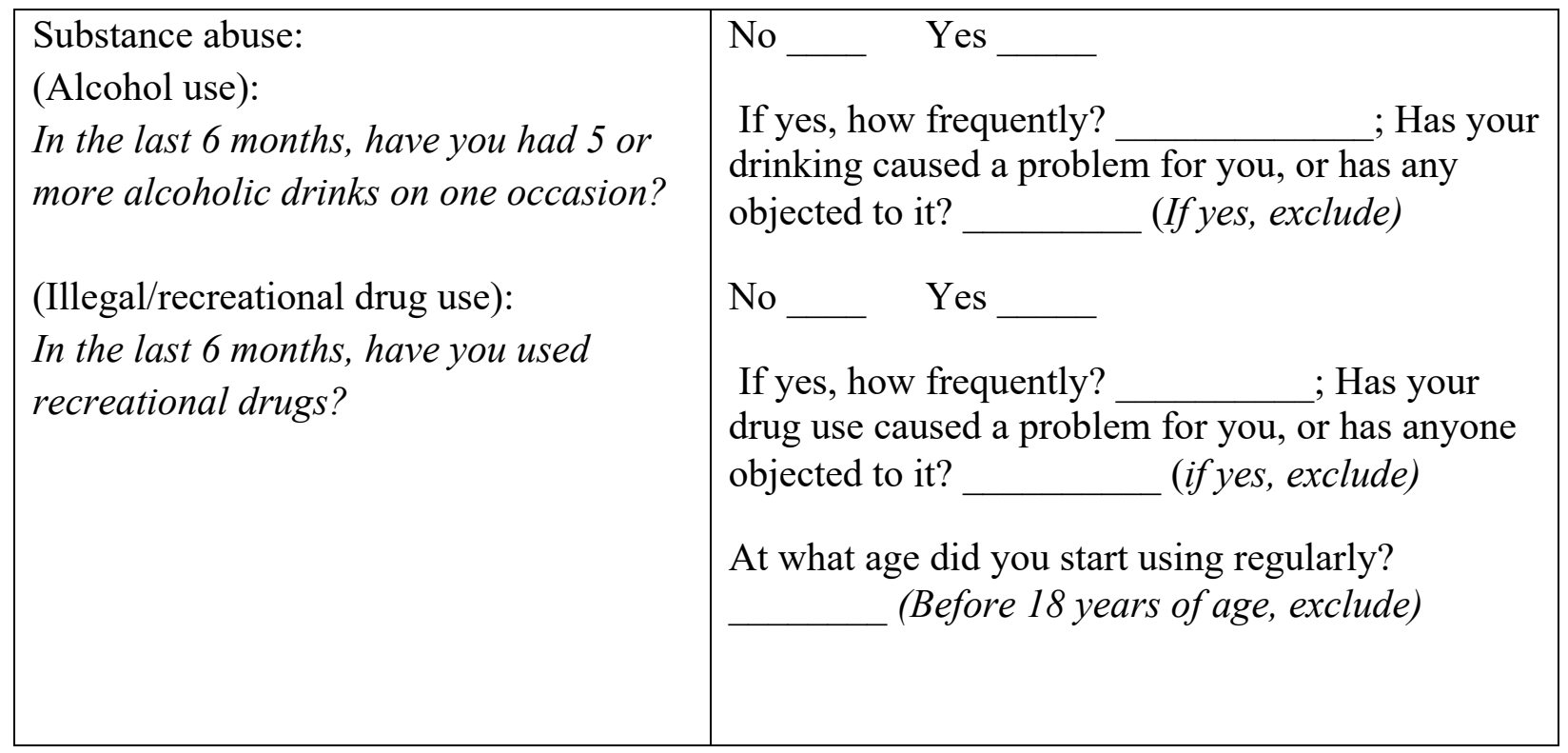




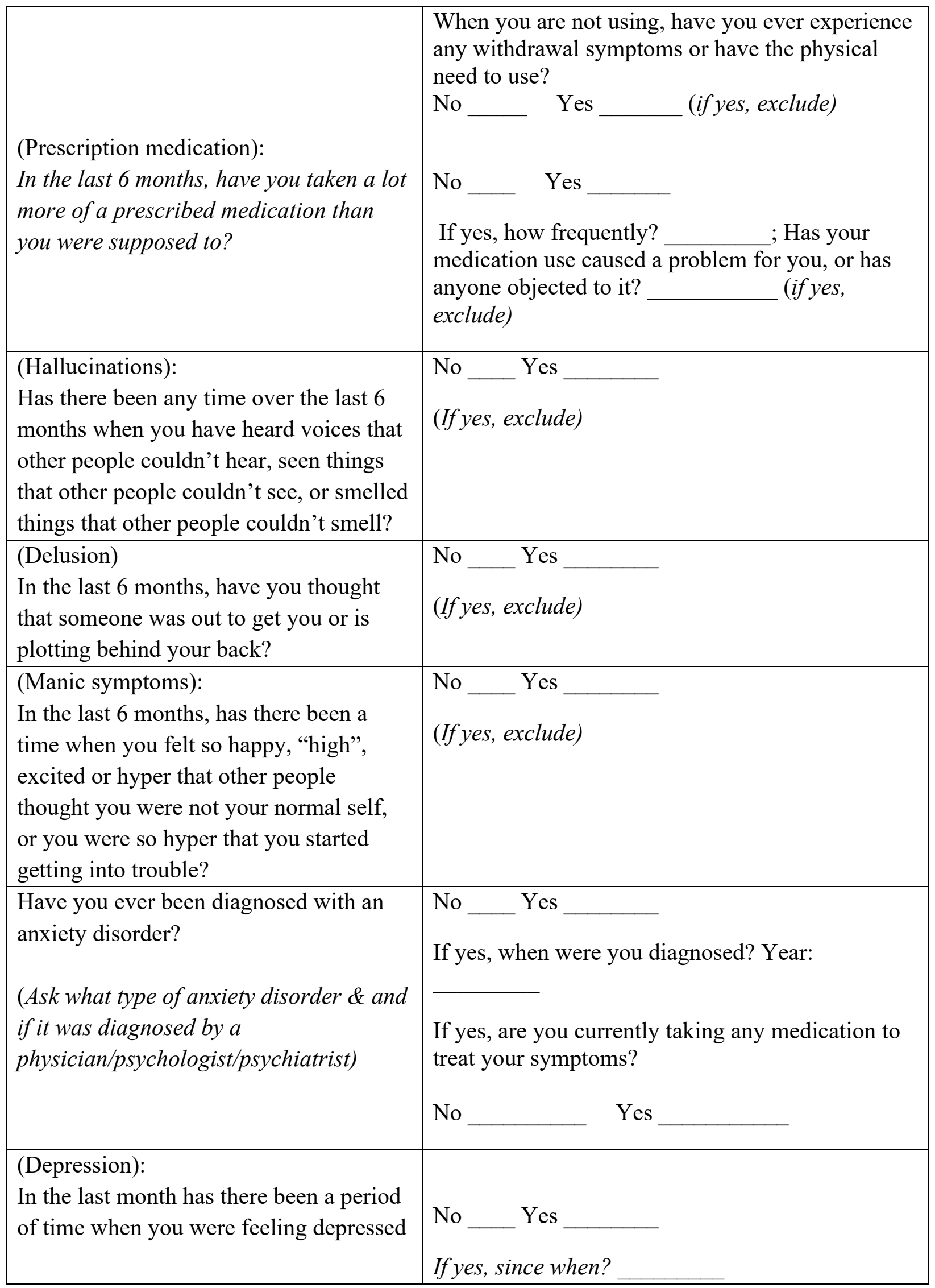




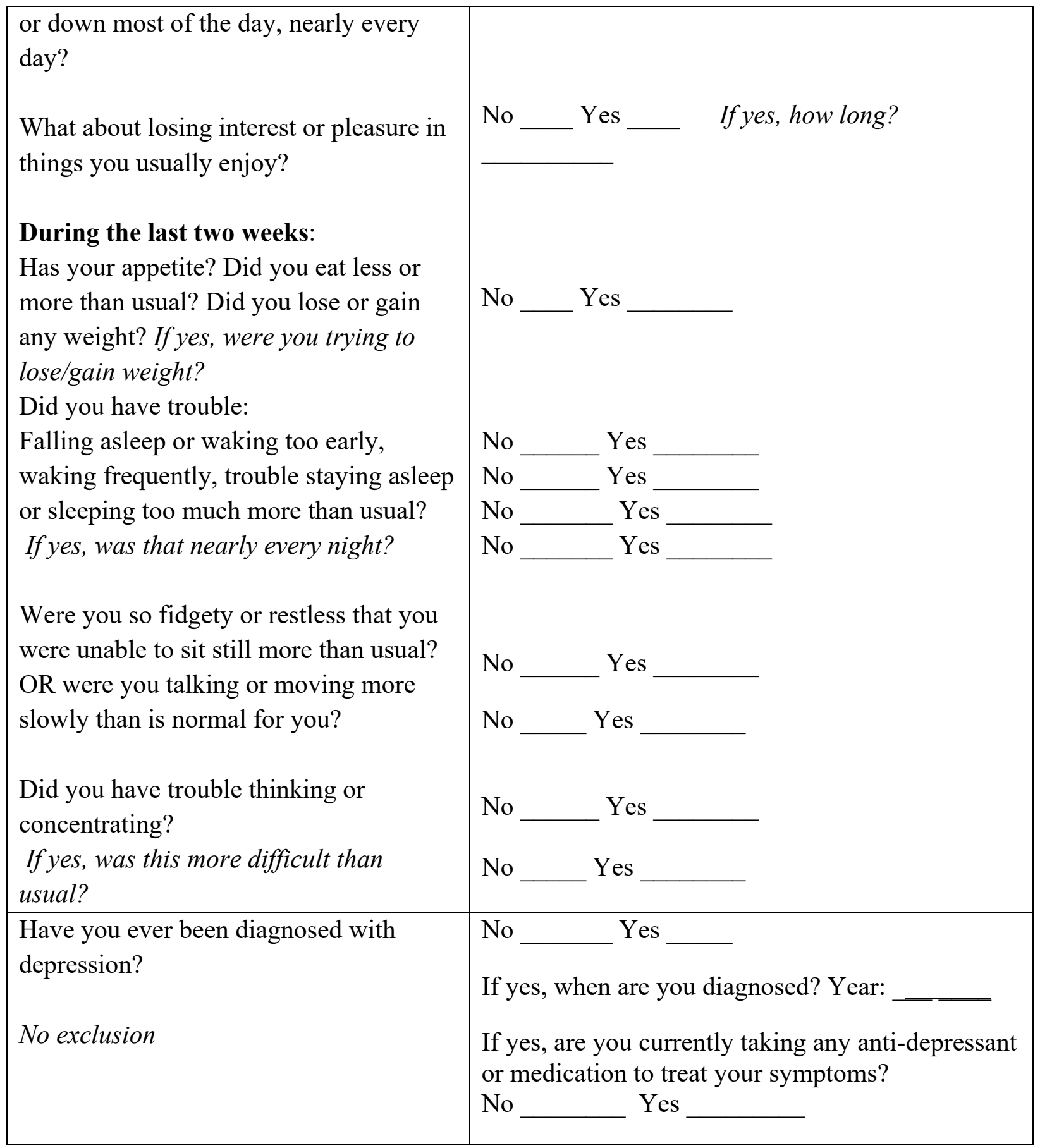




\section{Appendix C}

\section{Ryerson \\ University}

Consent Agreement

\section{The Biopsychosocial Profile of High and Low Cognitive Performance in Older Adults}

You are being asked to participate in a research study. Before you give your consent to be a volunteer, it is important that you read the following information and ask as many questions as necessary to be sure you understand what you will be asked to do.

\section{Investigators:}

Principal Investigator: Dr. Alexandra J. Fiocco, PhD., Department of Psychology, Ryerson University Student-Investigators: Vivian Huang, Laura Krieger, Danielle D'Amico, Department of Psychology, Ryerson University

\section{Purpose of the Study:}

Cognitive function, such as memory, is an important health factor, especially in late life. The effect of stress on cognitive function has received a lot of attention over the past 20 years; it is suggested that exposure to high levels of stress hormones over a person's lifespan plays a significant role in the aging process and may contribute to declines in cognitive function, such as memory. With an aging population on the rise, and an expected increase in dementia cases, prevention is key! By understanding the biological, psychological and social factors association with good and poor mental function, prevention programs may be developed, specifically created to change these factors.

The purpose of this study is to assess the individual and interacting effects of biological, psychological and social factors in their association with cognitive performance. Biological factors will include Apolipoprotein $E$ gene status and biological markers of stress, including cortisol and norepinephrine. Psychological factors will include personality and lifestyle behaviours such as exercise and smoking status. Finally, social factors will include marital status and social network (i.e. size of social network and time spent in social environments). The goal is to see which of these factors are most predictive of cognitive function in older adults.

Two hundred older adults aged 60 years and older will be recruited for the study. To be eligible for this study, you must have confirmed, in a phone screening, that you do not have any of the following: recent diagnosed mental disorder or mood disorder, cancer/chemotherapy, neuropsychological testing in past year, stroke, and significant vision or hearing problems. Participants who meet inclusion criteria will complete two testing sessions. In the first session, participants will undergo a blood draw and urine sample (blood analyses of cholesterol and glucose levels will be made available to the participant), saliva sample (for genetic information) and neuropsychological testing (i.e. completion of cognitive tests and psychological questionnaires). Approximately one week later, participants will return to the laboratory for a second testing session that will include undergoing electroencephalography $(E E G)$, which is a non-invasive technique that measures your brain activity. 


\section{Description of the Study:}

As a participant, you will be asked to come to the Stress and Healthy Aging Research Lab at Ryerson University for 2 sessions. You will be asked to sign this consent form before the first session and bring it with you to the first testing session. If you forget to bring the consent form on the day of testing, a copy will be made available, ready to sign.

\section{First Testing Session:}

As a participant, you will meet the study's research assistant at Saint Michael's Hospital in the morning in a fasting state (12 hours fasting) and will provide blood and urine for the measurement of biological markers including lipid levels, glucose and cortisol. In addition, a saliva sample will be taken for the genetic analysis of the APOE gene - this gene is involved in the transport of cholesterol. Following blood draw, you will be escorted to the Stress and Healthy Aging Research Lab where you will be provided a light snack (i.e. low glycemic protein bar and water/juice) before beginning the neuropsychological testing (i.e. tasks and questionnaires assessing things such as memory) session. The testing session will take approximately 2.5 hours. During this time, you will be asked to complete tasks that assess things like your memory, attention and thinking abilities (maximum 2 hours). You will also be asked to complete questionnaires that assess your mood and daily living habits (maximum 30 minutes). Depending on the wait time for blood draw and your speed in answering questions, this testing session is anticipated to last approximately 4 hours maximum. Additionally, we will also be collecting urine samples to measure your stress hormone levels. You will be given two, 24-hour urine collection bottles to take home to measure some of the biomarkers of interest. We will provide you with detailed instructions on the urine collection procedure.

\section{Second Testing Session:}

After completing session one, you will be asked to return to the Stress and Healthy Aging Research Lab where you will be asked to undergo EEG to assess your brain activity while at rest and during a memory task.

This session will last a maximum of 3 hours. The EEG entails placing a cap on your head. The cap will have electrodes embedded in it, which is what measures your brain activity along the scalp. A special gel is used to insert the electrodes into the cap and some of this gel will likely spill onto your hair. You can wash your hair at the research facility, either with your own shampoo/conditioner, or with that which will be provided. You will also be asked to return the completed urine collection containers along with the provided instruction sheet at the beginning of this session.

\section{What is Experimental in this Study:}

Participants will be asked to undergo testing on two separate occasions during which they will be exposed to biological (i.e. providing blood, urine and saliva), cognitive (i.e. completing various tasks assessing things like memory and attention) and brain imaging (i.e. EEG) testing.

\section{What is Genetic Testing:}

As everyone is born with a unique set of genes, a genetic test is an analysis used to look at a person's genetic makeup. Molecular genetic tests (or gene tests) study single genes or short lengths of DNA to identify variations or mutations that are associated with certain phenotypes (e.g. eye colour, height, muscle growth, personality etc). Genetic testing for this study will be performed on saliva instead of the common use of blood as it is less invasive and provides the same level of accuracy for results. The cells in your saliva will be extracted to get information on your DNA and the genes embedded in your DNA. Using special techniques, we can examine the 
structure of the genes that make up your DNA. For example, the APOE gene can come in 3 different forms: e2, e3, and $\mathrm{e} 4$. These different genetic forms, or variants, can determine how the proteins in your body function.

While genetic testing can be highly accurate, there are a few noted limitations. For example, problems may occur during laboratory processing. All certified laboratories have strict rules for handling samples-- from the time the sample is received to the reporting of results. In rare cases, problems may occur in handling the sample, which might lead to incorrect results. Examples include sample mislabeling, sample contamination, or misinterpretation of laboratory findings. Sometimes the test itself may not work properly. Genetic testing is still in an early stage and thus the genetic variants we are interested in are not diagnostic. Participants will not have access to their genetic results and all samples will not have any identifying information on it. Once you have completed the study and your personal identifying information has been destroyed, there will be no way to link you to the DNA results.

\section{Storage of DNA sample:}

A saliva sample will be taken which involves swabbing the inside of your cheek. No identifying information will be sent with your sample. The DNA from the cell lines will be stored for up to 7 years at the McGill Centre for Studies in Aging Stress following publication of results, after which all viable samples will be destroyed. During this time, and as research funds become available, the sample may be re-analyzed for additional genetic markers of interest (e.g. COMP, Brain-derived Neurotrophic Factor) that are associated with cognitive function and stress in older adults (but are not diagnostic of disease).

\section{Confidentiality, Storage and Safekeeping of DNA Samples:}

Your sample will be coded so that we will protect the confidentiality of the sample by assigning it a specific study code. Once you have completed the study, all of your identifying information will be destroyed and no link can be made between your identity and your samples/data. This means that we will not have access to any results from genetic testing, nor will any third party as there is no identifiable link between the sample and yourself. All data and viable samples will be securely stored up to 7 years following publication of results, after which all material will be properly destroyed.

\section{Risks or Discomforts:}

Some of the cognitive tasks (e.g. memorizing a list of words) may be challenging, causing frustration or fatigue; however, we emphasize that you are not expected to get everything correct and that we only ask you to try your best. Should you feel uncomfortable during the testing session and while filling out psychological questionnaires, you may take a break before moving on, or stop altogether.

Physical discomfort may arrive during the blood draw. Although a professional technician will be drawing blood, there is always the risk of bruising. This commonly occurs when it is difficult to find a good vein to draw from. However, this discomfort is short lived and no greater than what you would normally expect from a yearly physical. Common with blood draw, there may be a small amount of bleeding when blood is taken from a vein and there may be slight discomfort and bruising or redness that will usually disappear in a few days. While conducting the urine collection, you may experience some discomfort or inconvenience due to the nature of the collection procedure. Given that one of the urine collection containers contains a small of amount of acid, you must exercise extra caution to avoid coming in contact with the solution. However, you will be instructed on how to collect the samples with the proper procedure and precaution.

Although this study does not assess diagnostic genetic markers of disease, concern may pertain to the possibility that the results can affect a person's ability to obtain health, life, disability or long-term care insurance. 
However, it must be stressed that your sample will not have any identifying information on it. A study code will be used to identify your data (i.e. cognitive and psychological test scores, blood, saliva). All identifying information that links you to your data will be destroyed once you have completed the study.

\section{Benefits of the Study:}

Participants will be properly compensated for their time in the study ( $\$ 100$ total). In addition, upon request, participants will be provided with the results of the blood test from Saint Michael's Hospital (including cholesterol and glucose readings, which are important to monitor). As the genetic marker under evaluation is not a diagnostic tool, participants will not be told their carrier status. While there are no other direct benefits of participating in this study, your participation in this study is extremely valuable in helping researchers understand what contributes to healthy aging.

\section{Confidentiality:}

All data collected for this study, including salivary, urine and blood samples, will remain confidential. Research records will be kept in a cabinet file to which only the principal investigator of this study as well as her research assistants will possess the key. Data will be coded in order to prevent any assistant from making a link between a participant's name and test results, thus maintaining confidentiality of all test results. Once data is collected, identifying information (e.g name, contact information) will be destroyed. All coded data, including saliva and blood samples, will be securely stored up to 7 years following publication of results, after which all material will be properly destroyed. We will destroy all identifying information, including name and telephone numbers, following the second session.

\section{Costs and/or Compensation for Participation:}

Participants will be compensated $\$ 100$ in total: $\$ 50$ following the first session and $\$ 50$ following the second session. This amount will compensate for cost of time and travel to and from Ryerson University.

\section{Voluntary Nature of Participation:}

Participation in this study is voluntary. Your choice of whether or not to participate will not influence your future relations with Ryerson University. If you decide to participate, you are free to withdraw your consent and to stop your participation at any time without penalty or loss of benefits to which you are allowed.

At any particular point in the study, you may refuse to answer any particular question or stop participation altogether. If you decide to stop participating, all information that you provided before stopping will remain confidential in a secured database at Ryerson University and used for future analyses for up to 7 years. If you chose to withdraw before the final session, and thus before destroying your personal information, you may request to have your data removed from the database.

\section{What will be done if "abnormal" findings/results are obtained:}

The tests that you will complete are not "diagnostic" - i.e. no diagnosis can be made with the tests that are administered or the genes that are assayed. However, if there is anything about your performance on the tasks, questionnaires, or blood analyses (e.g. high cholesterol) that raise a concern for us, we will discuss it with you.

\section{Questions about the Study:}

If you have any questions about the research now, please ask. If you have questions later about the research, you may contact the principal investigator: Alexandra J. Fiocco via phone (416-979-5000 ext 3008) or email (afiocco@psych.ryerson.ca).

If you have questions regarding your rights as a human subject and participant in this study, you may contact Dr. Lynn Lavallee (Chair) or Toni Fletcher (REB Coordinator) of the Ryerson University Research Ethics Board for 
information via phone (416-979-5042) or email (rebchair@ryerson.ca). You may also write them at:

Research Ethics Board

c/o Office of the Vice President, Research and Innovation

Ryerson University

350 Victoria Street

Toronto, ON M5B 2 K3

\section{Agreement:}

Your signature below indicates that you have read the information in this agreement and have had a chance to ask any questions you have about the study. Your signature also indicates that you agree to be in the study and have been told that you can change your mind and withdraw your consent to participate at any time. You have been given a copy of this agreement.

You have been told that by signing this consent agreement you are not giving up any of your legal rights.

Name of Participant (please print)

Signature of Participant

Date

Signature of Investigator/Study Coordinator

Date

\section{Dissemination of Results:}

If you agree to participate in the study, are you interested in learning about the results of the study in a final report? If so, please provide your mailing or email address below:

Email_

Mailing 


\section{Genotyping Opt Out Form}

If you do not wish to provide a saliva sample for genetic genotyping, please sign this form below to opt out of this portion of the study.

Name of Participant (please print)

Signature of Participant

Signature of Investigator/Study Coordinator
Date

Date 


\section{Appendix D}

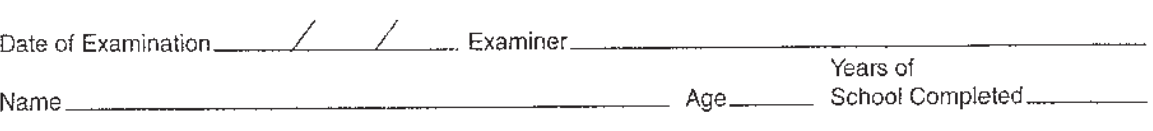

- Instructions: Woras in boldface type should be read aloud clearly and slowly to the examinee. Item substitutions appear in parentheses. Administration should be conducted privately and in the examinee's primary language. Circle 0 if the response is incorrect, or 1 if the response is correct. Begin by asking the following two questions:

Do you have any trouble with your memory?

May I ask you some questions about your memory?

ORIENTATION TO TIME

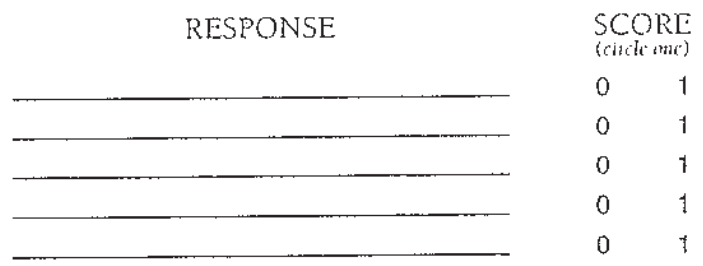

ORIENTATION TO PLACE*

Where are we now? What is the... state (province)?

county (or city/town)?

city/town (or part of city/neighborhood)?

building (name or type)?

floor of the building

(room number or address)?

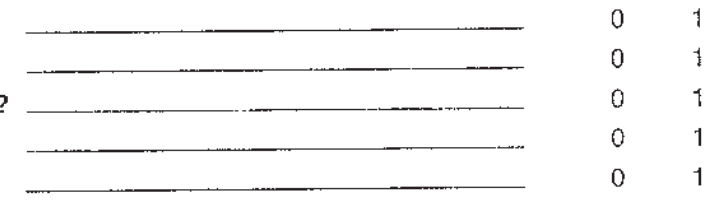

* Aliernative place words that are appropriate for the setting and increasingly precise may be substituted and noted.

REGISTRATION*

Listen carefully. I am going to say three words. You say them back after I stop. Ready?

Here they are... APPLE [pause], PENNY [pause]; TABLE [pause]. Now repeat those words back to me.

[Repeat up to 5 times, but score only the first trial.]
APPLE
PENNY
TABLE

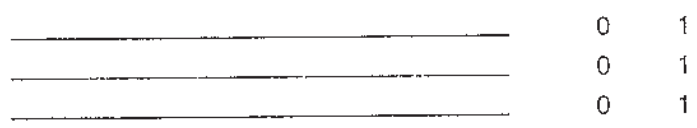

Now keep those words in mind. I am going to ask you to say them again in a few minutes.

*Alternative word sets (c.g., PONY, QUARTER, ORANGE) may be substituted and noted when retesting an examince.

\section{ATTENTION AND CALCULATION [Serial 7s] *}

Now l'd like you to subtract 7 from t00. Then keep subtracting 7 from each answer until l tell you to stop.

What is 100 take away 7 ?

If needed, say: Keep going.

[93]

If needed, say: Keep going.

[86]

If needed, say: Keep going.

[79]

[72]

If needed, say: Keep going.

[65]

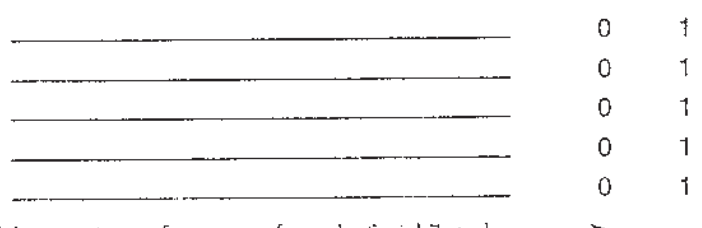

*Alternative item (WORJ.D backward) should only be administered if the examinee refuses to periorm the Serial $7 \mathrm{~s}$ task.

PAR Psychological Assessment Resources, Inc. • 16204 N. Florida Avenue • Lutz, FL $33549 \cdot 1.800 .331 .8378$ • www paritic.com MMSE Cupyright O 1975, 1998, 2001 lsy MiniMcntal, LLC. All rights reserved. Published 2001 by Psychological Assessment Resources, Inc. May not be reproduced whole or in part in any form or by any means without written pernission of Psychological Assessment Resources, Inc. This form is printed in red and balue ink. Any -uther version is unauthorized.

9876543

Reorder $\# \mathrm{RO}-4740$

P'rituced in the U.S.A. 
Substitute and score this item only if the examince retuses to perform the Serial $7 \mathrm{~s}$ task.

Spell WORLD forward, then backward.

"arrect forwaret spelling if misspelled,

out score only the hackward spelling.

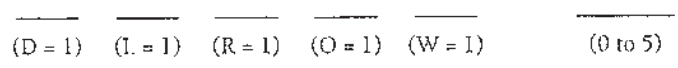

\section{RECALL}

RESPONSE

SC.ORE

What were those three words I asked you to remember? [Do not offer any hints.]

$$
\begin{aligned}
& \text { APPLE } \\
& \text { PENNY } \\
& \text { TABLE }
\end{aligned}
$$

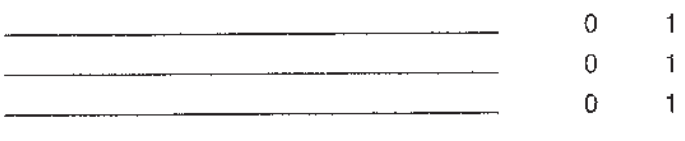

NAMING*

What is this? [Point to a pencil or pen.]

What is this? [Point to a watch.]

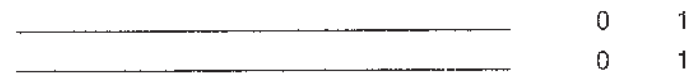

"Alternative common objects (e.g., eycglasses, chair, keys) may be substituted and noted.

\section{REPETITION}

Now I am going to ask you to repeat what I say. Ready? "NO IFS, ANDS, OR BUTS." Now you say that. [Repeat up to 5 times, but score only the first trial.]

$$
\text { NO IFS, ANDS, OR BUTS. }
$$

Detach the next page along the lengthwise perforation, and then tear it in half along the horizontal perforation. Use the upper half of the page (blank) for the Comprehension, Writing, and Drawing items that follow. Use the lower hall - of the page as a stimulus form for the Reading ("CLOSE YOUR EYES") and Drawing (intersecting pentagons) items.

\section{COMPREHENSION}

Listen carefully because $\mathrm{I}$ am going to ask you to do something.

Take this paper in your right hand [pause], fold it in half [pause], and put it on the floor (or table).

\section{TAKE IN RIGHT HAND \\ FOLD IN HALF \\ PUT ON FLOOR for TABLE)}

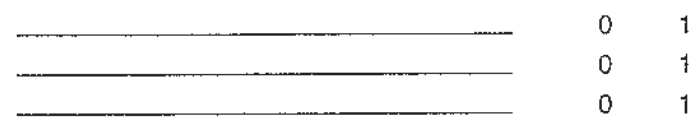

READING

Please read this and do what it says. [Show examinee the words on the stimulus form.]

$$
\text { CLOSE YOUR EYES }
$$

\section{WRITING}

Please write a sentence. [If examinee does not respond, say: Write about the weather.]

Place the blank piece of paper (unfolded) in front of the examinee and provide a pen or pencil. Score I point if the sentence is comprehensible and contains a subject and a verb. Ignore errors in grammar or spelling.

\section{DRAWING}

Please copy this design. [Display the intersecting pentagons on the stimulus form.]

Score I point tf the drawing consists of two 5-sided figures that intersect to form a t-sided figure.

\begin{tabular}{|c|c|c|c|}
\hline $\begin{array}{c}\text { Alert/ } \\
\text { Responsive }\end{array}$ & browsy & Stuprorosts & $\begin{array}{l}\text { Comatosef } \\
\text { Unrespyonsive }\end{array}$ \\
\hline
\end{tabular}
$-$

Assessment of level of consciousness 


\section{Appendix E}

\begin{tabular}{|c|c|c|c|}
\hline \multicolumn{3}{|c|}{ California Verbal Learning Test-Second Addition } & Standard Form \\
\hline 8 & Trial2 & Trials 3 and 4 & $\underline{5}$ \\
\hline $\begin{array}{l}\text { going to read a list of words to } \\
\text { fully, because when I'm throu } \\
\text { to tell me as many of the wor } \\
\text { You can say them in any orde } \\
\text { nany of them as you can. Are y }\end{array}$ & $\begin{array}{l}\text { I'm going to read the same list again. } \\
\text { Like before, tell me as many of the } \\
\text { words as you can, in any order. Be } \\
\text { sure to also say words from the list } \\
\text { that you told me the first time. }\end{array}$ & $\begin{array}{l}\text { I'm going to read the same list again. } \\
\text { Like before, tell me as many of the } \\
\text { words as you can, in any order, } \\
\text { including words from the list you've } \\
\text { said before. }\end{array}$ & $\begin{array}{l}\text { I'm going to read the sar } \\
\text { one more time. Like bef } \\
\text { as many of the words as } \\
\text { any order, including wor } \\
\text { list you've said before. }\end{array}$ \\
\hline
\end{tabular}

Read List A at an even pace, taking slightly longer Record all responses verbatim, in the order recalled. Prompt only once (e.g., Anything else?) at the end of each free and than one second per word, so the entire list takes cued recall trial (i.e., after 15 seconds with no response or when the examinee says he/she cannot remember more words). 18 to 20 seconds. Then say: Go ahead.

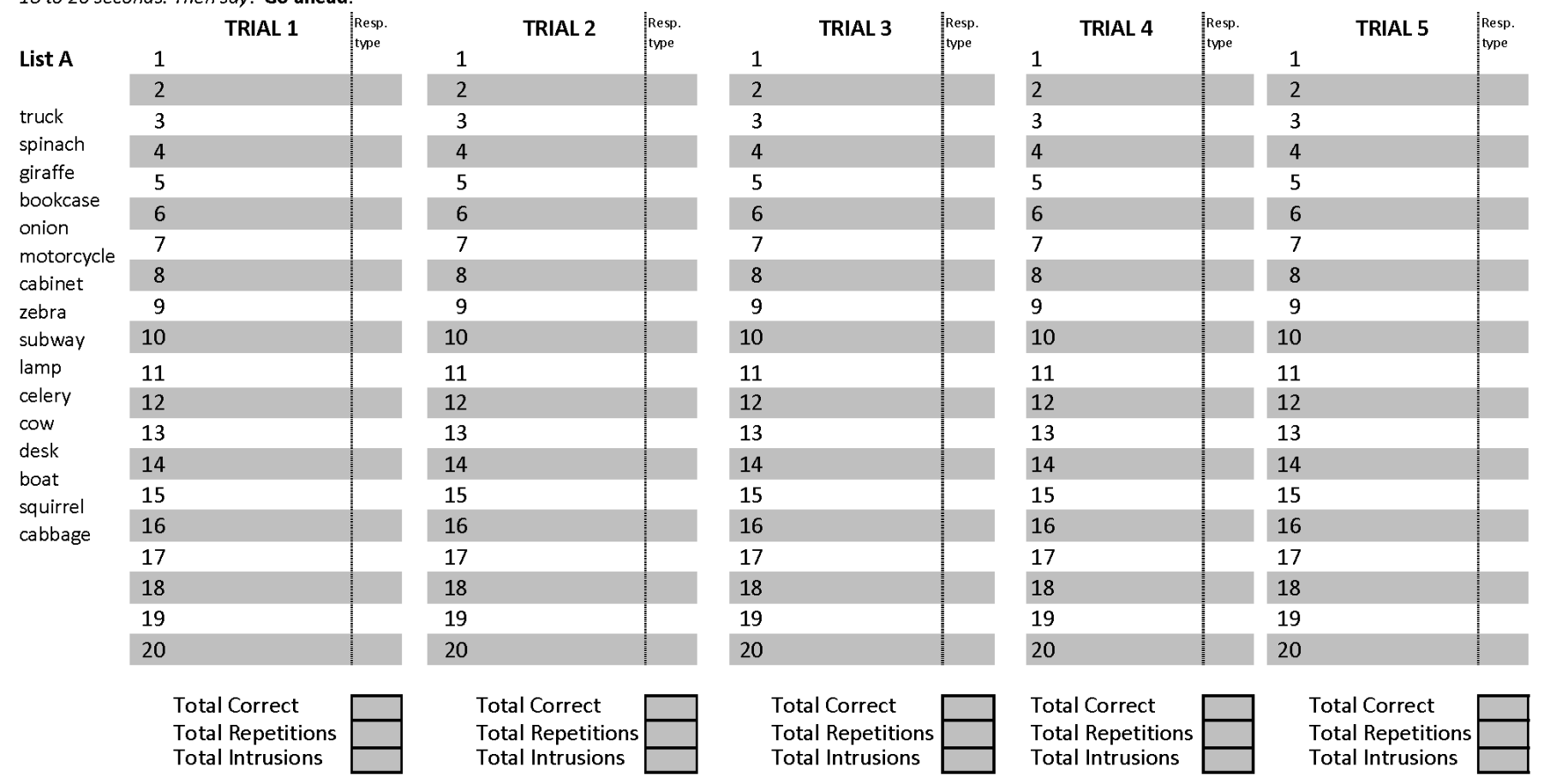


List B Immediate Free Recall

Now I'm going to read a second list of words to you. When I'm through, I want you to tell me as many words from this second list as you can, in any order. Don't tell me words from the first list, just this second list.

Read List $B$ at an even pace, taking slightly longer than one second per word, so the entire list takes 18 to 20 seconds. Then say: Go ahead.

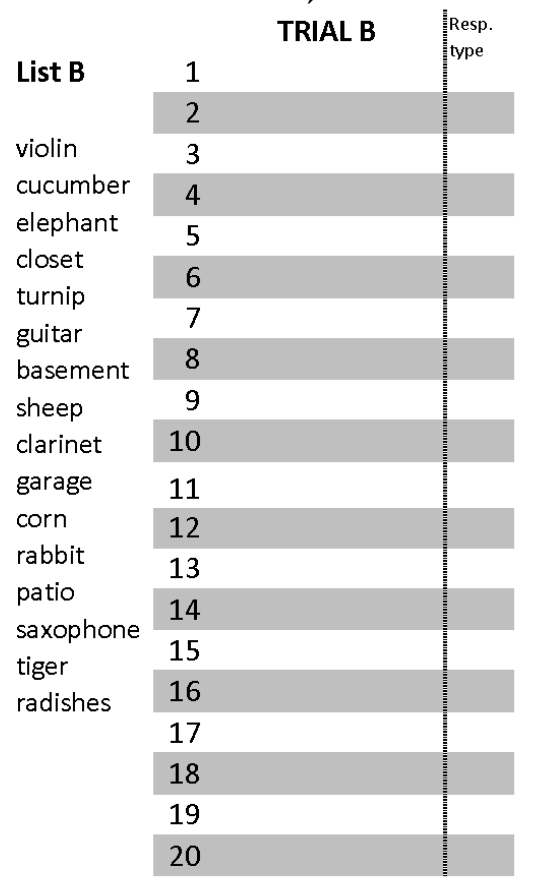

Total Correct

Total Repetitions

Total Intrusions
List A Short-Delay Free Recall

Now I want you to tell me all the words you can from the first list, the

one I read to you several times.

Don't tell me words from the second

list, just the first list. Go ahead.

Record all responses verbatim, in the order recalled. Prompt only once (e.g., Anything else?) at the end of each free and cued recall trial (i.e., after 15 seconds with no response or when the examinee says he/she cannot remember more words).

\begin{tabular}{|c|c|c|}
\hline $1 \quad$ List A & $\begin{array}{l}\text { Tesp. } \\
\text { type }\end{array}$ & $1 \quad$ Furniture \\
\hline 2 & & 2 \\
\hline 3 & & 3 \\
\hline 4 & & 4 \\
\hline 5 & & 5 \\
\hline 6 & & 6 \\
\hline 7 & & 7 \\
\hline 8 & & 8 \\
\hline
\end{tabular}
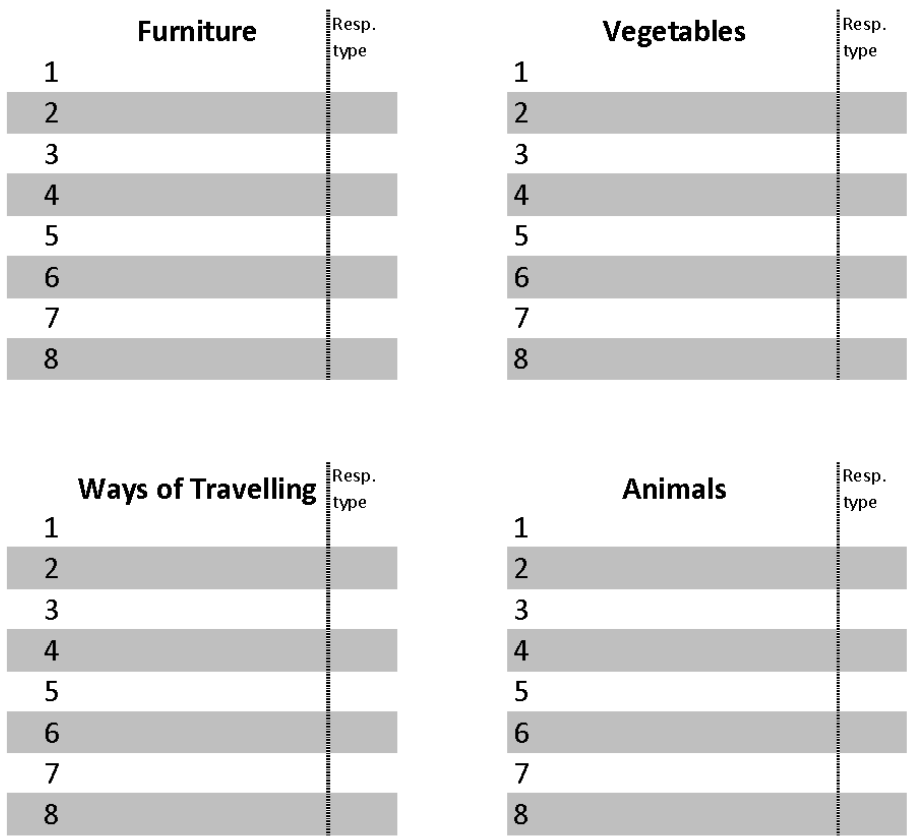

Total Correct Total Intrusions

Total Correct

Total Repetitions

Total Intrusions

There should be approximately a 20-minute delay between the completion of Short-Delay Cued Recall and the start of Long Delay Free Recall. Do not inform the examinee that there will be later CVLT-II trials. 
List A Long-Delay Free Recall

I read two different lists of words to you earlier: a first list that I read to you several times, and a second list that I read to you once. Tell me all the words you can that were from the first list. Don't tell me words from the second list, just the first list.

Go ahead.

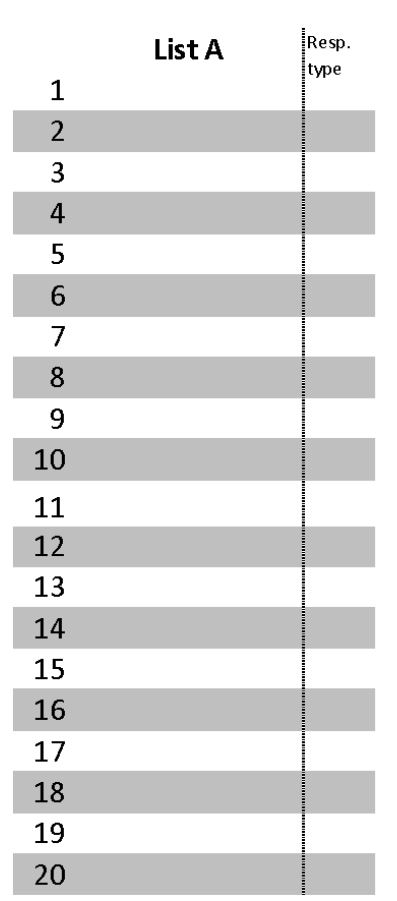

Total Correct

Total Repetitions

Total Intrusions

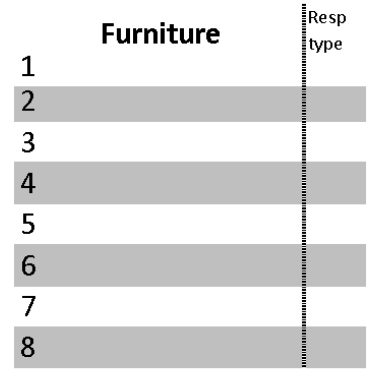

Total Correct

\section{List A Long-Delay Yes/No Recognition}

Now I'm going to read more words to you. After I read each one, say "Yes"

if that word was from the first list, or say "No" if it was not from the first list.

\begin{tabular}{l|ll|}
$\begin{array}{l}\text { wallet } \\
\text { boat }\end{array}$ & $\mathrm{Y}$ & $\mathrm{N}$ \\
\hline saxophone & $\mathrm{Y}$ & $\mathrm{N}$ \\
cucumber & $\mathrm{N}$ \\
\hline giraffe & $\mathrm{Y}$ & $\mathrm{N}$ \\
\hline carrot & $\mathrm{Y}$ & $\mathrm{N}$ \\
\hline patio & $\mathrm{Y}$ & $\mathrm{N}$ \\
\hline cabbage & $\mathrm{Y}$ & $\mathrm{N}$ \\
\hline desk & $\mathrm{N}$ \\
\hline bracelet & $\mathrm{Y}$ & $\mathrm{N}$ \\
\hline car & $\mathrm{Y}$ & $\mathrm{N}$ \\
\hline elephant & $\mathrm{Y}$ & $\mathrm{N}$ \\
\hline
\end{tabular}

\begin{tabular}{|c|c|c|}
\hline violin & $Y$ & $\mathrm{~N}$ \\
\hline cow & $Y$ & $\mathrm{~N}$ \\
\hline fork & $Y$ & $\mathrm{~N}$ \\
\hline bus & $Y$ & $\mathrm{~N}$ \\
\hline celery & $Y$ & $\mathrm{~N}$ \\
\hline lamp & $Y$ & $\mathrm{~N}$ \\
\hline radishes & $Y$ & $\mathrm{~N}$ \\
\hline table & $Y$ & $\mathrm{~N}$ \\
\hline rose & $Y$ & $\mathrm{~N}$ \\
\hline motorcycle & $Y$ & $\mathrm{~N}$ \\
\hline sheep & I & $\mathrm{N}$ \\
\hline basement & $Y$ & $\mathrm{~N}$ \\
\hline
\end{tabular}

\begin{tabular}{|c|c|}
\hline dog & $Y$ \\
\hline bookcase & $Y$ \\
\hline matches & $Y$ \\
\hline spinach & $Y$ \\
\hline clarinet & $Y$ \\
\hline truck & $Y$ \\
\hline rabbit & $Y$ \\
\hline chair & $Y$ \\
\hline corn & $Y$ \\
\hline seashell & $Y$ \\
\hline garage & $Y$ \\
\hline squirrel & $Y$ \\
\hline$\overline{\text { TOTAL HITS }}$ & \\
\hline
\end{tabular}

If the examinee responds "I don't know during Yes/No Recognition, say, "Tell me whether you was on the first list."

\begin{tabular}{|c|c|}
\hline turnip & I $\mathrm{Y}$ \\
\hline cabinet & $Y \quad N$ \\
\hline onion & $\begin{array}{ll}Y & N\end{array}$ \\
\hline lion & $Y N$ \\
\hline camera & Y N \\
\hline guitar & Y N \\
\hline subway & $Y \quad N$ \\
\hline tiger & $Y N$ \\
\hline coffee & $Y \quad N$ \\
\hline zebra & $Y N$ \\
\hline$\overline{\text { lettuce }}$ & $\begin{array}{ll}Y & N\end{array}$ \\
\hline closet & $Y \quad N$ \\
\hline
\end{tabular}




\section{Appendix F}

\section{TRAIL MAKING}

Port A

SAMPLE

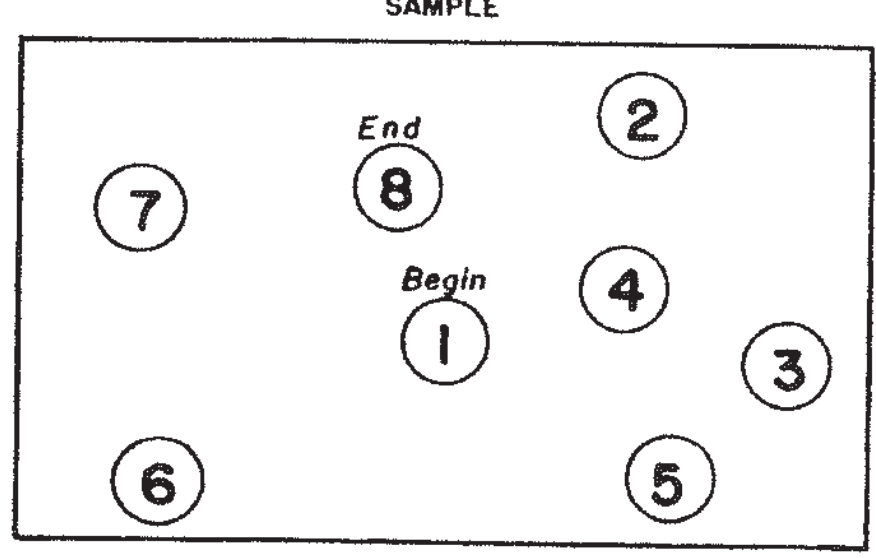


(15)

(17)

(21)

(20)

(19)

(16)

(18)

(5)

(4) (22)

(13)

(6)

(7)

(1) (24)

(14)

(8) (10)

(9)

(12)

(11) (25)

(23) 
TRAIL MAKING

Port B

SAMPLE

(4)

End

(A)

Begin

(1)

(B)

(2)

(c)

(3) 
End

(8) (9)

(B) 4

(1) (D)

(7)

(7)

(H)

(10)

5

(C)

(12)

(G)

(A) (J)

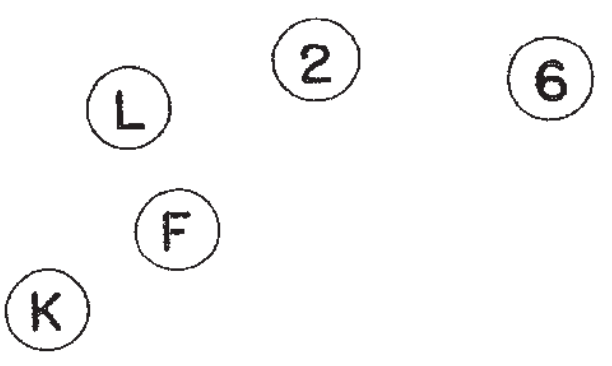

(E)

(11) 


\section{Appendix G}

\section{Perceived Stress Scale}

The questions in this scale ask you about your feelings and thoughts during the last month. In each case, you will be asked to indicate by circling how often you felt or thought a certain way.

Name

Date

Age Gender (Circle): M F Other

\section{$0=$ Never $\quad 1=$ Almost Never $\quad 2=$ Sometimes $\quad 3=$ Fairly Often $\quad 4=$ Very Often}

1. In the last month, how often have you been upset because of something that happened unexpectedly?

$\begin{array}{lllll}0 & 1 & 2 & 3 & 4\end{array}$

2. In the last month, how often have you felt that you were unable to control the important things in your life?

$\begin{array}{lllll}0 & 1 & 2 & 3 & 4\end{array}$

3. In the last month, how often have you felt nervous and "stressed"? $\begin{array}{lllll}0 & 1 & 2 & 3 & 4\end{array}$

4. In the last month, how often have you felt confident about your ability to handle your personal problems?

5. In the last month, how often have you felt that things were going your way?

6. In the last month, how often have you found that you could not cope with all the things that you had to do?

7. In the last month, how often have you been able to control irritations in your life?

8. In the last month, how often have you felt that you were on top of things?.. $\begin{array}{llllll}0 & 1 & 2 & 3 & 4\end{array}$

9. In the last month, how often have you been angered because of things that were outside of your control?

10. In the last month, how often have you felt difficulties were piling up so high that you could not overcome them?

Please feel free to use the Perceived Stress Scale for your research.

\section{Mind Garden, Inc.} info@mindgarden.com www.mindgarden.com

\section{References}

The PSS Scale is reprinted with permission of the American Sociological Association, from Cohen, S., Kamarck, T., and Mermelstein, R. (1983). A global measure of perceived stress. Journal of Health and Social Behavior, 24, 386-396.

Cohen, S. and Williamson, G. Perceived Stress in a Probability Sample of the United States. Spacapan, S. and Oskamp, S. (Eds.) The Social Psychology of Health. Newbury Park, CA: Sage, 1988. 
Appendix H

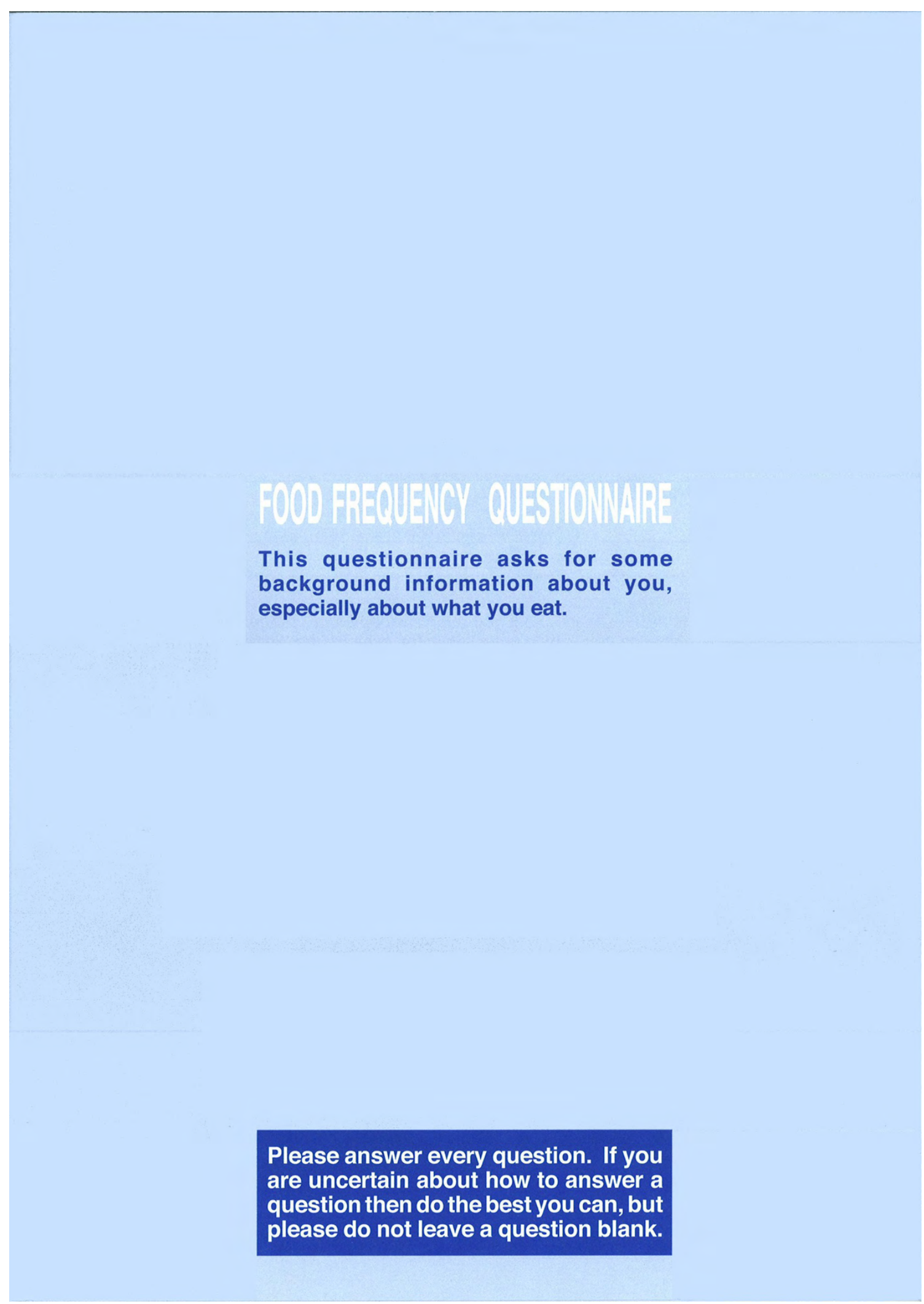


1. YOUR DIET LAST YEAR

For each food there is an amount shown, either a "medium serving" or a common household unit such as a slice or teaspoon. Please put a tick $(\checkmark)$ in the box to indicate how often, on average, you have eaten the specified amount of each food during the past year.

\section{EXAMPLES:}

For white bread the amount is one slice, so if you ate 4 or 5 slices a day, you should put a tick in the column headed " $4-5$ per day".

\begin{tabular}{|c|c|c|c|c|c|c|c|c|}
\hline \multirow{2}{*}{$\begin{array}{l}\text { FOODS AND AMOUNTS } \\
\text { BREAD AND SAVOURY BISCUITS } \\
\text { (one slice or biscuit) }\end{array}$} & \multicolumn{8}{|c|}{ AVERAGE USE LAST YEAR } \\
\hline & $\begin{array}{l}\text { Never or } \\
\text { less than } \\
\text { once/month }\end{array}$ & $\begin{array}{l}1-3 \\
\text { per } \\
\text { month }\end{array}$ & $\begin{array}{l}\text { Once } \\
\text { a } \\
\text { week }\end{array}$ & $\begin{array}{l}2-4 \\
\text { per } \\
\text { week }\end{array}$ & $\begin{array}{l}\text { 5-6 Once } \\
\text { per a } \\
\text { week day }\end{array}$ & $\begin{array}{l}2-3 \\
\text { per } \\
\text { day }\end{array}$ & $\begin{array}{l}4-5 \\
\text { per } \\
\text { day }\end{array}$ & $\begin{array}{l}6+ \\
\text { per } \\
\text { day }\end{array}$ \\
\hline White bread and rolls & & & & & & & $\checkmark$ & \\
\hline
\end{tabular}

For chips, the amount is a "medium serving", so ifyou had a helping of chips twice a week you should put a tick in the column headed "2-4 per week".

\begin{tabular}{|c|c|c|c|c|c|c|c|c|}
\hline FOODS AND AMOUNTS & \multicolumn{8}{|c|}{ AVERAGE USE LAST YEAR } \\
\hline $\begin{array}{l}\text { POTATOES, RICE AND PASTA } \\
\text { (medium serving) }\end{array}$ & $\begin{array}{ll}\text { Never or } & 1-3 \\
\text { less than } & \text { per } \\
\text { once/month month }\end{array}$ & $\begin{array}{l}\text { Once } \\
\text { a } \\
\text { week }\end{array}$ & $\begin{array}{l}2-4 \\
\text { per } \\
\text { week }\end{array}$ & $\begin{array}{l}5-6 \\
\text { per } \\
\text { week }\end{array}$ & $\begin{array}{l}\text { Once } \\
\text { a } \\
\text { day }\end{array}$ & $\begin{array}{l}2-3 \\
\text { per } \\
\text { day }\end{array}$ & $\begin{array}{l}4-5 \\
\text { per } \\
\text { day }\end{array}$ & $\begin{array}{l}6+ \\
\text { per } \\
\text { day }\end{array}$ \\
\hline Chips & & & $\checkmark$ & & & & & \\
\hline
\end{tabular}

For very seasonal fruits such as strawberries and raspberries you should estimate your average use when the fruits are in season, so if you ate strawberries or raspberries about once a week when they were in season you should put a tick in the column headed "once a week"

\begin{tabular}{|c|c|c|c|c|c|c|c|c|c|}
\hline FOODS AND AMOUNTS & AVERAGE & SE LAS & T YEA & & & & & & \\
\hline $\begin{array}{l}\text { FRUIT } \\
\text { (1 fruit or medium serving) }\end{array}$ & $\begin{array}{l}\text { Never or } \\
\text { less than } \\
\text { once/month }\end{array}$ & $\begin{array}{l}1-3 \\
\text { per } \\
\text { month }\end{array}$ & $\begin{array}{l}\text { Once } \\
\text { a } \\
\text { week }\end{array}$ & $\begin{array}{l}2-4 \\
\text { per } \\
\text { week }\end{array}$ & $\begin{array}{l}5-6 \\
\text { per } \\
\text { week }\end{array}$ & $\begin{array}{l}\text { Once } \\
\mathrm{a} \\
\text { day }\end{array}$ & $\begin{array}{l}2-3 \\
\text { per } \\
\text { day }\end{array}$ & $\begin{array}{l}4-5 \\
\text { per } \\
\text { day }\end{array}$ & $\begin{array}{l}6+ \\
\text { per } \\
\text { day }\end{array}$ \\
\hline Strawberries, raspberries, kiwi fruit & & & $\checkmark$ & & & & & & \\
\hline
\end{tabular}


Please estimate your average food use as best you can, and please answer every question do not leave ANY lines blank. PLEASE PUT A TICK $(\checkmark)$ ON EVERY LINE

\begin{tabular}{|c|c|c|c|c|c|c|c|c|c|}
\hline \multirow{2}{*}{$\begin{array}{l}\text { FOODS AND AMOUNTS } \\
\text { MEAT AND FISH } \\
\text { (medium serving) }\end{array}$} & \multicolumn{9}{|c|}{ AVERAGE USE LAST YEAR } \\
\hline & $\begin{array}{l}\text { Never or } \\
\text { less than } \\
\text { once/month }\end{array}$ & $\begin{array}{l}1-3 \\
\text { per } \\
\text { month }\end{array}$ & $\begin{array}{l}\text { Once } \\
\text { a } \\
\text { week }\end{array}$ & $\begin{array}{l}2-4 \\
\text { per } \\
\text { week }\end{array}$ & $\begin{array}{l}5-6 \\
\text { per } \\
\text { week }\end{array}$ & $\begin{array}{l}\text { Once } \\
\mathrm{a} \\
\text { day }\end{array}$ & $\begin{array}{l}2-3 \\
\text { per } \\
\text { day }\end{array}$ & $\begin{array}{l}4-5 \\
\text { per } \\
\text { day }\end{array}$ & $\begin{array}{l}6+ \\
\text { per } \\
\text { day }\end{array}$ \\
\hline \multicolumn{10}{|l|}{ Beef: roast, steak, mince, stew or casserole } \\
\hline \multicolumn{10}{|l|}{ Beefburgers } \\
\hline \multicolumn{10}{|l|}{ Pork: roast, chops, stew or slices } \\
\hline \multicolumn{10}{|l|}{ Lamb: roast, chops or stew } \\
\hline \multicolumn{10}{|l|}{ Chicken or other poultry eg. turkey } \\
\hline \multicolumn{10}{|l|}{ Bacon } \\
\hline \multicolumn{10}{|l|}{ Ham } \\
\hline \multicolumn{10}{|l|}{ Corned beef, Spam, luncheon meats } \\
\hline \multicolumn{10}{|l|}{ Sausages } \\
\hline \multicolumn{10}{|l|}{$\begin{array}{l}\text { Savoury pies, eg. meat pie, pork pie, } \\
\text { pasties, steak \& kidney pie, sausage rolls }\end{array}$} \\
\hline \multicolumn{10}{|l|}{ Liver, liver paté, liver sausage } \\
\hline \multicolumn{10}{|l|}{ Fried fish in batter, as in fish and chips } \\
\hline \multicolumn{10}{|l|}{ Fish fingers, fish cakes } \\
\hline \multicolumn{10}{|l|}{$\begin{array}{l}\text { Other white fish, fresh or frozen, eg. cod, } \\
\text { haddock, plaice, sole, halibut }\end{array}$} \\
\hline \multicolumn{10}{|l|}{$\begin{array}{l}\text { Oily fish, fresh or canned, eg. mackerel, } \\
\text { kippers, tuna, salmon, sardines, herring }\end{array}$} \\
\hline \multicolumn{10}{|l|}{ Shellfish, eg. crab, prawns, mussels } \\
\hline \multicolumn{10}{|l|}{ Fish roe, taramasalata } \\
\hline & $\begin{array}{l}\text { Never or } \\
\text { less than } \\
\text { once/month }\end{array}$ & $\begin{array}{l}1-3 \\
\text { per } \\
\text { month }\end{array}$ & $\begin{array}{l}\text { Once } \\
\text { a } \\
\text { week }\end{array}$ & $\begin{array}{l}2-4 \\
\text { per } \\
\text { week }\end{array}$ & $\begin{array}{l}5-6 \\
\text { per } \\
\text { week }\end{array}$ & $\begin{array}{l}\text { Once } \\
\text { a } \\
\text { day }\end{array}$ & $\begin{array}{l}2-3 \\
\text { per } \\
\text { day }\end{array}$ & $\begin{array}{l}4-5 \\
\text { per } \\
\text { day }\end{array}$ & $\begin{array}{l}6+ \\
\text { per } \\
\text { day }\end{array}$ \\
\hline
\end{tabular}

\section{Please check that you have a tick $(\checkmark)$ on EVERY line}


PLEASE PUT A TICK $(\checkmark)$ ON EVERY LINE

\begin{tabular}{|c|c|c|c|c|c|c|c|c|c|}
\hline \multirow{2}{*}{$\begin{array}{l}\text { FOODS AND AMOUNTS } \\
\text { BREAD AND SAVOURY BISCUITS } \\
\text { (one slice or biscuit) }\end{array}$} & \multicolumn{9}{|c|}{ AVERAGE USE LAST YEAR } \\
\hline & $\begin{array}{l}\text { Never or } \\
\text { less than } \\
\text { once/month }\end{array}$ & $\begin{array}{l}1-3 \\
\text { per } \\
\text { month }\end{array}$ & $\begin{array}{l}\text { Once } \\
\text { a } \\
\text { week }\end{array}$ & $\begin{array}{l}2-4 \\
\text { per } \\
\text { week }\end{array}$ & $\begin{array}{l}5-6 \\
\text { per } \\
\text { week }\end{array}$ & $\begin{array}{l}\text { Once } \\
\text { a } \\
\text { day }\end{array}$ & $\begin{array}{l}2-3 \\
\text { per } \\
\text { day }\end{array}$ & $\begin{array}{l}4-5 \\
\text { per } \\
\text { day }\end{array}$ & $\begin{array}{l}6+ \\
\text { per } \\
\text { day }\end{array}$ \\
\hline \multicolumn{10}{|l|}{ White bread and rolls } \\
\hline \multicolumn{10}{|l|}{ Brown bread and rolls } \\
\hline \multicolumn{10}{|l|}{ Wholemeal bread and rolls } \\
\hline \multicolumn{10}{|l|}{ Cream crackers, cheese biscuits } \\
\hline \multicolumn{10}{|l|}{ Crispbread, eg. Ryvita } \\
\hline \multicolumn{10}{|l|}{ CEREALS (one bowl) } \\
\hline \multicolumn{10}{|l|}{ Porridge, Readybrek } \\
\hline \multirow{2}{*}{\multicolumn{10}{|c|}{$\begin{array}{l}\text { Breakfast cereal such as } \\
\text { cornflakes, muesli etc. } \\
\text { POTATOES. RICE AND PASTA (medium senving) }\end{array}$}} \\
\hline \multicolumn{7}{|c|}{ POTATOES, RICE AND PASTA (medium serving) } & & & \\
\hline \multicolumn{10}{|l|}{ Boiled, mashed, instant or jacket potatoes } \\
\hline \multicolumn{10}{|l|}{ Chips } \\
\hline \multicolumn{10}{|l|}{ Roast potatoes } \\
\hline \multicolumn{10}{|l|}{ Potato salad } \\
\hline \multicolumn{10}{|l|}{ White rice } \\
\hline \multicolumn{10}{|l|}{ Brown rice } \\
\hline \multicolumn{10}{|l|}{$\begin{array}{l}\text { White or green pasta, eg. spaghetti, } \\
\text { macaroni, noodles }\end{array}$} \\
\hline \multicolumn{10}{|l|}{ Wholemeal pasta } \\
\hline \multicolumn{10}{|l|}{ Lasagne, moussaka } \\
\hline \multicolumn{10}{|l|}{ Pizza } \\
\hline & $\begin{array}{l}\text { Never or } \\
\text { less than } \\
\text { once/month }\end{array}$ & $\begin{array}{l}1-3 \\
\text { per } \\
\text { month }\end{array}$ & $\begin{array}{l}\text { Once } \\
\text { a } \\
\text { week }\end{array}$ & $\begin{array}{l}2-4 \\
\text { per } \\
\text { week }\end{array}$ & $\begin{array}{l}5-6 \\
\text { per } \\
\text { week }\end{array}$ & $\begin{array}{l}\text { Once } \\
\text { a } \\
\text { day }\end{array}$ & $\begin{array}{l}2-3 \\
\text { per } \\
\text { day }\end{array}$ & $\begin{array}{l}4-5 \\
\text { per } \\
\text { day }\end{array}$ & $\begin{array}{l}6+ \\
\text { per } \\
\text { day }\end{array}$ \\
\hline
\end{tabular}

\section{Please check that you have a tick $(\checkmark)$ on EVERY line}




\section{PLEASE PUT A TICK $(\checkmark)$ ON EVERY LINE}

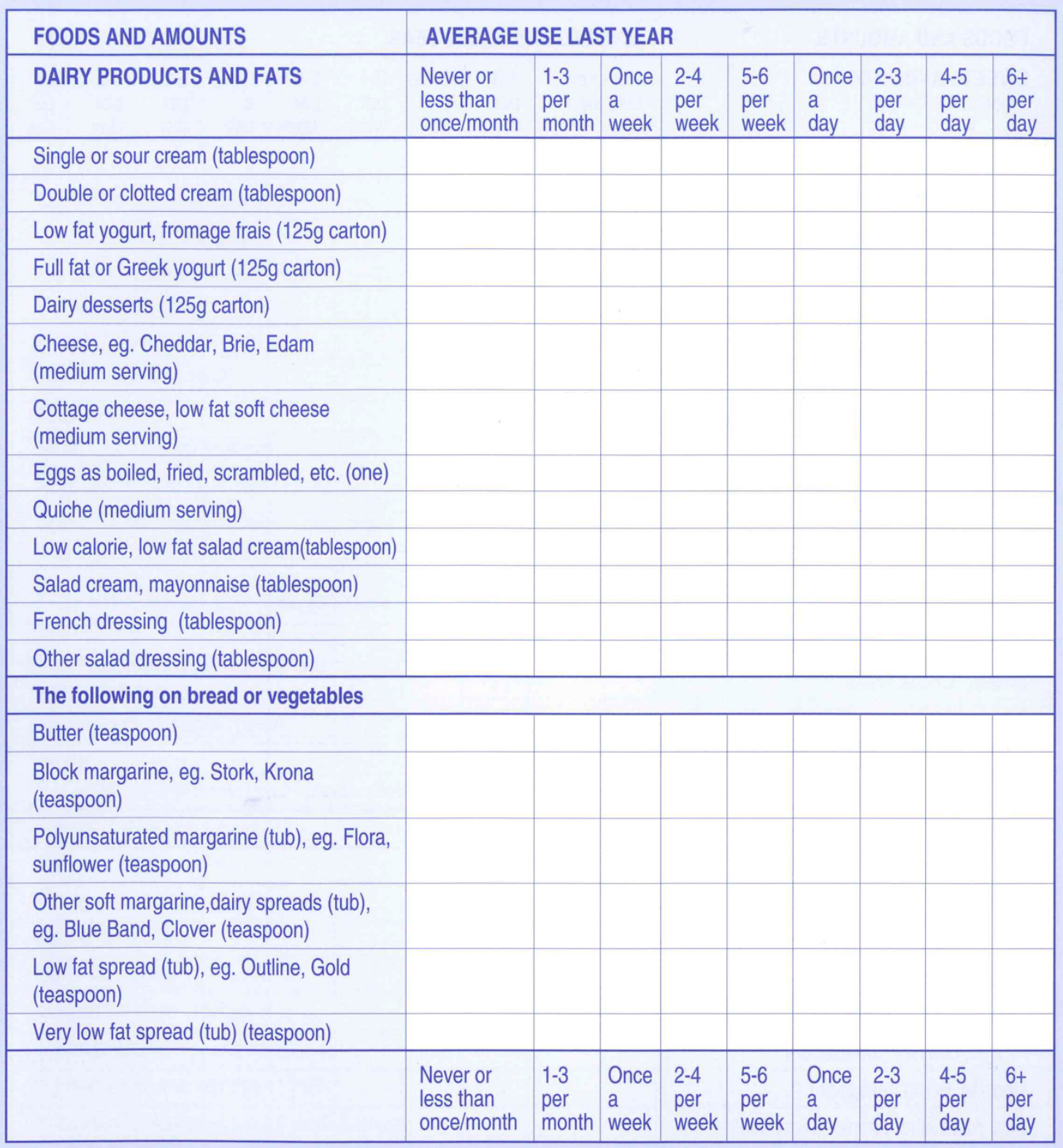

\section{Please check that you have a tick $(\checkmark)$ on EVERY line}


PLEASE PUT A TICK $(\checkmark)$ ON EVERY LINE

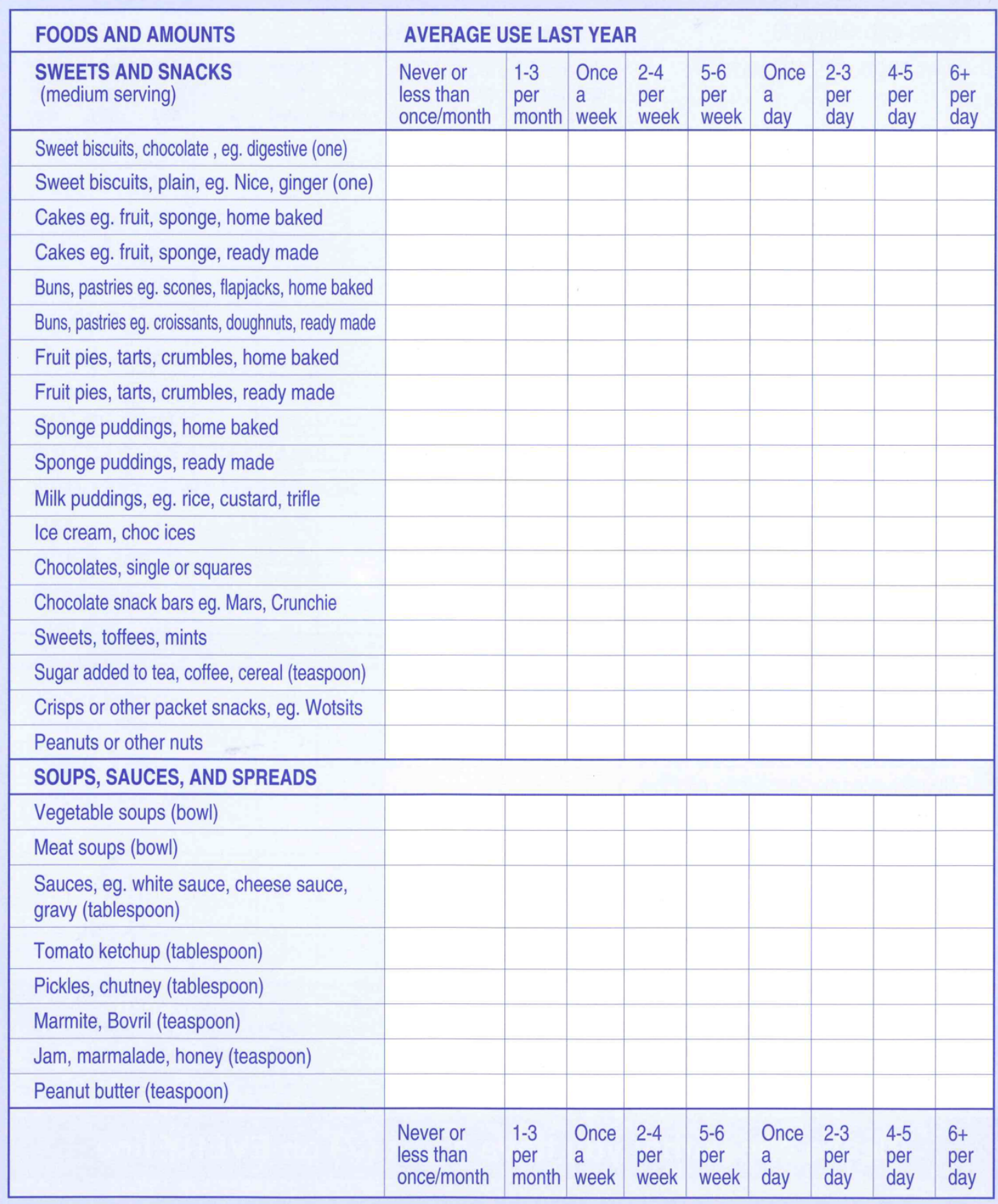

\section{Please check that you have a tick $(\checkmark)$ on EVERY line}




\section{PLEASE PUT A TICK $(\checkmark)$ ON EVERY LINE}

\begin{tabular}{|c|c|c|c|c|c|c|c|c|c|}
\hline \multirow{2}{*}{$\begin{array}{l}\text { FOODS AND AMOUNTS } \\
\text { DRINKS }\end{array}$} & \multicolumn{9}{|c|}{ AVERAGE USE LAST YEAR } \\
\hline & $\begin{array}{l}\text { Never or } \\
\text { less than } \\
\text { once/month } \\
\end{array}$ & $\begin{array}{l}1-3 \\
\text { per } \\
\text { month } \\
\end{array}$ & $\begin{array}{l}\text { Once } \\
\text { a } \\
\text { week } \\
\end{array}$ & $\begin{array}{l}2-4 \\
\text { per } \\
\text { week } \\
\end{array}$ & $\begin{array}{l}5-6 \\
\text { per } \\
\text { week }\end{array}$ & $\begin{array}{l}\text { Once } \\
\text { a } \\
\text { day } \\
\end{array}$ & $\begin{array}{l}2-3 \\
\text { per } \\
\text { day }\end{array}$ & $\begin{array}{l}4-5 \\
\text { per } \\
\text { day }\end{array}$ & $\begin{array}{l}6+ \\
\text { per } \\
\text { day }\end{array}$ \\
\hline \multicolumn{10}{|l|}{ Tea (cup) } \\
\hline \multicolumn{10}{|l|}{ Coffee, instant or ground (cup) } \\
\hline \multicolumn{10}{|l|}{ Coffee, decaffeinated (cup) } \\
\hline \multicolumn{10}{|l|}{$\begin{array}{l}\text { Coffee whitener, eg. Coffee-mate } \\
\text { (teaspoon) }\end{array}$} \\
\hline \multicolumn{10}{|l|}{ Cocoa, hot chocolate (cup) } \\
\hline \multicolumn{10}{|l|}{ Horlicks, Ovaltine (cup) } \\
\hline \multicolumn{10}{|l|}{ Wine (glass) } \\
\hline \multicolumn{10}{|l|}{ Beer, lager or cider (half pint) } \\
\hline \multicolumn{10}{|l|}{ Port, sherry, vermouth, liqueurs (glass) } \\
\hline Spirits, eg. gin, brandy, whisky, vodka (single) & & & & & . & & & & \\
\hline \multicolumn{10}{|l|}{ Low calorie or diet fizzy soft drinks (glass) } \\
\hline \multicolumn{10}{|l|}{$\begin{array}{l}\text { Fizzy soft drinks, eg. Coca cola, lemonade } \\
\text { (glass) }\end{array}$} \\
\hline \multicolumn{10}{|l|}{$\begin{array}{l}\text { Pure fruit juice (100\%) eg. orange, } \\
\text { apple juice (glass) }\end{array}$} \\
\hline \multicolumn{10}{|l|}{ Fruit squash or cordial (glass) } \\
\hline \multicolumn{10}{|c|}{$\begin{array}{l}\text { FRUIT } \\
\text { For seasonal fruits marked *, please estimate your average use when the fruit is in season }\end{array}$} \\
\hline \multicolumn{10}{|l|}{ Apples (1 fruit) } \\
\hline \multicolumn{10}{|l|}{ Pears (1 fruit) } \\
\hline \multicolumn{10}{|l|}{ Oranges, satsumas, mandarins ( 1 fruit) } \\
\hline \multicolumn{10}{|l|}{ Grapefruit (half) } \\
\hline \multicolumn{10}{|l|}{ Bananas (1 fruit) } \\
\hline \multicolumn{10}{|l|}{ Grapes (medium serving) } \\
\hline \multicolumn{10}{|l|}{ Melon (1 slice) } \\
\hline \multicolumn{10}{|l|}{ * Peaches, plums, apricots (1 fruit) } \\
\hline \multicolumn{10}{|l|}{ * Strawberries, raspberries, kiwi fruit (medium serving) } \\
\hline \multicolumn{10}{|l|}{ Tinned fruit (medium serving) } \\
\hline \multicolumn{10}{|l|}{ Dried fruit, eg. raisins, prunes (medium serving) } \\
\hline & $\begin{array}{l}\text { Never or } \\
\text { less than } \\
\text { once/month }\end{array}$ & $\begin{array}{l}1-3 \\
\text { per } \\
\text { month }\end{array}$ & $\begin{array}{l}\text { Once } \\
\text { a } \\
\text { week }\end{array}$ & $\begin{array}{l}2-4 \\
\text { per } \\
\text { week }\end{array}$ & $\begin{array}{l}5-6 \\
\text { per } \\
\text { week }\end{array}$ & $\begin{array}{l}\text { Once } \\
\text { a } \\
\text { day }\end{array}$ & $\begin{array}{l}2-3 \\
\text { per } \\
\text { day }\end{array}$ & $\begin{array}{l}4-5 \\
\text { per } \\
\text { day }\end{array}$ & $\begin{array}{l}6+ \\
\text { per } \\
\text { day }\end{array}$ \\
\hline
\end{tabular}

\section{Please check that you have a tick $(\checkmark)$ on EVERY line}


PLEASE PUT A TICK $(\checkmark)$ ON EVERY LINE

\begin{tabular}{|c|c|c|c|c|c|c|c|c|c|}
\hline \multirow{2}{*}{$\begin{array}{l}\text { FOODS AND AMOUNTS } \\
\text { VEGETABLES } \\
\text { Fresh, frozen or tinned } \\
\text { (medium serving) }\end{array}$} & \multicolumn{9}{|c|}{ AVERAGE USE LAST YEAR } \\
\hline & $\begin{array}{l}\text { Never or } \\
\text { less than } \\
\text { once/month }\end{array}$ & $\begin{array}{l}1-3 \\
\text { per } \\
\text { month }\end{array}$ & $\begin{array}{l}\text { Once } \\
\mathrm{a} \\
\text { week } \\
\end{array}$ & $\begin{array}{l}2-4 \\
\text { per } \\
\text { week }\end{array}$ & $\begin{array}{l}5-6 \\
\text { per } \\
\text { week }\end{array}$ & $\begin{array}{l}\text { Once } \\
\text { a } \\
\text { day }\end{array}$ & $\begin{array}{l}2-3 \\
\text { per } \\
\text { day }\end{array}$ & $\begin{array}{l}\text { 4-5 } \\
\text { per } \\
\text { day }\end{array}$ & $\begin{array}{l}6+ \\
\text { per } \\
\text { day }\end{array}$ \\
\hline \multicolumn{10}{|l|}{ Carrots } \\
\hline \multicolumn{10}{|l|}{ Spinach } \\
\hline \multicolumn{10}{|l|}{ Broccoli, spring greens, kale } \\
\hline \multicolumn{10}{|l|}{ Brussels sprouts } \\
\hline \multicolumn{10}{|l|}{ Cabbage } \\
\hline \multicolumn{10}{|l|}{ Peas } \\
\hline \multicolumn{10}{|c|}{ Green beans, broad beans, runner beans } \\
\hline \multicolumn{10}{|l|}{ Marrow, courgettes } \\
\hline \multicolumn{10}{|l|}{ Cauliflower } \\
\hline \multicolumn{10}{|l|}{ Parsnips, turnips, swedes } \\
\hline \multicolumn{10}{|l|}{ Leeks } \\
\hline \multicolumn{10}{|l|}{ Onions } \\
\hline \multicolumn{10}{|l|}{ Garlic } \\
\hline \multicolumn{10}{|l|}{ Mushrooms } \\
\hline \multicolumn{10}{|l|}{ Sweet peppers } \\
\hline \multicolumn{10}{|l|}{ Beansprouts } \\
\hline \multicolumn{10}{|l|}{ Green salad, lettuce, cucumber, celery } \\
\hline \multicolumn{10}{|l|}{ Watercress } \\
\hline \multicolumn{10}{|l|}{ Tomatoes } \\
\hline \multicolumn{10}{|l|}{ Sweetcorn } \\
\hline \multicolumn{10}{|l|}{ Beetroot } \\
\hline \multicolumn{10}{|l|}{ Coleslaw } \\
\hline \multicolumn{10}{|l|}{ Avocado } \\
\hline \multicolumn{10}{|l|}{ Baked beans } \\
\hline \multicolumn{10}{|l|}{ Dried lentils, beans, peas } \\
\hline \multicolumn{10}{|l|}{ Tofu, soya meat, TVP, Vegeburger } \\
\hline & $\begin{array}{l}\text { Never or } \\
\text { less than } \\
\text { once/month }\end{array}$ & $\begin{array}{l}1-3 \\
\text { per } \\
\text { month }\end{array}$ & $\begin{array}{l}\text { Once } \\
\text { a } \\
\text { week }\end{array}$ & $\begin{array}{l}2-4 \\
\text { per } \\
\text { week }\end{array}$ & $\begin{array}{l}5-6 \\
\text { per } \\
\text { week }\end{array}$ & $\begin{array}{l}\text { Once } \\
\text { a } \\
\text { day }\end{array}$ & $\begin{array}{l}2-3 \\
\text { per } \\
\text { day }\end{array}$ & $\begin{array}{l}4-5 \\
\text { per } \\
\text { day }\end{array}$ & $\begin{array}{l}6+ \\
\text { per } \\
\text { day }\end{array}$ \\
\hline
\end{tabular}

\section{Please check that you have a tick $(\checkmark)$ on EVERY line}




\section{YOUR DIET LAST YEAR, continued}

2. Are there any OTHER foods which you ate more than once a week? If yes, please list below

\begin{tabular}{|l|}
\hline Food \\
\hline \hline \\
\hline \hline \\
\hline \hline \\
\hline
\end{tabular}

\begin{tabular}{|l|}
\hline Usual serving size \\
\hline \hline \\
\hline \hline \\
\hline \hline \\
\hline \hline \\
\hline
\end{tabular}

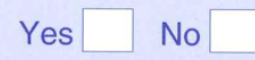

Number of times eaten each week

3. What type of milk did you most often use?

Select one only Full cream, silver

Skimmed/blue

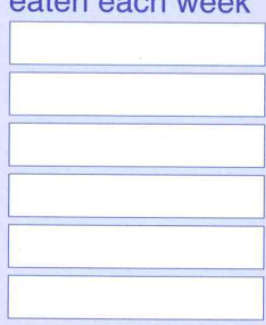

Sect one only

Other, specify $\quad$ Dried milk

4. How much milk did you drink each day, including milk with tea, coffee, cereals etc?

None
Quarter of a pint
Half a pint $\quad$ Three quarters of a pint $\square$

5. Did you usually eat breakfast cereal (excluding porridge and Ready Brek mentioned earlier)?

$$
\text { Yes } \square \text { No } \square
$$

If yes, which brand and type of breakfast cereal, including muesli, did you usually eat? List the one or two types most often used

Brand e.g. Kellogg's

Type e.g. cornflakes

6. What kind of fat did you most often use for frying, roasting, grilling etc?
Select one only
Butter
Solid vegetable fat

Lard/dripping
Vegetable oil
Margarine
None
If you used vegetable oil, please give type eg. corn, sunflower

7. What kind of fat did you most often use for baking cakes etc?
Select one only
Butter
Solid vegetable fat
Lard/dripping
Vegetable oil
Margarine
None
If you used margarine, please give name or type eg. Flora, Stork 
8. How often did you eat food that was fried at home?

\begin{tabular}{|c|c|}
\hline Daily & 1-3 times a week \\
\hline
\end{tabular}

4-6 times a week

Never

9. How often did you eat fried food away from home?

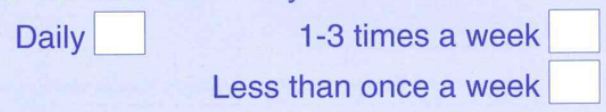

4-6 times a week

10. What did you do with the visible fat on your meat?

$$
\begin{aligned}
& \text { Ate most of the fat } \\
& \text { Ate some of the fat }
\end{aligned}
$$

11. How often did you eat grilled or roast meat?

12. How well cooked did you usually have grilled or roast meat?

$$
\begin{array}{r}
\text { Well done /dark brown } \\
\text { Medium }
\end{array}
$$

Ate as little as possible

Did not eat meat

times a week

13. How often did you add salt to food while cooking?

Always
Usually
Sometimes

Rarely

Never

\section{Did not eat meat}

14. How often did you add salt to any food at the table?

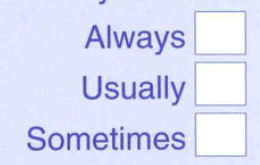

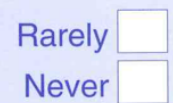

Never

15. Did you regularly use a salt substitute (eg LoSalt)?

If yes, which brand?

16. During the course of last year, on average, how many times a week did you eat the following foods?

Food type

Vegetables (not including potatoes)

Salads

Fruit and fruit products (not including fruit juice)

Fish and fish products

Meat, meat products and meat dishes (including bacon, ham and chicken)

\section{Times/week Portion size}

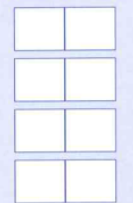

medium serving

medium serving medium serving or 1 fruit medium serving medium serving 
17. Have you taken any vitamins, minerals, fish oils, fibre or other food supplements during the past year?

Yes $\square$ No $\square$ Don't know

If yes, please complete the table below. If you have taken more than 5 types of supplement please put the most frequently consumed brands first.

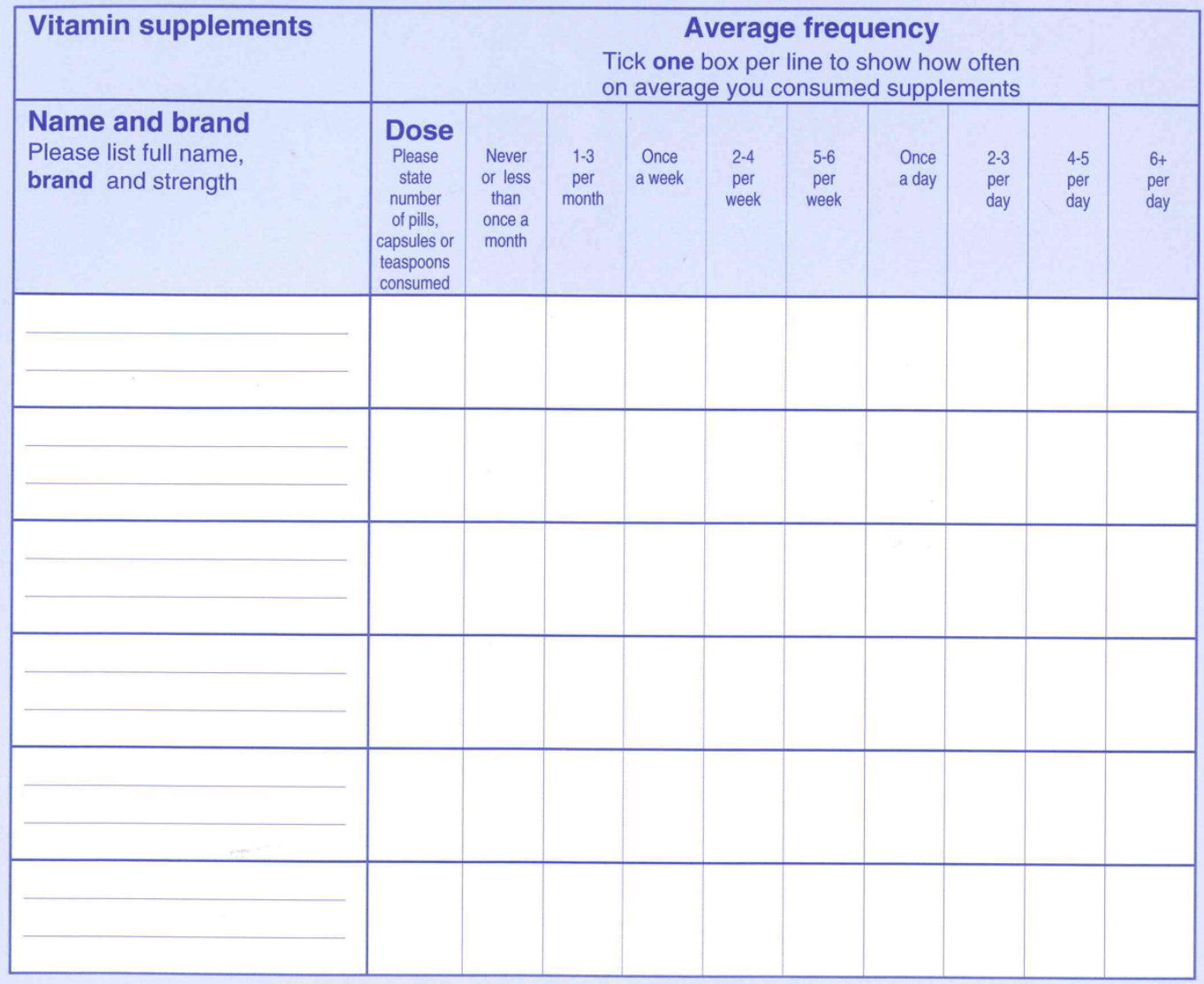

Thank you for your help 


\section{Appendix I \\ DEBRIEFING FORM}

Evaluating Biopsychosocial Profile of High and Low Cognitive Performers in Late Life.

Thank you for participating in this study. Your time and effort are much appreciated. This study investigates the association between biopsychosocial factors (i.e. the combination of biological and psychosocial factors) and cognitive function in older adults. Cognitive function includes memory, attention, and speed of processing (or how quickly you can do certain tasks). You were asked to complete a few tests of cognitive function and to fill out questions related to your mood, personality and lifestyle behaviors. You also provided bodily fluids to measure biological markers of stress, called the allostatic load $(A L)$ index, and genetic variance in a gene that is hypothesized to associate with brain health. You also underwent an electroencephalography (EEG) procedure where your brain activity was measured while at rest and while performing an attention task. Overall, we predict that older adults who display a negative AL index and psychosocial factors associated with poor brain health (e.g. sedentary, poor nutrition, low social support) will perform more poorly on cognitive tasks, which will also be found in brain activity patterns measured by the EEG. We also predict that certain biological and psychosocial factors will interact to create a biopsychosocial profile that can differentiate between high and low cognitive performance.

This study has received ethics clearance through the Psychology Department Research Ethics Committee at Ryerson University. If you have any questions about this study or concerns about your participation in this study, please contact Dr. Alexandra Fiocco at 416-979-5000-3008 or afiocco@psych.ryerson.ca. If you are interested in knowing how to receive a summary of the study findings, please call the Stress and Healthy Aging Research Lab at 416-979-5000-3233. If you have any concerns about the ethical procedures of this study, please contact the Chair of the Ryerson University Research Ethics Board at 416-979-5042 or rebchair@ryerson.ca.

Thank you again! 


\section{Appendix J}

Culinary categories of the food items on the EPIC-Norfolk Food Frequency Questionnaire

\begin{tabular}{ll}
\hline Culinary Category & Food Item \\
\hline Processed meats & $\bullet$ Corned beef, spam, luncheon meats \\
& $\bullet$ Sausages \\
& $\bullet$ Hacon \\
\hline Organ meats & $\bullet$ Liver, liver pate, liver sausage \\
\hline Poultry & $\bullet$ Chicken or other poultry (e.g., turkey) \\
\hline Meats (other) & $\bullet$ Beef \\
& $\bullet$ Beef burger \\
& $\bullet$ Pork \\
& $\bullet$ Lamb \\
& $\bullet$ Savoury pies
\end{tabular}

Fish and seafood

Fatty fish

Tofu and soy

Eggs and egg dishes

Refined grains
- Fish fingers, fish cakes

- Shellfish (e.g., crab, prawns, mussels)

- Fish roe, taramasalata

- Other white fish (e.g., cod, haddock, plaice, sole, halibut)

- Oily fish (e.g., Mackerel, kippers, tuna, salmon, sardines, herring)

\begin{tabular}{ll}
\hline Tofu and soy & $\bullet$ Tofu, soya meat, veggie-burger \\
\hline Eggs and egg dishes & $\bullet$ Eggs \\
& $\bullet$ Quiche \\
\hline Refined grains & $\bullet$ White bread and rolls \\
& $\bullet$ White rice \\
& $\bullet$ White or green pasta \\
& $\bullet$ Lasagne, moussaka \\
\hline Whole grains & $\bullet$ Brown bread and rolls \\
& $\bullet$ Wholemeal bread and rolls \\
& $\bullet$ Brown rice \\
& $\bullet$ Wholemeal pasta \\
\hline Potatoes & $\bullet$ Boiled, mashed, instant, or jacket potatoes \\
\hline
\end{tabular}




\begin{tabular}{|c|c|}
\hline & - $\quad$ Potato salad \\
\hline Candy and sugars & $\begin{array}{l}\text { - } \text { Chocolate } \\
\text { - } \text { Chocolate snack bars } \\
\text { - Sweets, toffee, mints } \\
\text { - } \quad \text { Sugar added to coffee/tea, cereal } \\
\text { - Jam, marmalade, honey }\end{array}$ \\
\hline Baked goods & $\begin{array}{ll}\text { - } & \text { Sweet biscuits (chocolate) } \\
\text { - } & \text { Sweet biscuits (plain) } \\
\text { - } & \text { Home baked cakes } \\
\text { - } & \text { Readymade cakes } \\
\text { - } & \text { Home baked buns and pastries } \\
\text { - } & \text { Readymade buns and pastries } \\
\text { - } & \text { Home baked fruit pies, tarts, crumbles } \\
\text { - } & \text { Readymade fruit pies, tarts, crumbles } \\
\text { - } & \text { Home baked sponge pudding } \\
\text { - } & \text { Readymade sponge pudding }\end{array}$ \\
\hline Butter & - Butter \\
\hline Margarine & $\begin{array}{ll}\text { - } & \text { Block margarine } \\
\text { - } & \text { Polyunsaturated margarine } \\
\text { - } & \text { Low fat spread } \\
\text { - } & \text { Very low fat spread } \\
\text { - } & \text { Other soft margarine, dairy spread }\end{array}$ \\
\hline Condiments & $\begin{array}{l}\text { - } \text { Sauces (e.g., white sauce, cheese sauce, } \\
\text { gravy) } \\
\text { - } \text { Ketchup } \\
\text { - } \quad \text { Pickles, chutney } \\
\text { - } \quad \text { Marmite, Bovril }\end{array}$ \\
\hline Salty snacks & $\begin{array}{ll}\text { - } & \text { Crispbread } \\
\text { - } & \text { Cream crackers, cheese biscuits } \\
\text { - } & \text { Crisps (i.e., chips) }\end{array}$ \\
\hline Fried foods & $\begin{array}{ll}\text { - } & \text { Pizza } \\
\text { - } & \text { Fried fish in batter } \\
\text { - } & \text { Chips (i.e., French fries) }\end{array}$ \\
\hline Soups & $\begin{array}{l}\text { - } \quad \text { Vegetable soups } \\
\text { - } \quad \text { Meat soups }\end{array}$ \\
\hline Dressings and dips & $\begin{array}{l}\text { - } \quad \text { Salad cream (i.e., mayonnaise) } \\
\text { - } \quad \text { Low calorie, low fat salad cream }\end{array}$ \\
\hline
\end{tabular}




\begin{tabular}{|c|c|}
\hline & $\begin{array}{ll}\text { - } & \text { French dressing } \\
\text { - } & \text { Other salad dressing }\end{array}$ \\
\hline High-fat dairy & $\begin{array}{ll}\text { - } & \text { Single or sour cream } \\
\text { - } & \text { Double or clotted cream } \\
\text { - } & \text { Full fat or Greek yogurt } \\
\text { - } & \text { Dairy desserts } \\
\text { - } & \text { Cheese (e.g., cheddar, brie, edam) } \\
\text { - } & \text { Ice cream } \\
\text { - } & \text { Milk puddings }\end{array}$ \\
\hline Low-fat dairy & $\begin{array}{l}\text { - } \text { Low fat yogurt } \\
\text { - } \text { Cottage cheese, low fat soft cheese }\end{array}$ \\
\hline Cereals & $\begin{array}{ll}\text { - } & \text { Porridge } \\
\text { - } & \text { Breakfast cereal (e.g., cornflakes, muesli) }\end{array}$ \\
\hline Cruciferous vegetables & $\begin{array}{ll}\text { - } & \text { Brussels sprouts } \\
\text { - } & \text { Cabbage } \\
\text { - } & \text { Cauliflower } \\
\text { - } & \text { Parsnips, turnips, swedes } \\
\text { - } & \text { Broccoli, spring greens, kale }\end{array}$ \\
\hline Vegetables & $\begin{array}{l}\text { - } \text { Carrots } \\
\text { - Peas } \\
\text { - } \text { Marrow, courgettes } \\
\text { - Leeks } \\
\text { - Onions } \\
\text { - Garlic } \\
\text { - Mushrooms } \\
\text { - Sweet Peppers } \\
\text { - Beansprouts } \\
\text { - Tomatoes } \\
\text { - Sweetcorn } \\
\text { - Coleslaw } \\
\text { - Avocado } \\
\text { - Beetroot }\end{array}$ \\
\hline Leafy vegetables & $\begin{array}{ll}\text { - } & \text { Spinach } \\
\text { - } & \text { Green salad, lettuce, cucumber, celery } \\
\text { - } & \text { Watercress }\end{array}$ \\
\hline Nuts and seeds & $\begin{array}{l}\text { - Peanuts, other nuts } \\
\text { - } \quad \text { Peanut butter }\end{array}$ \\
\hline
\end{tabular}




\begin{tabular}{|c|c|}
\hline Legumes & $\begin{array}{ll}\text { - } & \text { Baked beans } \\
\text { - } & \text { Dried lentils, beans, peas } \\
\text { - } & \text { Green beans, broad beans, runner beans }\end{array}$ \\
\hline Fruits & $\begin{array}{l}\text { - } \text { Apples } \\
\text { - } \text { Pears } \\
\text { - } \text { Oranges, satsumas, mandarins } \\
\text { - } \text { Grapefruit } \\
\text { - } \text { Bananas } \\
\text { - Grapes } \\
\text { - Melon } \\
\text { - Peaches, plums, apricots } \\
\text { - Tinned fruits } \\
\text { - } \text { Dried fruits }\end{array}$ \\
\hline Berries & - Strawberries, raspberries, kiwi fruit \\
\hline Sugary drinks & $\begin{array}{ll}\text { - } & \text { Fizzy soft drinks } \\
\text { - } & \text { Pure fruit juice } \\
\text { - } & \text { Fruit squash } \\
\text { - } & \text { Cocoa, hot chocolate } \\
\text { - } & \text { Horlicks, Ovaltine }\end{array}$ \\
\hline Diet drinks & - Low calorie/diet fizzy soft drinks \\
\hline Coffee/tea & $\begin{array}{ll}\text { - } & \text { Tea } \\
\text { - } & \text { Coffee, instant or ground } \\
\text { - } & \text { Decaffeinated coffee }\end{array}$ \\
\hline Alcohol & $\begin{array}{l}\text { - Wine } \\
\text { - Beer } \\
\text { - Port, sherry, vermouth, liqueurs } \\
\text { - Spirits }\end{array}$ \\
\hline Other & - Coffee whitener \\
\hline
\end{tabular}




\section{References}

Aggarwal, N. T., Wilson, R. S., Beck, T. L., Rajan, K. B., Mendes de Leon, C. F., Evans, D. A., \& Everson-Rose, S. A. (2014). Perceived stress and change in cognitive function among adults 65 years and older. Psychosomatic Medicine, 76, 80-85.

Alzheimer's Society of Canada (2016). Dementia numbers in Canada. Retrieved from http://alzheimer.ca/en/Home/About-dementia/What-is-dementia/Dementia-numbers

Anastasiou, C. A., Yannakoulia, M., Kosmidis, M. H., Dardiotis, E., Hadjigeorgiou, G. M., Sakka, P.,...Scarmeas, N. (2017). Mediterranean diet and cognitive health: Initial results from the Hellenic Longitudinal Investigation of Ageing and Diet. PLoS ONE, 12, e0182048.

Ansari, W. E. I., \& Berg-Beckhoff, G. (2015). Nutritional correlates of perceived stress among university students in Egypt. International Journal of Environmental Research and Public Health, 12, 14164-14176.

Attuguayefio, T., Stevenson, R. J., Baokes, R. A., Oaten, M. J., Yeomans, M. R., Mahmut, M., \& Francis, H. M. (2016). A high-fat high-sugar diet predicts poorer hippocampal-related memory and a reduced ability to suppress wanting under satiety. Journal of Experimental Psychology. Animal Learning and Cognition, 42, 415-428.

Barnes, D. E., Cauley, J. A., Lui, L. Y., Fink, H. A., McCulloch, C., Stone, K. L., \& Yaffe, K. (2007). Women who maintain optimal cognitive function into old age. Journal of the American Geriatrics Society, 55, 259-264. 
Barrington, W. E., Beresford, S. A. A., McGregor, B. A., White, E. (2014). Perceived stress and eating behaviours by gender, obesity-status, and stress vulnerability: Findings from the Vitamins and Lifestyle (VITAL) study. Journal of the Academy of Nutrition and Dietetics, 114, 1791-1799.

Barrios, H., Narciso, S., Guerreiro, M., Maroco, J., Logsdon, R., \& de Mendonca, A. (2013). Quality of life in patients with mild cognitive impairment. Aging and Mental Health, $17,287-292$.

Bingham, S. A., Gill, C., Welch, A., Cassidy, A., Runswick, S. A., Oakes, S.,...Day, N. E. (1997). Validation of dietary assessment methods in the UK arm of EPIC using weighted records, and 24-hour urinary nitrogen and potassium and serum vitamin $\mathrm{C}$ and carotenoids as biomarkers. International Journal of Epidemiology, 26, S137-S151.

Bingham, S. A., Welch, A. A., McTaggart, A., Mulligan, A. A., Rinswick, S. A., Luben, R. ... Day, N. E. (2001). Nutritional methods in the European Prospective Investigation of Cancer in Norfolk. Public Health Nutrition, 4, 847-858.

Blazer, D. G., Yaffe, K., \& Karlawish, J. (2015). Cognitive aging: A report from the Institute of Medicine. JAMA, 313, 2121-2122.

Bremner, J. D., \& Narayan, M. (1998). The effects of stress on memory and the hippocampus throughout the life cycle: Implications for child development and aging. Development and Psychopathology, 10, 871-885.

Brown, S. C., \& Park, D. C. (2003). Theoretical models of cognitive aging and implications for translational research in medicine. The Gerontologist, 43, 57-67. 
Butterfeld, D. A., Castegna, A., Pocernich, P. B., Drake, J., Scapagnini, G., \& Calabrese, V. (2002). Nutritional approaches to combat oxidative stress in Alzheimer's disease. The Journal of Nutritional Biochemistry, 13, 444-461.

Cespedes, E. M., \& Hu, F. B. (2015). Dietary patterns: From nutritional epidemiologic analysis to national guidelines. American Journal of Clinical Nutrition, 101, 899-900.

Cohen, S., Kamarch, T., \& Mermelstein, R. (1983). A global measure of perceived stress. Journal of Health and Social Behaviour, 24, 385-396.

Conrad, C. D. (2008). Chronic stress-induced hippocampal vulnerability: the glucocorticoid vulnerability hypothesis. Reviews in the Neurosciences, 19, 395-411.

Corley, J., Starr, J. M., McNeill, G., \& Deary, I. J. (2013). Do dietary patterns influence cognitive function in old age? International Psychogeriatrics, 25, 1393-1407.

Craik, F. I. M. (2008). Memory changes in normal and pathological aging. The Canadian Journal of Psychiatry, 53, 343-345.

Crichton, G. E., Elias, M. F., Davey, A., Alkerwi, A., \& Dore, G. A. (2016). Higher cognitive performance is prospectively associated with healthy dietary choices: The Maine Syracuse Longitudinal Study. Journal of Preventative Alzheimer's Disease, 2, 24-32.

Dai, J., Buijs, R., \& Swaab, D. (2004). Glucocorticoid hormone (cortisol) affects axonal transport in human cortex neurons but shows resistance in Alzheimer's disease. Neurology, 54, 588-593.

Darowski, E. S., Helder, E., Zacks, R. T., Hasher, L., \& Hambrick, D. Z. (2008). Age-related differences in cognition: The role of distraction control. Neuropsychology, 22, 638-644. 
Davis, J. C., Marra, C. A., Najafzadeh, M., \& Liu-Ambrose, T. (2010). The independent contribution of executive functions to health-related quality of life in older women. $B M C$ Geriatrics, 10 .

Delis, D. C., Kramer, J. H., Kaplan, E., \& Ober, B. A. (2000). California Verbal Learning Testsecond edition. Adult version. Manual. San Antonio, TX: Psychological Corporation.

Dickerson, S. S., \& Kemeny, M. E. (2004). Acute stressors and cortisol responses: A theoretical integration and synthesis of laboratory research. Psychological Bulletin, 130, 355-391.

Duff, K., Schoenberg, M. R., Scott, J. G., \& Adams, R. L. (2005). The relationship between executive functioning and verbal and visual learning and memory. Archives of Clinical Neuropsychology, 20, 111-122.

Epel, E., Lapidus, R., McEwen, B., \& Brownell, K. (2001). Stress may add bite to appetite in women: A laboratory study of stress-induced cortisol and eating behaviour. Psychoneuroendocrinology, 26, 37-49.

Ezzati, A., Jiang, J., Katz, M. J., Sliwinski, M. J., Zimmerman, M. E., \& Lipton, R. B. (2014). Validation of the perceived stress scale in a community sample of older adults. International Journal of Geriatric Psychiatry, 29, 645-652.

Faul, F., Erdfelder, E., Lang, A.-G., \& Buchner, A. (2007). G*Power3: A flexible statistical power analysis program for social, behavioural, and biomedical science. Behaviour Research Methods, 39, 175-191.

Feart, C., Samieri, C., Alles, B., \& Barberger-Gateau, P. (2013). Potential benefits of adherence to the Mediterranean diet on cognitive health. Proceedings of the Nutrition Society, 72, $140-152$. 
Feart, C., Samieri, C., Rondeau, V., Amieva, H., Portet, F., Dartigues, J. F. ... BarBergerGateau, P. (2009). Adherence to Mediterranean diet, cognitive decline, and risk of dementia. Journal of the American Medical Association, 302, 638-648.

Fiocco, A J., \& Yaffe, K. (2010). Defining successful aging: The importance of including cognitive function over time. Archives of Neurology, 67, 876-880.

Folstein, M. F., Folstein, S. E., \& McHugh, P. R. (1975). "Mini mental state”. A practical method for grading the cognitive state of patients for the clinician. Journal of Psychiatry Research, 12, 189-198.

Fowles, E. R., Sterling, B. S., \& Walker, L. O. (2007). Measuring dietary intake in nursing research. Canadian Journal of Nursing Research, 39, 146-165.

Freeman, L. R., \& Granholm, A. C. (2012). Vascular changes in rat hippocampus following a high saturated fat and cholesterol diet. Journal of Cerebral Blood Flow and Metabolism, $32,643-653$.

Friedman, D., Nessler, D., \& Johnson, R. Jr. (2007). Memory encoding and retrieval in the aging brain. Clinical EEG and Neuroscience, 38, 2-7.

Gardener, S. L., Rainey-Smith, S. R., Barnes, M. B., Sohrabi, H. R., Weinborn, M., Lim, Y., ...,Martins, R. N. (2015). Dietary patterns and cognitive decline in Australian study of ageing. Molecular Psychiatry, 20, 860-866.

Garrido, P. (2011). Aging and stress: Past hypotheses, present approaches and perspectives. Aging and Disease, 2, 80-99.

Geda, Y. E., Ragossnig, M., Roberts, L. A., Roberts, R. O., Pankratz, V. S., Christianson, T. J. H. ... Petersen, R. C. (2013). Caloric intake, aging, and mild cognitive impairment: A population-based study. Journal of Alzheimer's Disease, 34, 501-507. 
Glisky, E. L. (2007). Changes in cognitive function in human aging. In Brain Aging: Models, Methods, and Mechanisms. Retrieved from https://www.ncbi.nlm.nih.gov/books/ NBK3885/

Gnjidic, D., Stanaway, F. F., Cumming, R., Waite, L., Blyth, F., Naganathan, V. ... Le Couteur, D. G. (2012). Mild cognitive impairment predicts institutionalization among older men: A population-based cohort study. PLOS ONE, 7, E46061.

Gomez-Pinilla, F. (2008). The influences of diet and exercise on mental health through hormesis. Ageing Research Reviews, 7, 49-62.

Granic, A., Davies, K., Adamson, A., Kirkwood, T., Hill, T. R., Siervo, M. ... Jagger, C. (2016). Dietary patterns high in red meat, potato, gravy, and butter are associated with poor cognitive functioning but not with rate of cognitive decline in very old adults. The Journal of Nutrition, 146, 265-274.

Gross, A. L., Rebok, G. W., Unverzagt, F. W., Willis, S. L., \& Brandt, J. (2011). Cognitive predictors of everyday functioning in older adults: Results from the ACTVE Cognitive Intervention Trial. The Journals of Gerontology: Series B, 66B, 557-566.

Gu, Y., Brickman, A. M., Stern, Y., Habeck, C. G., Razlighi, Q. R., Luchsinger, J. A.... Scarmeas, N. (2015). Mediterranean diet and brain structure in a multiethnic elderly cohort. Neurology, 85, 1744-1751.

Harada, C. N., Natelson Love, M. C., \& Triebel, K. (2013). Normal cognitive aging. Clinics in Geriatric Medicine, 29, 737-752.

Harper, C. R., \& Jacobson, T. A. (2003). Beyond the Mediterranean diet: The role of omega-3 fatty acids in the prevention of coronary heart disease. European Journal of Preventive Cardiology, 6, 136-146. 
Hart, R. P., \& Bean, M. K. (2011). Executive function, intellectual decline and daily living skills. Neuropsychology, Development, and Cognition. Section B, aging, Neuropsychology and Cognition. 18, 64-85.

Hasher, L., \& Zacks, R. T. (1979). Automatic and effortful processes in memory. Experimental Psychology: General, 108, 356-388.

Hayes, A. F. (2017). Introduction to mediation, moderation, and conditional process analyses: A regression-based approach. New York, NY: The Guilford Press.

Henry, J. D., MacLeod, M. S., Phillips, L. H., \& Crawford, J. R. (2004). A meta-analytic review of prospective memory and aging. Psychology and Aging, 19, 27-39.

Hoaglin, D. C., \& Iglewicz, B. (1987). Fine tuning some resistant rules for outlier labeling. Journal of the American Statistical Association, 82, 1147-1149.

Horn, J. L., \& Cattell, R. B. (1967). Age differences in fluid and crystallized intelligence. Acta Psychologica, 26, 107-129.

Hu, F. B. (2002). Dietary pattern analysis: A new direction in nutritional epidemiology. Current Opinion in Lipidology, 13, 3-9.

Issa, A. M., Rowe, W., Gauthier, S., \& Meaney, M. J. (1990). Hypothalamic-pituitary-adrenal activity in aged, cognitively impaired, and cognitively unimpaired rats. Journal of Neuroscience, 10, 3247-3257.

Jacka, F. N., Cherbuin, N., Anstey, K. J., Sachdev, P., \& Butterworth, P. (2015). Western diet is associated with smaller hippocampus: A longitudinal investigation. BMC Medicine, 13, 215.

Jacobs, D. R. Jr., Gross, M. D., \& Tapsell, L. C. (2009). Food synergy: An operational concept for understanding nutrition. American Journal of Clinical Nutrition, 89, 1543S-1548S. 
Jacobson, L., \& Sapolsky, J. (1991). The role of the hippocampus in feedback regulation of the hypothalamic-pituitary-adrenocortical axis. Endocrine Reviews, 12, 118- 134.

Jurdak, N., \& Kanarek, R. (2009). Sucrose-induced obesity impairs novel object recognition learning in young rats. Physiology \& Behaviour, 96, 1-5.

Kandiah, J., Yake, M., Meyer, M., \& Jones, J. (2006). Stress influences appetite and comfort food preferences in college women. Nutrition Research, 26, 118-123.

Kanoski, S. E., \& Davidson, T. L. (2011). Western diet consumption and cognitive impairment: Links to hippocampal dysfunction and obesity. Physiology and Behaviour, 103, 59-68.

Khansari, N., Shakiba, Y., \& Mahmoudi, M. (2009). Chronic inflammation and oxidative stress as a major cause of age-related diseases and cancer. Recent Patents on Inflammation \& Allergy Drug Discovery, 3, 73-80.

Korten, N. C., Comijs, H. C., Penninx, B. W., \& Deeg, D. J. (2017). Perceived stress and cognitive function in older adults: Which aspect of perceived stress is important? International Journal of Geriatric Psychiatry, 32, 439-455.

Kritchevsky, S. B., \& Houston, D. K. (2012). Nutritional Epidemiology in Aging: The Epidemiology of Aging. Springer.

Lalkovicova, M., \& Danielisova, V. (2016). Neuroprotection and antioxidants. Neural Regeneration Research, 11, 865-874.

Laugero, K. D., Falcon, L. M., \& Tucker, K. L. (2011). Relationship between perceived stress and dietary patterns in older adults participating in the Boston Puerto Rican Health Study. Appetite, 56, 194-204.

Lazarus, R. S. (1966). Psychological Stress and the Coping Process. New York: McGraw-Hill. 
Lee, B. K., Glass, T. A., \& McAtee, M. J. (2007). Associations of salivary cortisol with cognitive function in the Baltimore Memory Study. Archives of General Psychiatry, 64, 810818.

Lee, B. K., Glass, T. A., Wand, G. S., McAtee, M. J., \& Bandeen-Roche, K. (2008). Apolipoprotein E genotype, cortisol, and cognitive function in community-dwelling older adults. The American Journal of Psychiatry, 165, 1456-1464.

Li, G., Cherrier, M. M., Tsuang, D. W., Petrie, E. C., Colasurdo, E. A., Craft, S. ...Wilkinson, C. W. (2006). Salivary cortisol and memory function in human aging. Neurobiology of Aging, 27, 1705-1714.

Luszcz, M. A., \& Bryan, J. (1999). Toward understanding age-related memory loss in late adulthood. Gerontology, 45, 2-9.

Lugrin, J., Rosenblatt-Velin, N., Parapanov, R., \& Liaudet, L. (2014). The role of oxidative stress during inflammatory processes. Biological Chemistry, 395, 203-230.

Lupien, S. J., DeLeon, M., DeSanti, S., Convit, A., Tarshish, C., Nair, N. P. V.,... Meaney, M. J. (1998). Longitudinal increase in cortisol during human aging predict hippocampal atrophy and memory deficits. Nature Neuroscience, 1, 69-73.

Lupien, S., Lecours, A. R., Lussier, I., Schwartz, G., Nair, N. P., \& Meaney, M. J. (1994). Basal cortisol levels and cognitive deficits in human aging. Journal of Neuroscience, 14, 2893-2903.

Marseglia, A., Xu, W., Fratiglioni, L., Fabbri, C., Berendsen, A. A. M., Bialecka-Debek, A. ... Franceschi, C. (2018). Effects of the NU-AGE diet on cognitive functioning in older adults: A randomized controlled trial. Frontiers in Psychology, 9, 349. 
May, C. P., Hasher, L., \& Stoltzfus, E. R. (1993). Optimal time of day and the magnitude of age differences in memory. Psychological Science, 4, 326-330.

McCarrey, A. C., An, Y., Kitner-Triolo, M. H., Ferrucci, L., \& Resnick, S. M. (2016). Sex differences in cognitive trajectories in clinically normal older adults. Psychology and Aging, 31, 166-175.

McEwen, B. S. (2007). Physiology and neurobiology of stress and adaptation: central role of the brain. Physiological Reviews, 87, 873-904.

Mikolajczyk, R. T., Ansari, W. E. I., \& Maxwell, A. E. (2009). Food consumption frequency and perceived stress and depressive symptoms among students in three European countries. Nutrition Journal, 8, 31 .

Milte, C. M., \& McNaughton, S. A. (2016). Dietary patterns and successful aging: A systematic review. European Journal of Nutrition, 55, 423-450.

Moeller, S. M., Reedy, J., Millen, A. E., Dixon, B., Newby, P. K., Tucker, K. L.,...Guenther, P. M. (2007). Dietary patterns: Challenges and opportunities in dietary patterns research. Journal of the American Dietetic Association, 107, 1233-1239.

Morris, M. C. (2012). Nutritional determinants of cognitive aging and dementia. The Proceedings of the Nutrition Society, 71, 1-13.

Morris, M. C., Evans, D. C., Bienias, J. L., Tangney, C. C., \& Wilson, R. S. (2002). Vitamin E and cognitive decline in older persons. Archives of Neurology, 59, 1125-1132.

Morris, M. C., Evans, D. C., Bienias, J. L., Tangney, C. C., \& Wilson, R. S. (2004). Dietary fat intake and 6-year cognitive change in an older biracial community population. Neurology, 62, 1573-1579. 
Muir, S. W., Gopaul, K., \& Odasso, M. M. M. (2012). The role of cognitive impairment in fall risk among older adults: A systematic review and meta-analysis. Age and Ageing, 41, 299-308.

Mulligan, A. A., Luben, R. N., Bhaniani, A., Parry-Smith, D. J., O’Conner, L., Khawaja, A. P.,...Khaw, K.-T. (2014). A new tool for converting food frequency questionnaire data into nutrient and food group values: FETA research methods and availability. BMJ Open, 4, e004503.

Munoz, E., Sliwinski, M. J., Scott, S. B., \& Hofer, S. (2015). Global perceived stress predicts cognitive change among older adults. Psychology and Aging, 30, 487-499.

Murman, D. L. (2015). The impact of age on cognition. Seminars in Hearing, 36, 111-121.

Newman, E., O’Connor, D. B., \& Connor, M. (2007). Daily hassles and eating behavior: the role of cortisol reactivity status. Psychoneuroendocrinology, 32, 125-132.

Ng, D. M., \& Jeffery, R. W. (2003). Relationships between perceived stress and health behaviours in a sample of working adults. Health Psychology, 22, 638-642.

Norman, G. R., \& Streiner, D. L. (2000). Biostatistics: The Bare Essentials, Second Edition. Lewiston, NY: B.C. Decker Inc.

O’Shea, A., Cohen, R. A., Porgres, E. C., Nissim, N. R., \& Woods, A. J. (2016). Cognitive aging and the hippocampus in older adults. Frontiers in Aging Neuroscience, 8, 298.

Okubo, H., Inagaki, H., Gondo, Y., Kamide, K., Ikevbe, K., Masui, Y,.., Maeda, Y. (2017). Association between dietary patterns and cognitive function among 70-year-old Japanese elderly: A cross-sectional analysis of the SONIC study. Nutrition Journal, 16, 56. 
Osmanovic-Thunstrom, A., Mossello, E., Akerstedt, T., Fratiglioni, L., \& Wang, H.-X. (2015). Do levels of perceived stress increase with increasing age after age 65? A populationbased study. Age and Ageing, 44, 828-834.

Panza, F., Solfrizzi, V., Colacicco, A. M., D’Introno, A., Capurso, C., Torres, F.,...,Capurso, A. (2004). Mediterranean diet and cognitive decline. Public Health Nutrition, 7, 959-963.

Park, D. C., Lautenschlager, G., Hedden, T., Davidson, N. S., Smith, A. D., \& Smith, P. K. (2002). Models of visuospatial and verbal memory across the adult lifespan. Psychology and Aging, 17, 299-320.

Parrott, M. D., Shatenstein, B., Ferland, G., Payette, H., Morais, J. A., Belleville, S. ... Greenwood, C. E. (2013). Relationship between diet quality and cognition depends on socioeconomic position in healthy older adults. The Journal of Nutrition, 143, 17671773.

Pathan, A., Gaikwad, A., Viswanad, B., \& Ramarao, P. (2008). Rosiglitazone attenuates the cognitive deficits induced by high fat diet feeding in rats. European Journal of Pharmacology, 589, 176-179.

Pelletier, C., Robitaille, C., Mcrae, L., \& Toews, J. (2017). Monitoring the burden of Alzheimer's disease (AD) and dementias in Canada: First prevalence, incidence and allcause mortality estimates from the public health agency of Canada's Canadian Chronic Disease Surveillance System (CCDSS). The Journal of the Alzheimer's Association, 13, P910.

Petersson, S. D., \& Philipou, E. (2016). Mediterranean diet, cognitive function, and dementia: A systematic review of the evidence. Advances In Nutrition, 7, 889-904. 
Piazza, J. R., Almeida, D. M., Dmitrieva, N. O., \& Klein, L. C. (2010). Frontiers in the use of biomarkers of health in research on stress and aging. The Journals of Gerontology, $65 B, 513-525$

Reitan, R. M. (1958). Validity of the trail-making test as an indicator of organic brain damage. Perceptual and Motor Skills, 8, 271-276.

Reuben, A., Brickman, A. M., Muraskin, J., Steffener, J., \& Stern, Y. (2013). Hippocampal atrophy relates to fluid intelligence decline in the elderly. Journal of International Neuropsychological Society, 17, 56-61.

Roman, B., Carta, L., Martinez-Gonzalez, M. A., \& Serra-Majem, L. (2003). Effectiveness of the Mediterranean diet in the elderly. Clinical Interventions in Aging, 3, 97-109.

Rostamian, S., Mahinrad, S., Stijnen, T., Sabayan, B., \& de Craen, A. J. M. (2014). Cognitive impairment and risk of stroke: A systematic review and meta-analysis of prospective cohort studies. Stroke, 45, 1342-1348.

Rowe, J. W., \& Kahn, R. L. (1987). Human aging: Usual and successful. Science, 237, 143-149.

Rutters, F., Nieuwenhuizen, A. G., Lemmens, S. G., Born, J. M., \& Westerterp-Plantenga, M. S. (2009). Acute stress-related changes in eating in the absence of hunger. Obesity (Silver Spring), 17, $72-77$.

Salthouse, T. A. (2004). What and when of cognitive aging. Current Directions in Psychological Science, 13, 140-144.

Salthouse, T. A. (2009). When does age-related cognitive begin? Neurobiology of Aging, 30, $507-514$ 
Sanchez-Cubillo, I., Perianez, J. A., Adrover-Roig, D., Rodriguez-Sanchez, J. M., Rios-Lago, M., Tirapu, J., \& Barcelo, F. (2009). Construct validity of the Trail Making Test: Role of task-switching, working memory, inhibition/interference control, and visuomotor abilities. Journal of the International Neuropsychological Society, 15, 438-450.

Sapolsky, R. M., Krey, L. C., \& McEwen, B. S. (1986). The neuroendocrinology of stress and aging: The glucocorticoid cascade hypothesis. Endocrine Reviews, 7, 284-301.

Sauro, M. D., Jorgensen, R. S., \& Pedlow, C. T. (2003). Stress, glucocorticoids, and memory: A meta-analytic review. Stress, 6, 235-245.

Schaie, K. W. (1996). Intellectual Development in Adulthood: The Seattle Longitudinal Study. Cambridge, UK: Cambridge University Press.

Seeman, T. E., McEwen, B. S., Singer, B. H., Albert, M. S., \& Rowe, J. W. (1997). Increase in urinary cortisol excretion and memory declines: MacArthur studies of successful aging. The Journal of Clinical Endocrinology \& Metabolism, 82, 2458-2465.

Segerstrom, S. C., Geiger, P. J., Boggero, I. A., Schmitt, F. A., \& Sephton, S. E. (2016). Endogenous cortisol exposure and declarative memory: A longitudinal study of healthy older adults. Psychosomatic Medicine, 78, 182-191.

Selye, H. (1956). The Stress of Life. New York, NY: McGraw Hill.

Shakersain, B., Santoni, G., Larsson, S. C., Faxen-Irving, G., Fastborn, J., Fratiglioni, L., \& Xu, W. (2016). Prudent diet may attenuate the adverse effects of Western diet on cognitive decline. Alzheimer's and Dementia, 12, 100-109.

Shipley, W. C. (1946). Institute of Living Scale. Los Angeles, CA: Western Psychological Services. 
Shlisky, J., Bloom, D. E., Beaudreault, A. R., Tucker, K. L., Keller, H. H., Freund-Levi, Y.,...Meydani, S. N. (2017). Nutritional considerations for healthy aging and reduction in age-related chronic disease. Advances in Nutrition, 8, 17-26.

Sliwinski, M. J., Smyth, J. M., Hofer, S. M., \& Stawski, R. S. (2006). Intraindividual coupling of daily stress and cognition. Psychology and Aging, 21, 545-557.

Smith, P. J., \& Blumenthal, J. A. (2016). Dietary factors and cognitive decline. The Journal of Preventation of Alzheimer's Disease, 3, 53-64.

Sofi, F., Abbate, R., \& Casini, A. (2008). Adherence to a Mediterranean diet and health status: meta-analysis. BMJ, 337, A1344.

Solfrizzi, V., Custodero, C., Lozupone, M., Imbimbo, B. P., Valiani, V., Agosti, P. ... Panza, F. (2017). Relationships of dietary patterns, foods, and micro- and macronutrients with Alzheimer's disease and late-life cognitive disorders: A systematic review. Journal of Alzheimer's Disease, 59, 815-849.

Staubo, S. C., Aarke, J. A., Vemuri, P., Syrjanen, J. A., Mielke, M. M., Geda, Y. E. ... Roberts, R. O. (2017). Mediterranean diet, micronutrients and macronutrients, and MRI measures of cortical thickness. Alzheimer's and Dementia, 13, 168-177.

Starcke, K., Wiesen, C., Trotzke, P., \& Brand, M. (2016). Effects of acute laboratory stress on executive functions. Frontiers in Psychology, 7, 461.

Statistics Canada. (2011). Living Arrangements of Seniors. Retrieved from https://www12.statcan.gc.ca/census-recensement/2011/as-sa/98-312-x/98-312x2011003_4-eng.cfm

Statistics Canada. (2016). An aging population. Retrieved from http://www.statcan.gc.ca/pub/11402-x/2010000/chap/pop/pop02-eng.htm 
Statistics Canada. (2016b). Prevalence and monetary costs of dementia in Canada (2016): A report by the Alzheimer's Society of Canada-HPCDP: Volume 36-10, October 2016. Retrieved from https://www.canada.ca/en/public-health/services/reportspublications/health-promotion-chronic-disease-prevention-canada-research-policypractice/vol-36-no-10-2016/report-summary-prevalence-monetary-costs-dementiacanada-2016-report-alzheimer-society-canada.html

Stawski, R. S., Sliwinski, M. J., \& Smyth, J. M. (2006). Stress-related cognitive interference predicts cognitive function in old age. Psychology and Aging, 21, 535-544.

Takeda, E., Terao, J., Nakaya, Y., Miyamoto, K., Baba, Y., Chuman, H.,...Rokutan, K. (2004). Stress control and human nutrition. The Journal of Medical Investigation, 51, 139145.

Tangney, C. C., Kwasny, M. J., Wilson, R. S., Evans, D. A., \& Morris, M. C. (2011). Adherence to a Mediterranean-type dietary pattern and cognitive decline in a community population. The American Journal of Clinical Nutrition, 93, 601-607.

Tangney, C. C., Li, H., Wang, Y., Barnes, L., Schneider, J. A., Bennett, D. A., \& Morris, M. C. (2014). Relation of DASH- and Mediterranean-like dietary patterns to cognitive decline in older persons. Neurology, 83, 1410-1416.

Thayer, R. (2001). Calm energy: How people regulate mood with food and exercise. Oxford: Oxford University Press.

Tschanz, J. T., Pfister, R., Wanzek, J., Corcoran, C., Smith, K., Tschanz, B. T. ... Norton, M. C. (2012). Stressful life events and cognitive decline in late life: Moderation by education and age. The Cache County Study. Geriatric Psychiatry, 28, 821-830. 
Tsigos, C. \& Chrousos, G. P. (2002). Hypothalamic-pituitary-adrenal axis, neuroendocrine factors and stress. Journal of Psychosomatic Research, 53, 865-871.

Turner, A. D., James, B. D., Capuano, A. W., Aggarwal, N. T., \& Barnes, L. L. (2017).

Perceived stress and cognitive decline in different cognitive domains in a cohort of older African Americans. The American Journal of Geriatric Psychiatry, 25, 25-34.

Wagner, J. T., Muri, R. M., Nef, T., \& Mosimann, U. P. (2011). Cognition and driving in older persons. Swiss Medical Weekly, 140, w13136.

Warnberg, J., Gomez-Martinez, S., Romeo, J., Diaz, L. E., \& Marcos, A. (2009). Nutrition, inflammation, and cognitive function. Neuroimmunomodulation: From Fundamental Biology to Therapy. Malden, MA: Wiley-Blackwell.

Wecker, N. S., Kramer, J. H., Hallam, B. J., \& Delis, D. C. (2005). Mental flexibility: Age effects on switching. Neuropsychology, 19, 345-352.

Wengreen, H. J., Neilson, C., Munger, R., \& Corcoran, C. (2009). Diet quality is associated with better cognitive test performance among aging men and women. Journal of Nutrition, 139, 1944-1949.

Wilson, R. S., Hebert, L. E., Scherr, P. A., Barnes, L. L., Mendes de Leon, C. F., \& Evans, D. A. (2009). Educational attainment and cognitive decline in old age. Neurology, 72, 460465.

Yaffe, K., Fiocco, A. J., Lindquist, K., Vittinghoff, E., Simonsick, E. M., Newman, A. B., ... Health ABC Study. (2009). Predictors of maintaining cognitive function in older adults: The Health ABC Study. Neurology, 72, 2029-2035.

Yau, Y. H. C., \& Potenza, M. N. (2013). Stress and eating behaviours. Minerva Endocrinologica, 38, 255-267. 
Zelazo, P. D., Craik, F. I., \& Booth, I. (2004). Executive function across the lifespan. Acta Psychologica, 115, 167-83.

Zhang, X. Y., Shu, L., Si, C. J., Yu, X. L., Liao, D., Gao, W.,...Zheng, P. F. (2015). Dietary patterns, alcohol consumption and risk of coronary heart disease in adults: A metaanalysis. Nutrients, 7, 6582-6605. 